UNIVERSIDAD POLITÉCNICA DE MADRID

Facultad de Ciencias de la Actividad Física y del Deporte (INEF)

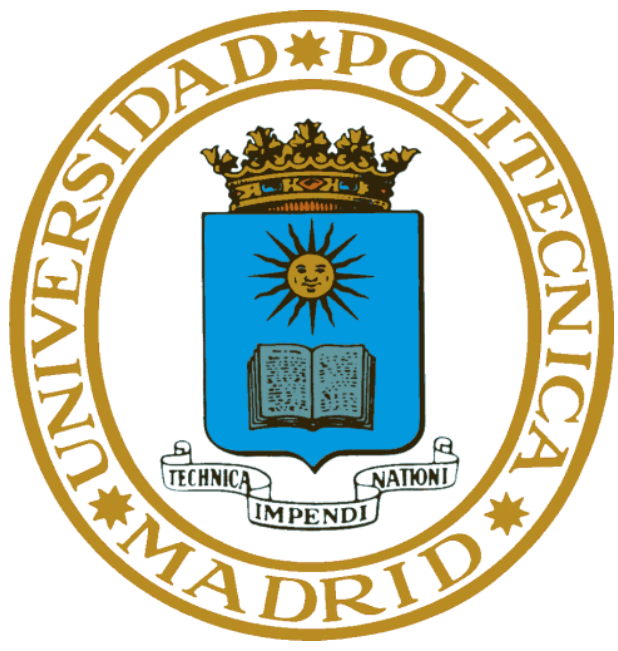

\title{
TRANSITION PHASE - A NEW PHASE FROM START/TURN TO FREE SWIMMING IN COMPETITIVE SWIMMERS
}

Tesis Doctoral

\author{
Jelena Stosic
}

Јелена Стошић

Madrid, 2020 



\section{POLITÉCNICA}

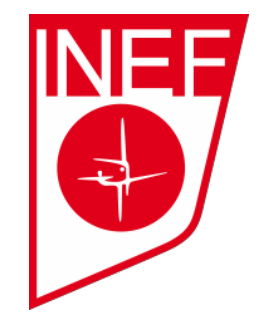

UNIVERSIDAD POLITÉCNICA DE MADRID

Facultad de Ciencias de la Actividad Física y del Deporte (INEF)

\section{TRANSITION PHASE - A NEW PHASE FROM START/TURN TO FREE SWIMMING IN COMPETITIVE SWIMMERS}

TESIS DOCTORAL

Jelena Stosic

Madrid, 2020 



\title{
DEPARTAMENTO DE SALUD Y RENDIMIENTO HUMANO
}

Facultad de Ciencias de la Actividad Física y del Deporte (INEF)

\section{TRANSITION PHASE - A NEW PHASE FROM START/TURN TO FREE SWIMMING IN COMPETITIVE SWIMMERS}

\author{
AUTHOR: \\ Jelena Stosic \\ Master's Degree in Sports Sciences \\ University of Jyväskylä \\ DIRECTOR: \\ Dr. Santiago Veiga Fernandez
}

Doctor en en Rendimiento Deportivo, Licenciado en Ciencias de la Actividad Física y del Deporte, Profesor Asociado, Universidad Politécnica de Madrid 


\section{ACTA DEL TRIBUNAL}

Tribunal nombrado por el Magfco. y Excmo. Sr. Rector de la Universidad Politécnica de Madrid,

el día.....de.................................de 2020.

Presidente: D

Vocal: D.

Vocal: D.

Vocal: D

Secretario: D

Realizando el acto de defensa y lectura de la Tesis el día.......de..... de 2020 .

En.

Calificación

EL PRESIDENTE

LOS VOCALES

EL SECRETARIO 


\section{MIEMBROS DEL TRIBUNAL}

\section{Presidente:}

Facultad

Universidad

Secretaria:

Facultad

Universidad

Vocal 1:

Facultad

Universidad

Vocal 2:

Facultad

Universidad

Vocal 3:

Facultad

Universidad

\section{SUPLENTES}

\section{Suplente 1:}

Facultad

Universidad

Suplente 2:

Facultad

Universidad 


\begin{abstract}
For the best swimming performance, it is important to keep the highest possible velocity in each portion of the swimming event. Traditionally, the segments of swimming events are divided into: starting, free swimming and turning portions. Starting and turning mainly belong to underwater, while free swimming to surface swimming. The swimming process of transitioning from underwater to free swimming in this thesis is defined as breakout phase or transitioning swimming phase.
\end{abstract}

Aim: The purpose of this study was to examine breakout phase in the four strokes and two genders regarding kinematics, coordination and segmental factors. This purpose was achieved through three main aims of the study. The first aim was to characterize the kinematics, coordinative and segmental variables of the breakout phase in elite competitive swimmers of both genders (Chapter 4). The second aim was to compare the kinematic and coordinative parameters of elite competitive swimmers during the transition phase and the free swimming phases (Chapter 5). The third aim was to examine the role of the segmental, kinematic and coordinative parameters on the swimming velocity during the pre-transition and transition phases of the push start (Chapter 6).

Methods: 74 competitive swimmers (33 males and 41 females) with a personal best time within the $85 \%$ of world record participated in this study. Swimmers performed 4 x 25 m maximal efforts (one of each stroke in random order) from a push start and were recorded $(50 \mathrm{~Hz})$ by two sequential video cameras in sagittal plane. The average velocity, stroke length, stroke frequency, the relative duration $(\%)$ of the stroke phases, segmental variables (body and trunk inclinations, body depths) as well as the inter-limb discrete relative phases were calculated with direct linear transformation (DLT) algorithms for the breakout and free-swimming phases.

Results (Study 1 - Chapter 4) Stroke rate was higher in males than in females in freestyle $(\mathrm{F}=10.24$, $\mathrm{p}=0.002)$, backstroke $(\mathrm{F}=10.80, \mathrm{p}=0.002)$ and breaststroke $(\mathrm{F}=4.70, \mathrm{p}=0.034)$ during the transition 
phase. There was large effect of gender on transition inclinations, but only in butterfly $(\mathrm{F}=4.75$, $\mathrm{p}=0.033)$ and breaststroke $(\mathrm{F}=4.75, \mathrm{p}=0.033)$.

Results (Study 2 - Chapter 5) In general terms, swimming velocity during breakout was faster $(\delta$ $0.27 \pm 0.04 \mathrm{~m} / \mathrm{s}, \mathrm{p}<0.001, \mathrm{ES}=0.33$ ) than free-swimming (in all strokes but breaststroke), not because of a faster previous underwater kicking or a modified coordinative swimming pattern, but because of an increase in the stroking rate $(\delta 4.68 \pm 0.79$ cycles/min, $\mathrm{p}<0.001$, ES $=0.36)$, with changes to the relative duration of selected stroke phases.

Results (Study 3 - Chapter 6) Body position and inter-limb coordinative parameters of competitive swimmers during transition phase predicted between the $15 \%$ and $29 \%$ of the variance in the average velocity. Body inclinations and depths were predictors in the alternate strokes (freestyle $(\mathrm{p}=0.05)$ and backstroke $(\mathrm{p}=0.04))$, while coordinative parameters were predictor in butterfly stroke $(\mathrm{p}=0.006)$.

Conclusion: Results indicate how swimmers manage the changing constraints during breakout and give clear applications for coaches on the key technical aspects that should be stressed when transitioning from underwater to surface swimming.

Keywords: performance; kinematics; body inclinations; inter-limb coordination; relative phase; underwater swimming; 


\section{Resumen}

Para obtener el mejor rendimiento en la natación, es importante mantener la mayor velocidad posible en cada una de las partes de la prueba. Tradicionalmente, los eventos de natación se dividen en: salida, nado y viraje. La salida y el viraje corresponden principalmente al nado subacuático, mientras que el nado se realiza en superficie. La transición del nado subacuático al nado en superficie en esta tesis se define como fase de transición de natación.

Objetivo: El propósito de este estudio fue examinar la fase de transición en los cuatro estilos de competición con respecto a la cinemática, la coordinación y los factores segmentarios. Este objetivo se logró a través de estudios principales. El primer objetivo fue caracterizar la cinemática, las variables coordinativas y segmentarias de la fase de transición en nadadores competitivos en ambos géneros (Capítulo 4). El segundo objetivo fue comparar los parámetros cinemáticos y coordinativos de nadadores competitivos en la fase de transición y el nado en superficie (Capítulo 5). El tercer objetivo fue examinar el papel de los parámetros segmentarios, cinemáticos y coordinativos en la velocidad de nado durante las fases de pretransición y transición d (Capítulo 6). Métodos: 74 nadadores de nivel competitivo nacional (33 hombres y 41 mujeres) con una mejor marca personal en el $85 \%$ del récord mundial participaron en esta investigación mediante la firma del documento de consentimiento informado aprobado por el Comité de Ética de la Universidad Politécnica de Madrid y de acuerdo con a la Declaración de Helsinki. Los nadadores realizaron las pruebas en una piscina de 50x25 m. Se efectuaron 4x $25 \mathrm{~m}$ (uno de cada estilo en orden aleatorio) desde salida con empuje y se registraron $(50 \mathrm{~Hz})$ con dos cámaras de video secuenciales filmando en plano sagital. La velocidad media, la longitud de ciclo, la frecuencia de ciclo, la duración relativa $(\%)$ de las fases de la brazada, las variables segmentarias (inclinaciones del cuerpo y del tronco, profundidad del cuerpo) así como las fases relativas discretas entre las extremidades se 
calcularon por medio de algoritmos de Direct Linear Transformation (DLT) para las fases de transición y nado en superficie.

Resultados (Estudio 1 - Capítulo 4) La frecuencia de ciclo difirió entre los géneros para el estilo libre $(\mathrm{F}=10.24, \mathrm{p}=0.002)$, espalda $(\mathrm{F}=10.80, \mathrm{p}=0.002)$ y braza $(\mathrm{F}=4.70, \mathrm{p}=0.034)$ durante la fase de transición. El género de los deportistas tuvo un efecto significativo sobre la inclinación en la fase de transición, pero solo en los estilos mariposa $(\mathrm{F}=4.75, \mathrm{p}=0.033)$ y braza $(\mathrm{F}=4.75, \mathrm{p}=$ 0.033). Resultados (Estudio 2 - Capítulo 5) En términos generales, la velocidad de nado durante la transición fue más rápida $(\delta 0.27 \pm 0.04 \mathrm{~m} / \mathrm{s}, \mathrm{p}<0.001, \mathrm{ES}=0.33)$ que en el nado en superficie (en todos los estilos excepto en el braza), no debido a una batido subacuático previo más rápido o un patrón coordinativo modificado, pero debido a un aumento en la frecuencia de ciclo $(\delta 4.68 \pm$ 0.79 ciclos $/ \min , \mathrm{p}<0.001, \mathrm{ES}=0.36$ ), con cambios en la duración relativa de las fases de brazada seleccionadas.

Resultados (Estudio 3 - Capítulo 6) La posición corporal y los parámetros de coordinación entre las extremidades de los nadadores de competición durante la fase de transición predijeron entre el $15 \%$ y el $29 \%$ de la varianza en la velocidad media de nado. Se demostró que las inclinaciones y la profundidad del cuerpo son más importantes para los estilos alternativos (crol $(\mathrm{p}=0.05)$ y espalda $(\mathrm{p}=0.04))$, mientras que los parámetros coordinativos son elementos clave para el estilo mariposa $(\mathrm{p}=0.006)$.

Conclusión: Estos resultados indican cómo los nadadores manejan los limitantes de la fase de transición y dan aplicaciones claras a los entrenadores en los aspectos técnicos clave aspectos que se deben enfatizar al hacer la transición del nado subacuático al nado en superficie. 


\section{Declaration}

I, Jelena Stosic, declare that the Doctor of Philosophy thesis entitled "Transition phase - a new phase from start to free swimming phase in competitive swimmers" is no more than 100,000 words in length including tables, figures, appendices, and references. This $\mathrm{PhD}$ thesis contains no material that has been submitted previously, in whole or in part, for the award of any other academic degree or diploma. Except where otherwise indicated, this thesis is my own work.

Signature:

Date: 


\section{Acknowledgments}

I would like to express my greatest gratitude to my supervisor Associate Professor Santiago Veiga for his greatest knowledge about the swimming science and practice. His enormous and in depth knowledge and experience and his unreserved giving of advices all the time throughout all the stages of my doctoral pathway, definitely help me in my maturation as a researcher. Santi, thank you for being patient, wise and virtuous in delivering timely each of the advices and for encouraging my critical thinking in the process of my research trail.

I would also like to express my great gratitude to Maria de Gador Faura, who was helping me since I set foot in Madrid. She was reminding me and advising me not only about the administrative things, but we also shared inter-cultural ideas and I learned a lot from her about Madrid, Spanish life and culture, and more. Thank you Gador, very much.

I would like to thank to Professor Enrique Navarro, his lab and his PhD students from which I learned about research in between working on my thesis.

I would like to thank to Professor Milivoj Dopsaj for his enormous experience and knowledge about swimming science and practice and for sharing some interesting ideas about swimming research, practice and statistics.

I would like to thank to staff from INEF library for being enormous friendly, fully dedicated to all my questions, quickly answering and addressing the issues that were far above their duties and which they did just to help me, simply because they have the greatest traits of all, and that is simply being human for no reason. Thank you guys, I hope I can send you some sweets from my country (Serbia), as I will not be able to be physically present with you as I promised a while ago. 
I would like to express my thanks to INEF Faculty and to many other people in INEF and in Madrid in general, and in my country (Serbia), who helped me in expected and unexpected situations, some of them that I do not remember, but which good gests are written somewhere.

My greatest thanks belong to my family. First of all to my mum. Mum, no pages are enough to express how deeply gratitude I am. Mum, you are the first and the most important person thanks to who I have this thesis finished. Thank you until the sky and back, billion times thank you. Thank you, my mum, thank you my dad, thank you my sister, thank you my niece Nina and thank you my brother. You all are my alfa and omega, my support and my strength. My dear Mum, this thesis is my gift to you, because you most believed in me and always encouraged me. 


\section{Agradecimientos}

Mi mayor agradecimiento se lo debo a mi profesor Santiago Veiga por su gran conocimiento acerca de la natacion como ciencia y práctica. Por su gran y profundo conocimiento y experiencia y sus consejos dados sin reservas todo el tiempo que me ayudaron definitivamente en mi crecimiento como investigadora. Santi, gracias por ser paciente, inteligente y por sobre todo el tiempo que me dedicaste dándome consejos y levantando mi pensamiento crítico en el proceso de mi investigación.

Quisiera darle mi mayor agradecimiento a Maria de Gádor Faura quien me ayudó desde que llegué a Madrid. Ella me recordaba y me advertía no solo en las cosas administrativas sino también intercambiamos ideas de cultura, donde aprendí mucho sobre Madrid, su vida y su cultura y mucho más. Muchas gracias, Gádor.

Quisiera agradecer al profesor Enrique Navarro, su laboratorio y sus alumnos del doctorado de los cuales aprendí sobre la investigación y mi trabajo de investigación.

Quisiera agradecer al profesor Milivoje Dopsaj por su gran conocimiento acerca de la natación como ciencia y práctica, y por compartir conmigo algunas ideas interesantes sobre la natacion como ciencia e investigación, práctica y estadística.

Quisiera agradecer al personal de la biblioteca INEF por su increíble amistad conmigo, por su completa dedicación a mis preguntas, por su rapidez en responderme y por su atención a mis problemas fuera de sus deberes, porque ustedes tienen la mayor de las cualidades y es ser humanos. Gracias a todos, y espero poder mandarles algunos dulces de mi país Serbia porque no estaré presente físicamente con ustedes como se los prometí.

Quisiera agradecer a la Facultad de Ciencias de la Actividad Física y del Deporte (INEF) y otras personas del INEF, y en general en Madrid y a mi país Serbia por ayudarme en situaciones esperadas y no esperadas, de las que no me acuerdo, pero son buenas y quedaron grabadas. 
Mi mayor agradecimiento se lo debo a mi familia, ante todo a mi madre. No existen páginas suficientes para describir la profundidad de tu apoyo. Mami, eres la primera persona y la más importante por la cual esta tesis ha llegado a su fin. Gracias hasta el infinito. Gracias mamá, gracias papá, gracias a mi hermana Bilja, gracias a mi sobrina Nina y gracias a mi hermano Dejan. Ustedes son mi alfa y omega, mi soporte y fuerza. Mi querido Mami, esta tesis es mi regalo para ti, porque creíste en mí más y siempre me animaste. 


\section{Захвалност}

Своју највећу захвалност дугујем мом ментору, ванредном професору Сантиагу Веиги, за његово огромно знање о пливачкој науци и пракси. Његово огромно и дубоко знање и искуство и његово безрезервно давање савета све време кроз све фазе мог докторског путешествија, су ми дефинитивно помогли у мом сазревању као истраживача. Санти, хвала ти што си био стрпљив, мудар, и што си ми на време давао сваки од савета и што си подстицао моје критичко мишљење у процесу мог истраживачког пута.

Желела бих да изразим своју огромну захвалност Марији де Гадор Фаура која ми је помагала од како сам закорачила у Мадрид. Она ме је подсећала и саветовала ме не само о административним стварима, него смо такође делиле међу културне идеје и од ње сам научила много о Мадриду, шпанском животу и култури и још много тога. Хвала ти пуно, Гадор.

Желела бих да захвалим професору Енрикију Навару, његовој лабораторији и његовим докторским студентима од којих сам научила о истраживању између рада на мојој докторској тези.

Желела бих да захвалим професору Миливоју Допсају за његово огромно искуство и знање о пливачкој науци и пракси и што је поделио са мном неке интересантне идеје о пливачком истраживању, пливачкој пракси и статистици.

Желела бих да захвалим особљу ИНЕФ библблиотеке што су невероватно пријатељски настројени према мени, потпуно посвећени свим мојим питањима, брзо одговарајући и посвећујући се проблемима који су били ван њихових дужности, зато што имају највећу особину од свих, а то је да су једноставно човекољубиви, без посебног разлога. Хвала вам људи, надам се да ћу моћи да вам пошаљем неке слаткише из моје земље (Србије), пошто нећу бити физички присутна са вама јер сам вам још онда обећела. 
Желела бих да изразим своју захвалносту Факултету ИНЕФ и многим људима у ИНЕФ-у и Мадриду генерално, и у мојој земљи (Србији) који су ми помогли у очекиваним и неочекиваним ситуацијама, неких их се и не сећам, али чија су добра дела остала записана негде.

Моја највећа захвалност припада мојој породици. Пре свих мојој мами. Мама, странице нису довољне да опишу колико дубоко сам ти захвална. Мама, ти си прва и најважнија особа захваљујући којој имам ову тезу завршену. Хвала ти до неба и назад, милијарду пута ти хвала. Хвала ти мама, хвала ти тата, хвала ти сестро Биљо, хвала ти сестричино Нина и хвала ти брате Дејане. Ви сте моји алфа и омега, моја подршка и снага. Драга моја Маро, ова теза је мој поклон теби, јер си највише веровала у мене и увек ме бодрила. 


\section{Table of contents}

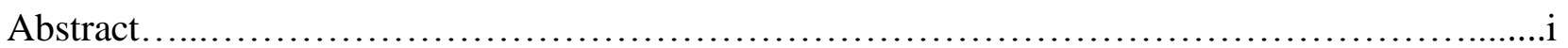

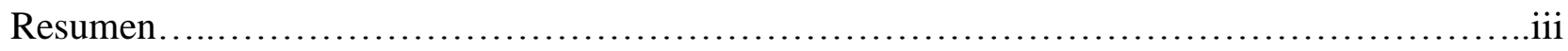

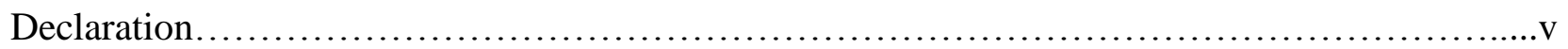

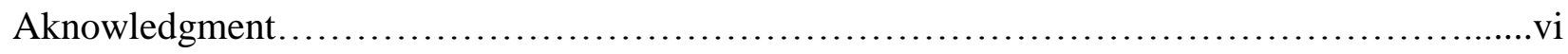

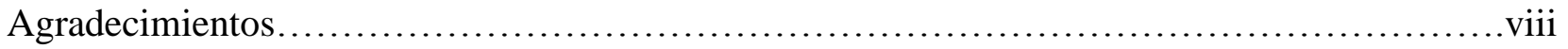

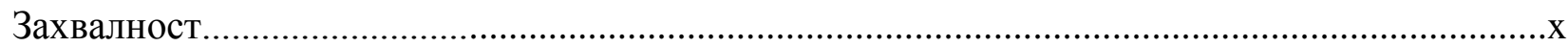

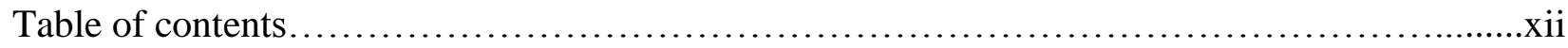

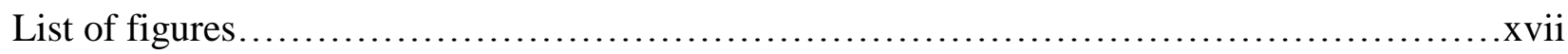

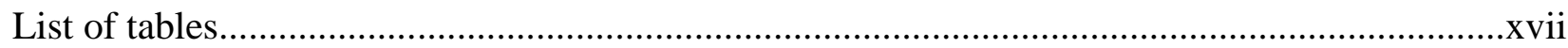

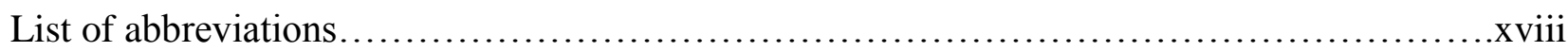

Chapter 1. Research background......................................................

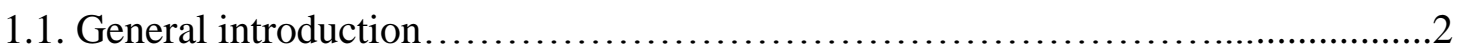

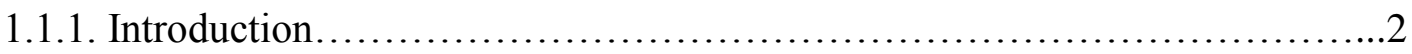

1.1.2. State of the problem................................................

1.2. A literature review..............................................................4

1.2.1. Kinematical aspects of swimming..................................

1.2.2. Coordinative aspects of swimming ................................ 
1.2.2.1. Freestyle coordination............................................6

1.2.2.2. Backstroke coordination..................................11

1.2.2.3. Butterfly coordination.................................14

1.2.2.4. Breaststroke coordination.................................16

1.2.3. Segmental aspects of swimming...............................23

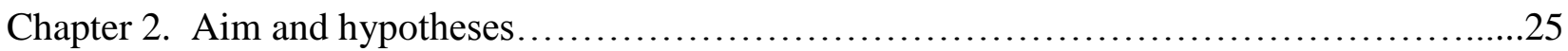

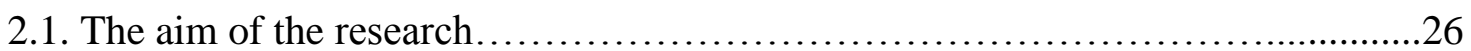

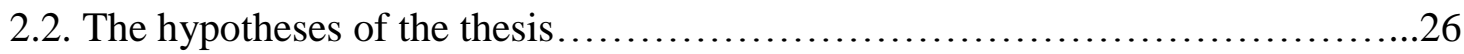

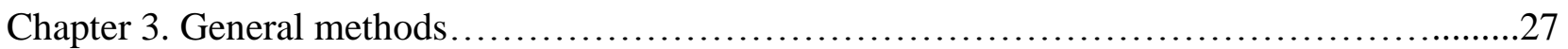

3.1. Participants' description..........................................28

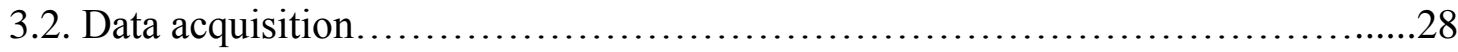

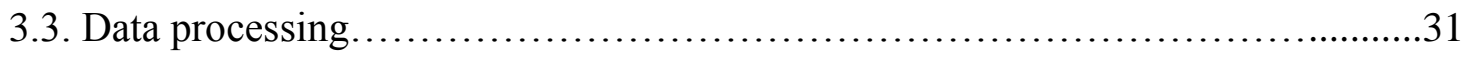

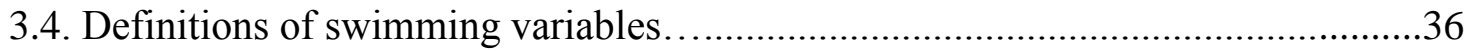

3.4.1. Breakout kinematics and segmental variables..............................36

3.4.1.1. Pre-transition variables......................................36

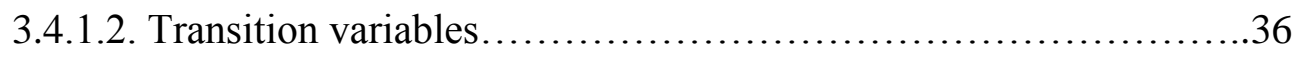

3.4.2. Free swimming kinematics variables...................................38

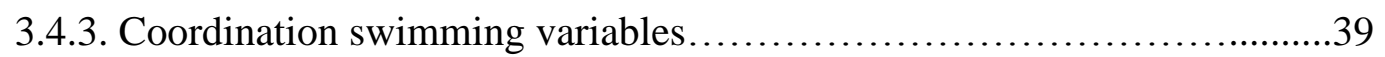

3.4.4. Stroke phase swimming variables................................41 


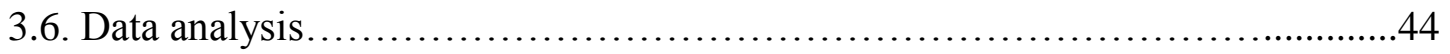

Chapter 4. Study 1 - Gender differences in performing a swimming breakout phase. .47

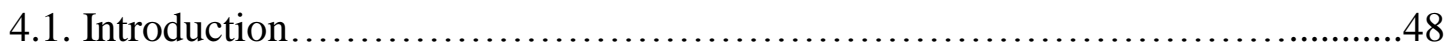

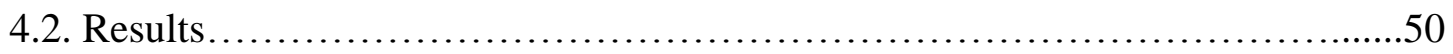

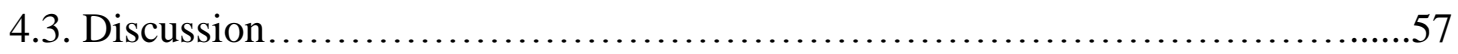

Chapter 5. Study 2 - Effect of breakout phase on kinematic and coordinative swimming

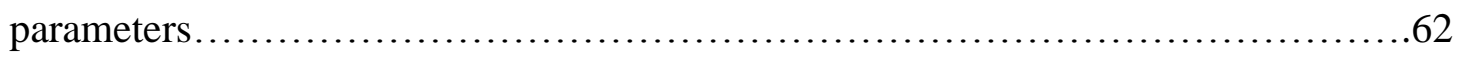

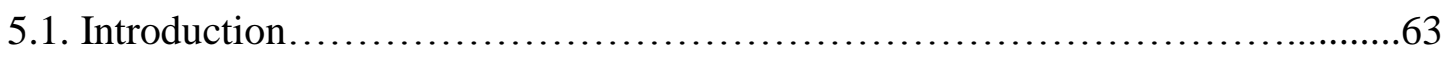

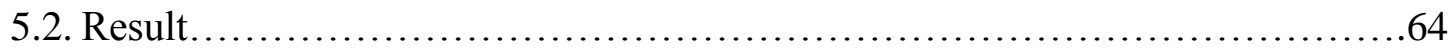

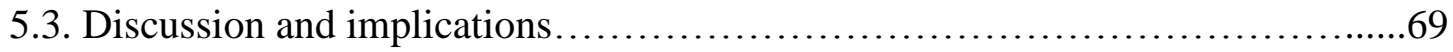

Chapter 6. Study 3 - How the transition from underwater to surface swimming should be

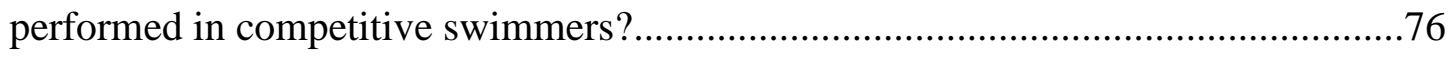

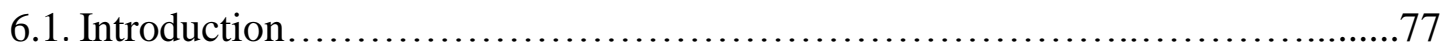

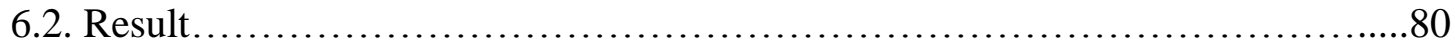

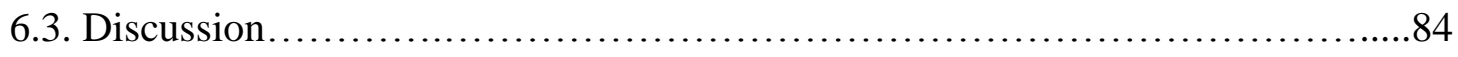

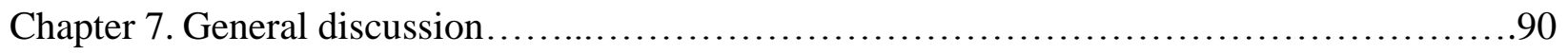

7.1. Summary and discussion of main findings................................91

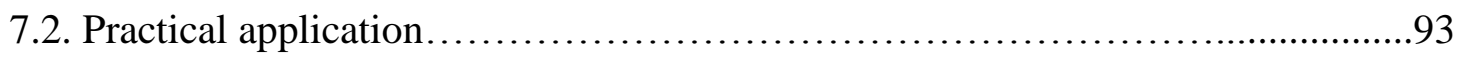


Chapter 8. General conclusion..................................................... 96

8.1. General conclusions...............................................97

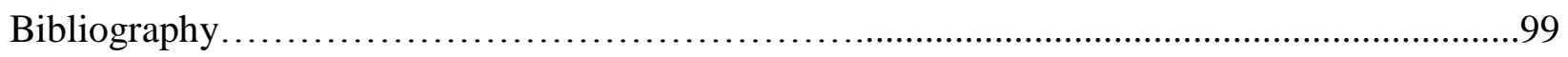

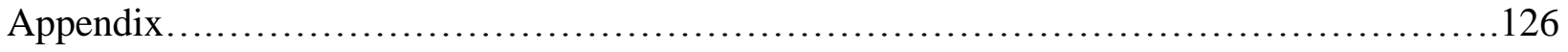




\section{List of figures}

Figure 2.1. Three types of freestyle coordination................................................

Figure 2.2. Arm stroke phases in backstroke of the left and right arms.........................12

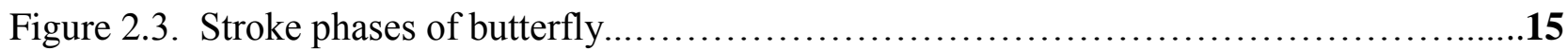

Figure 2.4. Arms and legs stroke phases in the flat breaststroke...............................19

Figure 2.5. Time gaps between arms and legs stroke phases in breaststroke......................20

Figure 3.1. Camera positions in relation to the starting pool-wall and to the swimmer's pool-

lanes.

Figure 3.2. Non-elastic ropes with a $5 \mathrm{~kg}$ dumbbell employed for calibration purposes with the DLT-2D technique.

Figure 3.3. PVC structure situated on the lanes ropes for calibration purposes with the DLT-2D technique

Figure 3.4. Schematic illustration of the pre-transition (a) and transition (b) phases from underwater to surface swimming..... .33

Figure 3.5. The interface of Photo 23D software.

Figure 3.6. The interface of BIOMECH.EXE software. 35

Figure 3.7. The pixels (notepad file) transferred into real meter units .35

Figure 3.8. Time lag ( $\mathrm{t}$ ) between two sinusoidal rhythmic cyclic activities; $\mathrm{T}$ - duration of a cycle

Figure 6.1. Relationships between the kinematic, segmental and coordination variables with average velocity of the competitive swimmers in the pre-transition (a) and transition (b) of the push start. 


\section{List of tables}

Table 3.1. Mean \pm standard deviation, minimum and maximum values of participants characteristics.

Table 4.1. Pairwise gender comparison of the kinematic variables (velocities, lengths and frequencies) across swimming phases within breakout (pre-transition and transition) and free swimming in all strokes

Table 4.2. Pairwise gender comparison of the coordinative variables (discrete relative phases, DRP) across swimming phases within breakout (i.e. transition phase) and free swimming in all strokes.

Table 4.3. Pairwise gender comparison of the segmental variables (body and trunk inclinations and body depths) within breakout (i.e. transition phase). .56

Table 5.1. Swimming kinematics of competitive swimmers in the different phases from underwater to surface swimming.... 65

Table 5.2. Stroke phases duration $(\%)$ of competitive swimmers from underwater to surface

swimming.

Table 5.3. Coordinative parameters (discrete relative phase, DRP) in degrees of competitive swimmers from underwater to surface swimming.

Table 6.1. Descriptive statistics - mean (standard deviation) - of the pre-transition and transition variables in all four strokes for competitive swimmers

Table 6.2. Backward regression analysis (the influence of segmental and coordination parameters on performance in pre-transition and transition phase in all four strokes). 


\section{List of abbreviations}

DRP - discrete relative phase

SL - stroke length

$\mathrm{SR}$ - stroke rate

TSL - transition stroke length

TSR - transition stroke rate 


\section{CHAPTER 1}

\section{RESEARCH BACKGROUND}




\section{Chapter 1 Research background}

\subsection{GENERAL INTRODUCTION}

\subsubsection{Introduction}

Competitive swimming is the most investigating form of human swimming in the last 45 years (Barbosa et al., 2010). According to Hay (Hay, 1985), the performance in competitive swimming is defined as the minimum time required to cover a given distance - in other words the better the average swimming velocity, the better the swimming performance. The total time employed to cover the race distance is divided for analysis in different segments, usually the start, free swimming and turn times. According to FINA regulations (www.fina.org) swimmers must resurface before a mark which is at $15 \mathrm{~m}$ from swimming start or turn wall. Free swimming is by the FINA rules defined as the time swimmer spends swimming at water surface after 15 m defined mark, regardless if swimming head breakout happened before. This is in swimming literature defined as fixed distance method for evaluating start and free swimming segments, although individual distance measure which take into account single distances of breakout for each swimmer, has been found to be more accurate for swimming performance evaluation (Veiga, Cala, Mallo, \& Navarro, 2013).

There are different stroke (Craig, Skehan, Pawelczyk, \& Boomer, 1985; Craig \& Pendergast, 1979), segmental (Blanksby, Simpson, Elliott, \& McElroy, 1998), kinetic (Lyttle, Blanksby, Elliott, \& Lloyd, 1998; Lyttle et al., 1999), kinematical (Atkison, Dickey, Dragunas, \& Nolte, 2014) and coordinative (Chollet \& Seifert, 2011) factors which influence velocity in each of the race segments. Most often those parameters are investigated in free swimming phase, although the non-swimming parts (start and turns) also make significant contribution to the total swimming performance (Mooney et al., 2016). Specifically, some of the subphases of the start and turn such as the gliding (Lyttle \& Blanksby, 2000) or the underwater undulatory kicking (Veiga, Roig, \& Gómez-Ruano, 2016) have been reported as key elements to significant time gains. 


\subsubsection{State of the problem}

However, to the best of our knowledge, there is no research dedicated to the transiting swimming performance from underwater to surface swimming. All the benefits swimmer gained during underwater swimming will not be automatically transferred to surface swimming if the proper transition from underwater to surface swimming is not performed. Although, there exists a large number of underwater kinematic swimming studies and a number of surface kinematic and coordinative studies, there is no studies that examined profoundly breakout phase. Therefore, in the present research, we pay attention to the swimmers' transition from the underwater to the surface swimming, which occurs in every start or turn of a swimming race and where no descriptive or inferential data have been reported for competitive swimmers. 


\subsection{A LITERATURE REVIEW}

\subsubsection{Kinematical aspects of swimming}

From the pioneering work of swimming research (Curry, 1975) until the end of twentieth century performance of swimming was evaluated by stroke distance (length) and stroke rate (frequency), which when multiplied give swimming velocity. In the $21^{\text {st }}$ century coordinative aspects of performance have been also taken into account (Chollet et al., 1999).

Swimming technique itself was evaluated by the redistribution of stroke length and stroke rate, as well as their relationship throughout the course of different swimming events. Strong correlations of SL and SR with velocity have been found in the pioneering work on swimming kinematics (Chatard et al., 1990). How swimmers will use stroke length and rate within one swimming event is dependent on physiological and speed demands. In other words, redistribution of stroke length and stroke rate will depend on whether the swimmers participate in sprint, middle or long distance events. Shorter (all and out events, i.e. $50 \mathrm{~m}$ ) events will have swimming velocity that is formed by high stroke rate. With increase in swimming distance (i.e. from $50 \mathrm{~m}$ to $200 \mathrm{~m}$ ), stroke rate and velocity start to decrease, while stoke length start to increase (Arellano et al., 1994). However, even in shorter events (100 m), progressive decrease of SL is present. Swimmers are able to keep high SL only in first lap, while in the second and third, there is a decrease, and final decrement is observed in the last lap (Letzelter \& Freitag, 1983). Similar pattern is observed in progressive increase in speed, when swimmers gradually increase speed, i.e. from long and middle distances to sprint distances; this happen on the expense of increasing stroke rate and at the same time decreasing stroke rate (Craig \& Pendergast, 1979).

Keskinen and Komi (1993) accentuated the importance of measuring (testing) fatigued swimmers as this situation reflects more real (i.e. competition situation). Namely, when swimmers overreach lactate threshold, there is a decrease of SL. When swimmers do not have enough neural capacity to increase SR, 
the velocity decrease will occur. However, in the situation of maximal swimming with no lactate constraint, it is up to swimmers, their training history and regime how they will organize contribution of stroke length and stroke rate in building velocity (Craig \& Pendergast, 1979).

From the above discussion, two conclusions could be made: 1) there exist orderliness of the behavior of stroke length and rate when swimming distances/events increase/decrease and when physiology demands change and 2) there is an individual aspect of each swimmer in terms of contribution of stroke rate and length to velocity seen in the situation of maximal swimming when physiology demands are not taken into account.

This second conclusion may be further tested in the situation when some other aspects of technique are analysed, when coordination aspects are examined in relation to kinematic aspects. Alberty and his colleagues (Alberty et al., 2008) kept stroke rate under control while examined what happened with coordination. They found out that keeping stroke rate constant also keep coordinative parameters constant. When stroke rate was not controlled, swimmers were increasing stroke rate in order to maintain velocity which caused changes of swimming coordination.

\subsubsection{Coordinative aspects of swimming}

Kinematics represents just one aspect of the swimming technical skills, while not giving full insights of the motor organization of the swimming skills (Seifert \& Chollet, 2009). Therefore, motor organization refers to coordinative aspects of swimming which are (in addition to kinematic aspects) largely important to understand full swimming skills.

The most traditional theory of the motor organization of movement is the one from Bernstein (1967) which suggests that human systems have more degrees of freedom than it is necessary to accomplish motor tasks. This redundancy at end point effector was considered negative and threated as motor noise or error. Therefore, it was advised that redundancy needs to be restricted by freezing unnecessary degrees 
of freedom to have movements with least possible error. However, redundancy is just one aspect of observing plentiful degrees of freedom. Rather, when observing them abundant, that indicates richness of movement and the origins may be found in dynamic system theory. The dynamic system theory suggests that degrees of freedom are "the number of independent coordinates required to uniquely describe the configuration of system." The coordinates or degrees of freedom will be evoked in circumstances of new constraints that act upon movement. This was suggested by Davids et al. (2008) indicating that adaption of human motor response to new constraints is called motor abundancy or variability of movement.

\subsubsection{Freestyle coordination}

In order to reveal coordination patterns in different swimming styles (strokes), it is necessary to identify stroke phases which represent combination of propulsive and non-propulsive phases / forces. Propulsion is a swimming force used to overcome swimming resistance (Karpovich, 1933; 1935). Regarding freestyle, propulsion has been investigated as early as in the middle of twentieth century (Alley, 1952). Belokovsky (1971) used force transducer to measure the amount of force freestyle swimmers produce during the underwater arm pull motion. According to the distribution of force within the propulsive cycle

(from the beginning to the middle) they identified three swimming stroke patterns: exponential, trapezoidal and sinusoidal.

Vaday \& Nemessuri (1971) further analyzed the motor action of limb motion (both arms and legs) used in freestyle with the voluminous explanations of the muscles involved. They noticed that freestyle motion happened due to actions of two propulsive forces which are "pulsion" and "traction" which correspond to pull and push actions. This work was introduction to nowadays swimming coordination display as it explained full swimming cycle of arms and legs from its beginning to its end. The authors observed a combination of pulsion and traction that resulted in total of eight movement parts. Propulsive action 
lasted around 40 percent of the duration of the swimming cycle, while rest (60 percent) implied preparation for propulsion and included release, recovery and gliding. Gliding in freestyle is nonpropulsive part of swimming and it actually refers to catch movement. During one arm(s) cycle, legs perform a total of six bits (strokes) which match to 3 bits (strokes) per leg. It is interesting to note that those authors also analyzed trunk movement and observed a total of four rotations: two inward and two outward.

Rackham (1975) stated that proper swimming technique relies on a proper combination of pulling and sculling movement, which has been also noticed by the studies of by Schleihauf (Shleihauf,, 1974; 1979) who observed three-dimensional arm movement and revealed that the largest propulsive force occurred at the end of arm pull (Schleihauf et al., 1988).

Maglischo et al. (1988) also measured propulsive phases / forces of the underwater arm motion accentuating three-dimensional arm pathway in which four distinctive phases were observed: 1) downsweep - it begins after arm's entry and also implies arm outward and backward movement and finishes when hand starts inward motion; 2) in-sweep - it implies arm (hand) inward motion and movement finish with beginning of outward motion; 3) out-sweep - it implies arm (hand) outward motion that ends when arms starts upward motion towards surface; 4) up-sweep - it implies upward (also backward and outward) arm (hand) movement until arm (hand) movement become upward and forward (usually this movement should coincide with water exit). All four phases Maglischo et al. (1988) described as propulsive, but also pinned down that only two out four phases were with propulsive peaks. Some swimmer had the first propulsive peak at the end of down-sweep and the second propulsive peak during up-sweep, while some other swimmer had one propulsive peak during in-sweep, and another propulsive peak during out-sweep. The authors also distinguished between two types of swimmers, one vertically oriented and other laterally oriented. Vertically oriented were very effective in down-sweep and upsweep motions and less effective in in-sweep and out-sweep, while laterally oriented swimmers were 
very effective in in-sweep and out-sweep motion, and less effective in down-sweep and up-sweep motion.

Although three-dimensional motion arm motion in swimming is indisputable, two-dimensional analysis of motion pattern could be an alternative and more easily afforded method for analyzing swimming coordination. Especially, when taken into account that in all three-dimensional studies it was analyzed the pattern of arm movement and the amount of produced propulsive forces, while at the same time it was neglected the phase relationship between the arms (i.e. an inter-limb coordination).

Following the idea of simple inter-limb rhythmic coordination (i.e. between two fingers or two hands) (Kelso et al., 1986), the swimmer researchers also wanted to numerically define more complex cyclic coordination between arms in freestyle swimmers. Therefore, a complete new approach into swimming coordination was proposed by Chollet et al. (Chollet, Chalies, \& Chatard, 1999), where lag between limbs (i.e. arms) was expressed as phase lag (relative phase angles). The authors offer simple and useful formulas to quantitatively measure swimmers' coordination, but the values were expressed as percentage of time of the total duration of cycle. Those percentages of times in inter-limb coordination were named (indexes of coordination, IdC) (Figure 2.1.), based on 1) the existence of lag time between arms, 2) when there was no lag time (continuous movement), or 3) when arms overlapped in propulsion. Lag time was defined as the time between the beginning of first right arm stroke and the end of first left arm stroke. The existence of lag was named catch-up coordination $(\mathrm{IdC}<0)$ and indicated that left arm stroke has finished propulsion before the right arm stroke started propulsion. When there was not lag time (opposition mode, $\mathrm{IdC}=0$ ) the propulsion of right arm started at the same time when left arm finished propulsion. Finally, when two arms' actions overlapped (superposition mode, $\operatorname{IdC}>0$ ), it indicated that left arm was still pushing the water (was in propulsion) at the time right arm started propulsion.

Arms stroke phases names in two-dimensional area of research are different than the names used in threedimensional area of research (i.e. in-sweep, out-sweep etc.) and are defined as follows: 1) enter and 
catch: this phase correspond to the arm movement from the entry to the water to the start of backward movements; 2) pull: this phase corresponds to the start of backward movement to the arm's (hand's) arrival in the vertical plane of the shoulder; 3) push: this phase refer to the arm's movement beyond the shoulder plane until the exit from the water, 4) recovery: this phase corresponds to the period from arm's exit from the water to arm's re-enter to the water. 


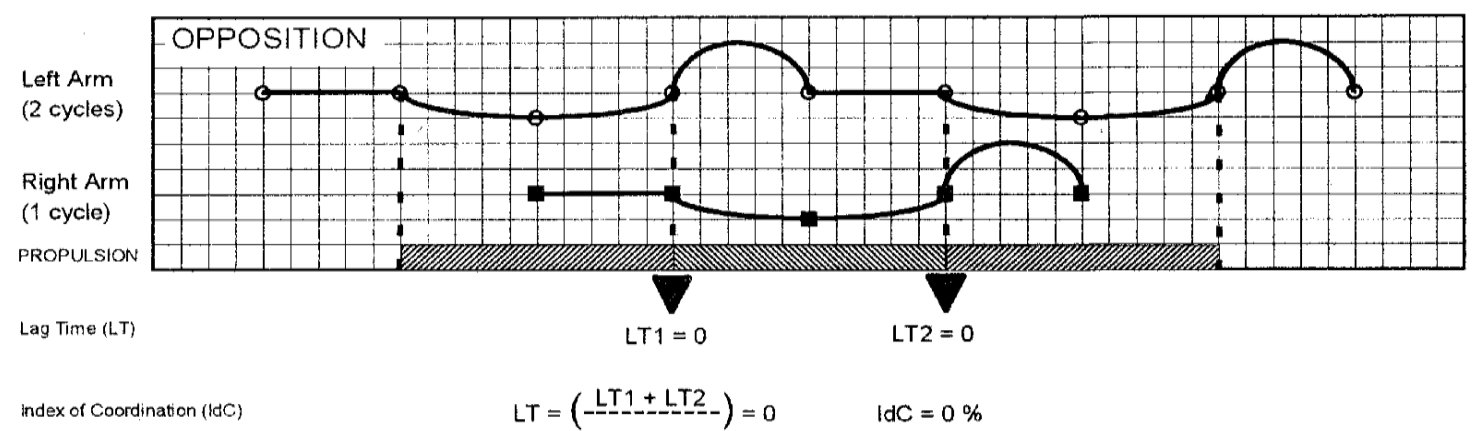

OPPOSITION : one arm begins the pull phase when the other is finishing the push phase

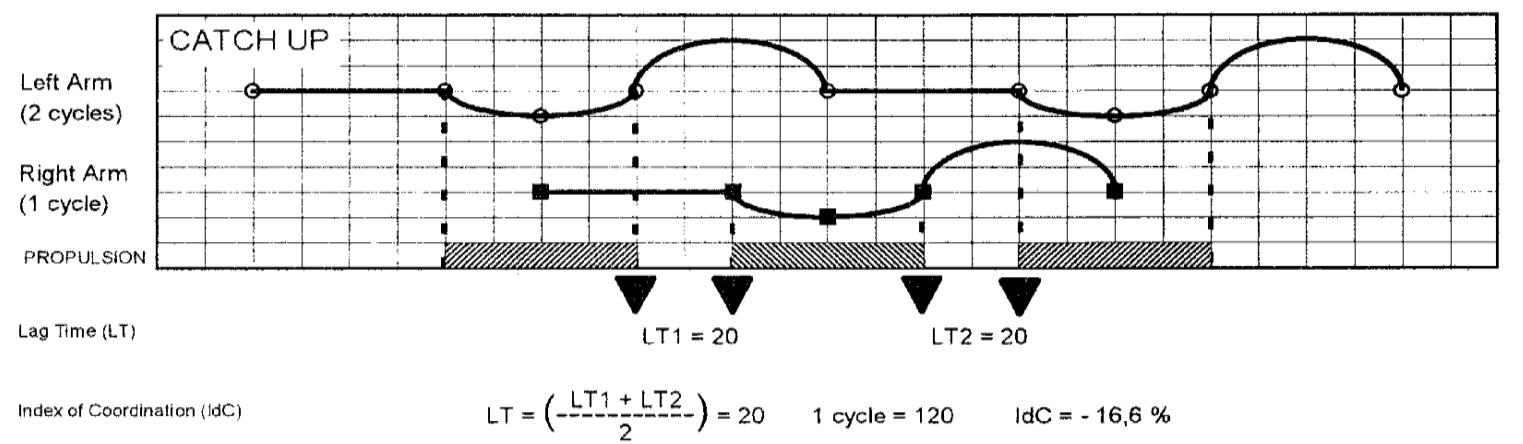

CATCH UP : a lag time takes place between propulsive phases of the two arms

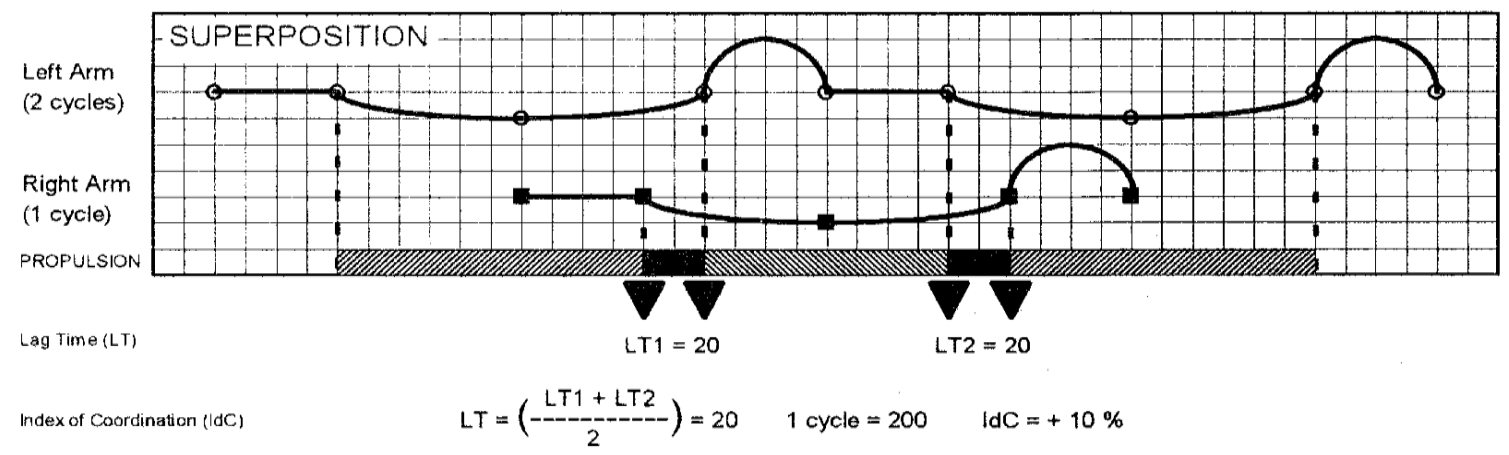

SUPERPOSITION : an overlap is situated in the propulsive phases

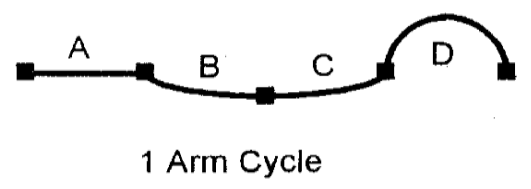
A : Non Propulsive Underwater Phase : ENTRY and $\mathrm{CATCH}$
$B$ : Propulsive Underwater Phase : PULL
$C$ : Propulsive Underwater Phase : PUSH
D : Non Propulsive Aerian Phase : RECOVERY

Figure 2.1.: Three types of freestyle coordination. Note: The figure is taken completely from Chollet and colleagues (Chollet, Chalies, \& Chatard, 1999). 
It is not common case that researchers apply three-dimensional swimming analysis to measure inter-limb swimming coordination (Figueiredo et al. 2010), but rather researchers use three-dimensional swimming analysis to observe arm's (hand's) pathway (Payton, \& Barlett, 1995). However, in the case when threedimensional swimming analysis is used, it is not oriented to intermittent relationship (temporal or phase lags) but rather continuous relationship between moving limb (i.e. continuous inter-limb coordination).

Classification of the freestyle coordination could be further done according to progression of an event, duration of events, swimmers expertise, gender etc.

\subsubsection{Backstroke coordination}

In addition to kinematical aspects of backstroke swimming, researchers of this stroke often addressed swimming economy aspects associated with physiological aspects (Smith et al., 1988; Klentrou \& Montpetit, 1992; Alves et al. 1996) to give some fundamental answers on bioenergetics of backstroke. However, motor coordination of backstroke was not addressed in prior 2000 year research. The only study which addressed swimming phases throughout the full stoke / cycle and therefore coordination swimming aspects prior 2000 year is the one from Masset and colleagues (Masset et al., 1999).

Earlier research (i.e. before 2000 year) addressed motor organization and coordination aspects in three strokes (freestyle, butterfly and breaststroke). Although these studies were not methodologically well grounded to give complete coordination measurement guide, they served as a good "guidebook" and solid base for future research in the three strokes.

Nevertheless, this "guidebook" did not exist for backstroke until 2000 year. However, after Chollet et al. (Chollet, Chalies, \& Chatard, 1999) proposed Indices of coordination (IdC) for freestyle Lerda \& Cardelli (2003) adapted the IdC1 and IdC2 for the backstroke. While in freestyle, all three scenarios exists (IdC = 0 - motor continuity between arms, IdC $<0$ - motor discontinuity between arms, IdC $>0$ - propulsive 
overlap between arms), in backstroke there is no theoretical chance for propulsive overlap between arms $(\mathrm{IdC}>0)$, mainly because of the nature of shoulder joint in this type of backstroke coordination.

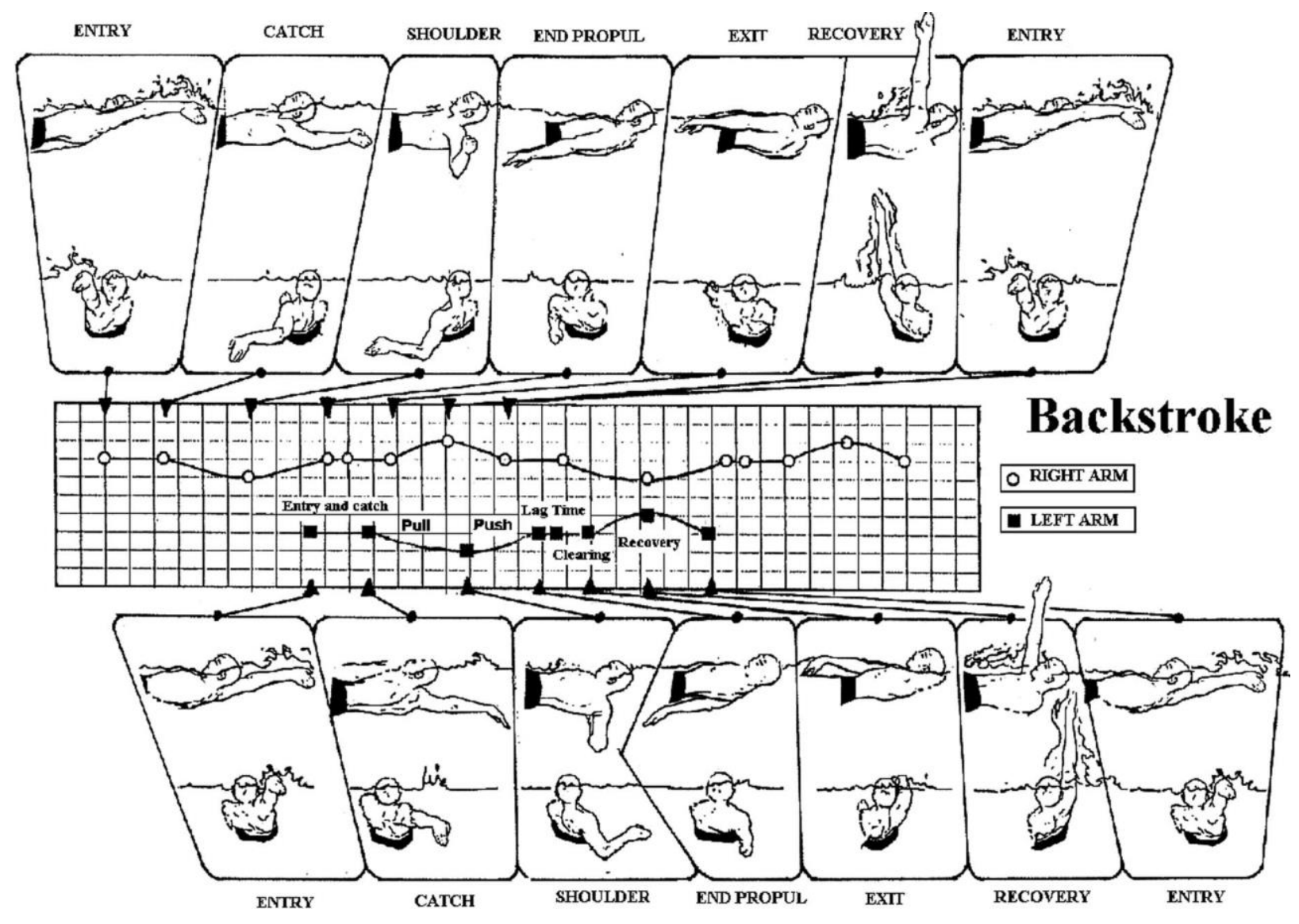

Figure 2.2.: Arm stroke phases in backstroke of the left and right arms. Note: The figure is taken completely from Chollet and colleagues (Chollet et al. 2008).

The coordination model for freestyle of Chollet et al. (Chollet, Chalies, \& Chatard, 1999) was starting point for Lerda \& Cardelli (2003) to determine indices of coordination in backstroke. First, the coordination between left and right arm in backstroke was characterized to be in lag mode (IdC $<0$ ), while there was no word about motor continuity between arms $(\mathrm{IdC}=0)$, or overlapping of arms propulsions ( $\mathrm{IdC}>0$ ). Therefore, rather than IdC, authors defined lag times (LT). LT was obtained when the beginning of pull of arm was subtracted from end of push (LT1) or from end of clearing (LT2). When 
the beginning left arm pull was subtracted from the end of right arm push or recovery, lag times were LT1a and LT2a, respectively. Alternatively, when the beginning of right arm pull was subtracted from the end of left arm push or recovery, lag times were LT1b and LT2b. Since there was no difference in the lag times between left and right arms were not significantly different they were averaged to get two single lag times LT1 and LT2 which were transferred to IdC. IdC1 was average value of LT1a and LT1a, while IdC2 was average value of LT1b and LT1b. The IdC1 measured continuity of propulsive action the greater the value the more propulsive continuity and finally if it approached $0-$ the coordination is perfectly continuous - i.e. in opposition. When it is less than 0 , coordination is in propulsive discontinuity, which means there is a lag in propulsive actions of arms - non propulsive arm activity. When IdC > 0, which in backstroke could not be achieved, propulsive arm actions overlap - the coordination is in superposition. IdC2 measured the degree of simultaneity between beginning of arm pull and recovery of the other arm. The closer this value to 0 , there is more simultaneity.

The reason why only non-propulsive continuity (i.e. $\mathrm{IdC}<0$ ) is possible in backstroke is determined by anatomical factors, packed in a limited flexibility of shoulder joint (Richardson, 1986; Richardson et al., 1980). In order to overcome this shoulder joint constraint, an extra phase after a push phase will enable exit from the water: the clearing phase. Indeed, it is the clearing phase which disables propulsive continuity between two arms and allows only catch up mode of coordination (where the gap between propulsive actions of arms is present).

Some years later, Chollet et al. (2008) gave graphical explanation (Figure 2.2.) of these stroke phases as well as the relationship between right and left, which was confirmed to be only catch-up (IdC < 0), as Lerda \& Cardelli (2003b) and Lerda \& Cardelli (2005) already revealed.

Chollet et al. (2008) proposed three solutions on how gap in propulsive activities between arms should be minimized and catch-up coordination mode brought closer to motor continuity (opposition mode). First, the clear phase should be diminished by increasing hand speed of this phase which could be achieved by 
rotating shoulder faster or larger. Second, swimmers should aim to make clearing phase more propulsive: that is to shift from "two peak propulsive stroke pattern" to "three peak propulsive stroke pattern" (Maglischo, 2014). Finally, the propulsive discontinuity from clearing phase and decrease in velocity due to non-propulsive should be balanced by increase in stroke length (i.e. distance per stroke).

Cortesi et al. (2012) showed that IdC of coordination decreased when swimming velocity increased from $70 \%$ of maximum velocity to maximum velocity, from $-6.5 \%$ to $-2.7 \%$ in $200 \mathrm{~m}$ specialist, and from $6.9 \%$ to $-2.1 \%$ in $50 \mathrm{~m}$ specialist. Therefore, swimmers increased propulsive continuity with increase in swimming velocity, but remained in catch-up, as only possible coordination mode for this swimming stroke.

The possibility to adapt coordination mode when changing pace from slowest to fastest is most limited in backstroke in comparison to other three strokes (Seifert et al., 2009).

\subsubsection{Butterfly coordination}

In order to establish swimmers' propulsive or motor continuity of butterfly stroke, proper coordination of arms and legs movements is required. Proper coordination between arms and legs in butterfly implies accurate congruence of the arms movement phases with leg movement phases. In the classic textbooks of Costill et al. (1992), Cousilman and Counsilman (1994), and Maglischo (1993), the authors gave precise recommendation when this coordination matching should happen: entry and outsweep should be during first down kick and upsweep should be during second down kick.

This initial recommendation served as starting position for Chollet and Boulesteix (2001) to describe graphically (Figure 2.3.) arms stroke phases and legs stroke phases of butterfly. Arms stroke phases are: catch phase, pull phase, push phase and recovery phase. Legs stroke phases are: down kick (downward phase) and up kick (upward phase). 


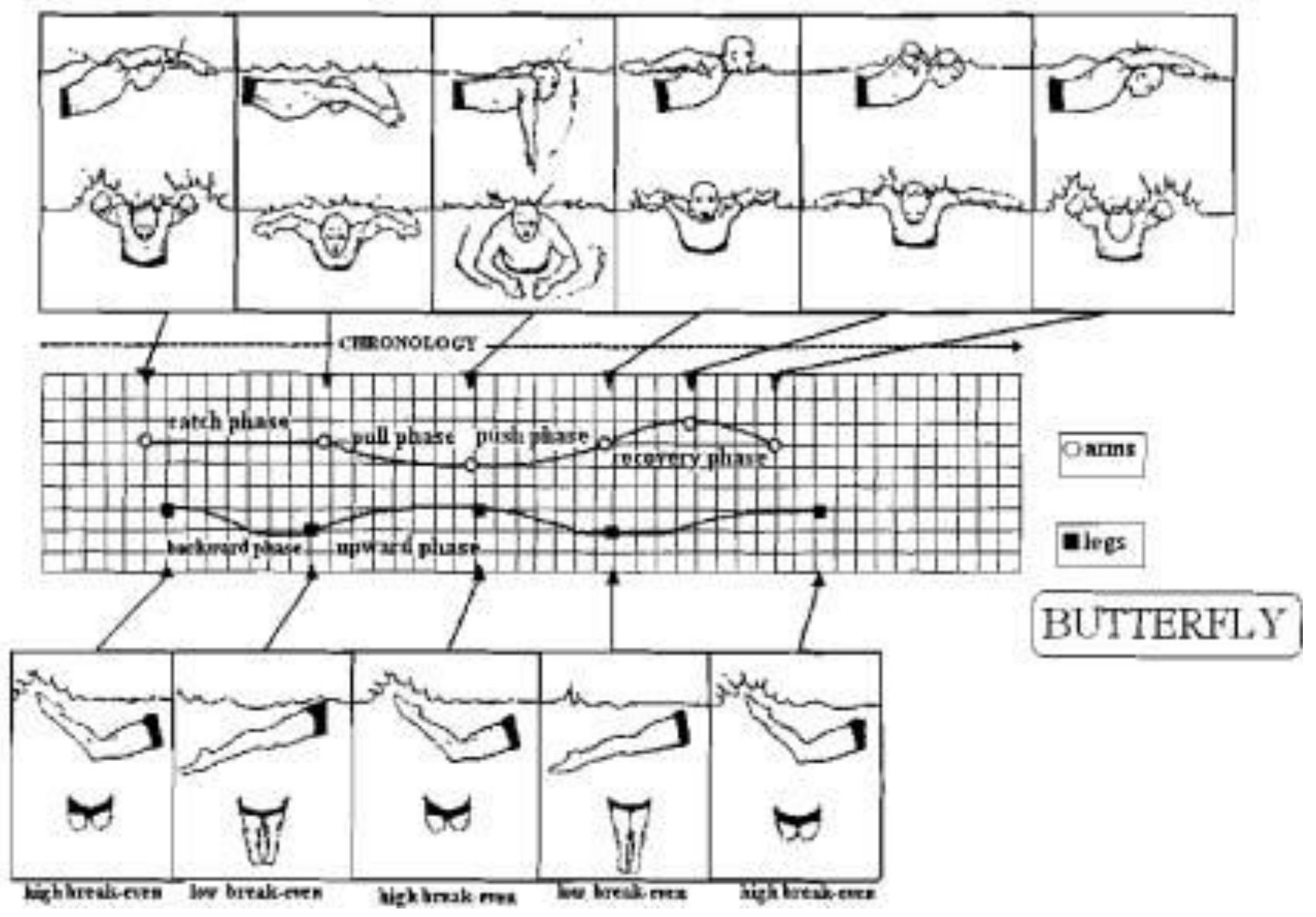

Figure 2.3.: Stroke phases of butterfly. Note: The figure is taken completely from Chollet and Boulesteix (2001)

Chollet et al. (2006) gave full explanation of the stroke phase of arms and legs, identifying in total four phases of arms and four phases of legs. Arms stroke phases are: 1) entry and catch phase - from arms entry to the beginning of backward movement, 2) pull phase - from the beginning of backward movement until arms reach vertical plane of shoulder, 3) push phase - from the arms in the vertical plane of shoulder until arms exit, 4) recovery phase- from arms exit until arms entry. Legs stroke are: 1) downward phase 1 - from the feet being in highest position to the point feet are in the lowest position of 
the first undulation, upward phase 1 - from the feet in the lowest position to the feet in the highest position of the first undulation, downward phase 2 - from the feet in the highest position to the feet in the lowest position of the second undulation, upward phase 2 - from the feet in the lowest position to the feet in the highest position of the second undulation.

Classification of the butterfly coordination could be further done according to the progression of an event, duration of events, swimmers expertise, gender etc.

\subsubsection{Breaststroke coordination}

Breaststroke is complex swimming stroke and as such is labeled as stroke where timing between arms and legs is of major importance (Barbosa et al., 2011). This could explain quite early research into the swimming breaststroke motor control (Nemessuri \& Vaday, 1971) and the organization of breaststroke coordination (Bober \& Czabanski, 1975).

The early research into motor control of breaststroke resulted in the models that characterize a full breaststroke cycle. Colman et al. (1992) compared flat and undulating breaststroke style and identified important frames (i.e. 6 stick figures) which served to measure the level of undulation which distinguish a flat from undulating breaststroke style. The first two stick figures were: the beginning of leg spreading and the end of leg spreading from which a leg phase was obtained: leg extension. The third stick figure measured one aspect of undulation and was named most dome-shaped position. The phase from the second to third stick figure could be referred to gliding. The fourth stick figure measured inverse aspect of undulation and was named s-shape position or $1 / 2$ arms spreading. The phase between the third and fourth stick figure could be named arm pull. Fifth stick figure was named most cambered uphill position and adequate phase between the fourth and the fifth stick figure could be related to arm push. Sixth and final stick figure was named knee $90^{\circ}$ recovery. The phase between the fifth and sixth stick figure could be named the first half of leg recovery, and the phase between the sixth and first stick figure - the second 
half of leg recovery. As it can be seen from this study the accent was given to the position of the body in relation to horizontal, namely to the level of body inclinations and the level of particular joints physical properties such are strength and flexibility that distinguish one breaststroke style from another in the most crucial phase points (i.e. stick figures or frames) within a cycle. There were no words about the important cycle phase names for legs and arms as well as their relationship.

A several year after, Chollet et al. (Chollet, Tourny-Chollet, \& Gleizes, 1999) accentuated the problem of not clearly defined breaststroke phases, as well as not established the relationship between phases (i.e. inter-limb coordination), which was meant to extend research efforts made by (Nemessuri \& Vaday, 1971) in defining breaststroke motor pattern. Chollet et al. (Chollet, Tourny-Chollet, \& Gleizes, 1999) initially stated the already known existence of four breaststroke phases: (1) arms propulsion, (2) simultaneous recovery of arms and legs, (3) legs propulsion and (4) glide. After addressing the time evolution of enumerated breaststroke phases in terms of manipulation (i.e. an increase) of velocity, they identified a total of 6 phases (including arms and legs): (1) leg propulsion, (2) arm propulsion, (3) glide, (4) arm recovery $90^{\circ}$, (5) leg recovery $90^{\circ}$, and (6) end leg recovery. Indeed, this study had not yet identified relationship between arms and legs phases (i.e. an inter-limb coordination).

In a similar manner, Silva et al. (2001) spelled out the phases distinctive for a breaststroke, which differed from the study of Chollet et al. (Chollet, Tourny-Chollet, \& Gleizes, 1999) in the way that they gave more detailed explanation of arm propulsion and leg propulsion. Silva et al. (2003) had a total of 9 breaststroke phases: (1) leg spreading, (2) $1^{\text {st }}$ leg squeezing, (3) $2^{\text {nd }}$ leg squeezing, (4) $1^{\text {st }}$ arm spreading, (5) $2^{\text {nd }}$ arm spreading, (6) $1^{\text {st }}$ arm squeezing, (7) $2^{\text {nd }}$ arm squeezing, (8) first arm recovery, (9) second arm recovery. Actually, for the first time authors identified the overlapping of phases (phase 3 and $4-2^{\text {nd }}$ arm squeezing and $1^{\text {st }}$ arm recovery) and consequently a total of 7 phases existed. The first important fact from this study is the division of arm propulsion on arms spreading and squeezing and of leg propulsion on legs spreading and squeezing. The second important information from this study is missing the 
mentioning or measuring of some phases: the leg recovery and glide.

Final identification of the breaststroke phases which was broadly accepted as final model nowadays for flat breaststroke was given by Chollet et al. (2004) who identified five phases in arms coordination and five phases in legs coordination. The five phases in legs coordination are: 1) leg propulsion - the time between legs are maximally flexed until the time legs are maximally extended, 2) leg insweep - the time between legs are extended until legs are joined, 3) legs glide - the time between legs are joined until first legs flexion movement / legs forward movement, 4) first part of the legs recovery - the time between first leg flexion movement until legs are flexed at 90 degrees, 5) the second part of the legs recovery - the time between legs are flexed at 90 degrees until legs are fully flexed. The five phases in arms coordination are: 1) arms glide - the time between arms fully extended until first backward arms movement, 2) arms propulsion (first part of arms propulsion) - the time between the beginning of backward movement until the end of backward movement, 3) elbow push (second part of arms propulsion) - the time between the end of arms backward movement until the beginning of arms forward movement and the end of inward elbows push, 4) first part of the arms recovery - the time between the end of elbows push and the beginning of arms extension until arms are at 90 degrees, 5) second part of the arms recovery - the time between arms are at 90 degreed flexed until full extension of arms (Figure 2.4). 


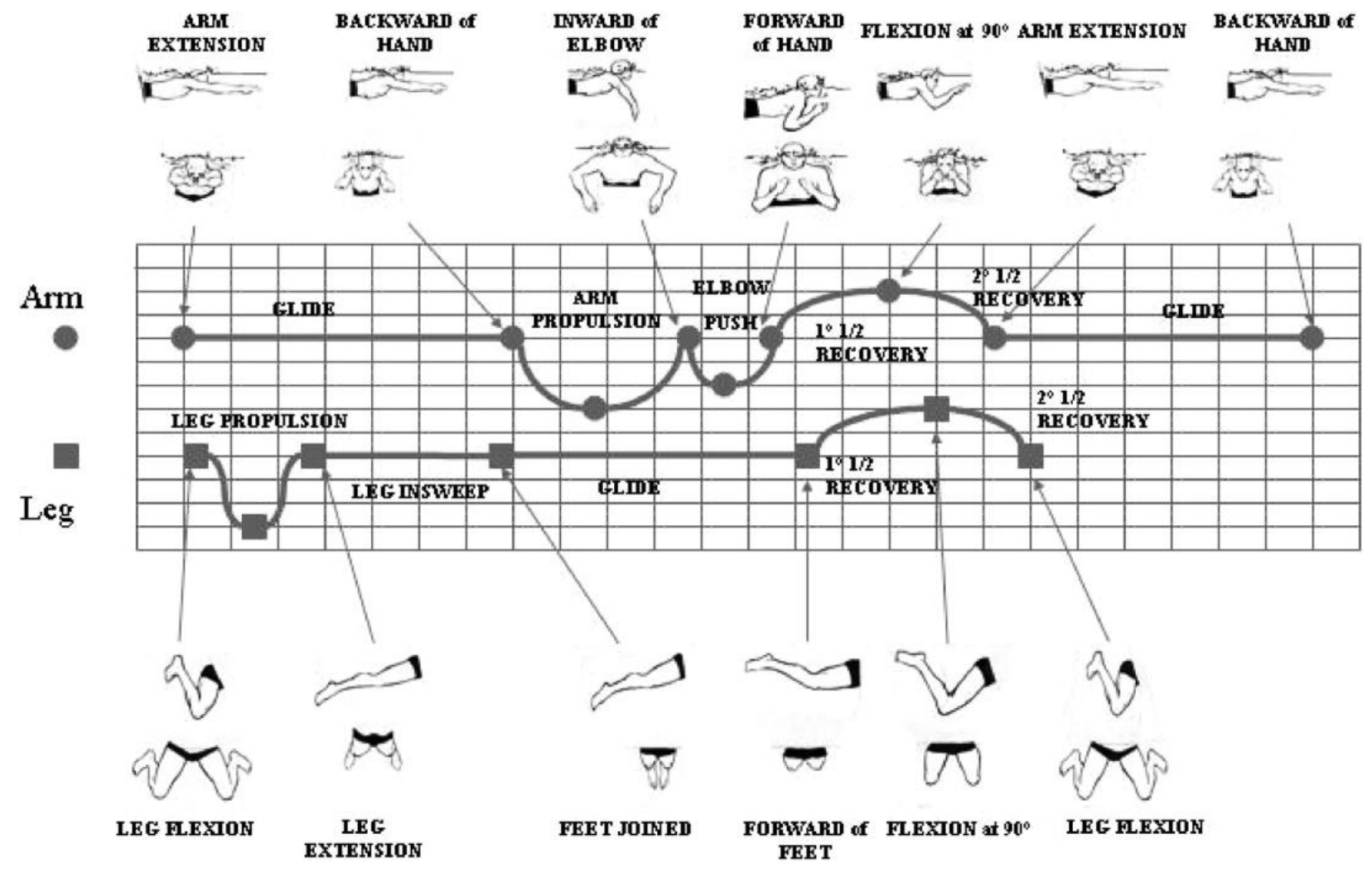

Figure 2.4. Arms and legs stroke phases in the flat breaststroke. Note: The graph (figure) is completely taken from Chollet et al. (2004).

In order to define coordination between arms and legs Chollet et al. (2004) used time gaps (Figure 2.5). This is widely accepted approach among swimming researchers and will be addressed here as well. However, this approach does not take into account the nature of movement (cyclic) and therefore the nature of the data (circular). Instead of explaining the coordinative gaps in terms of percentage of the total swimming cycle, the author of this thesis used phase angles (Wheat \& Glazier, 2005). The discrete relative phase angles will be explained in the method section of the thesis. 


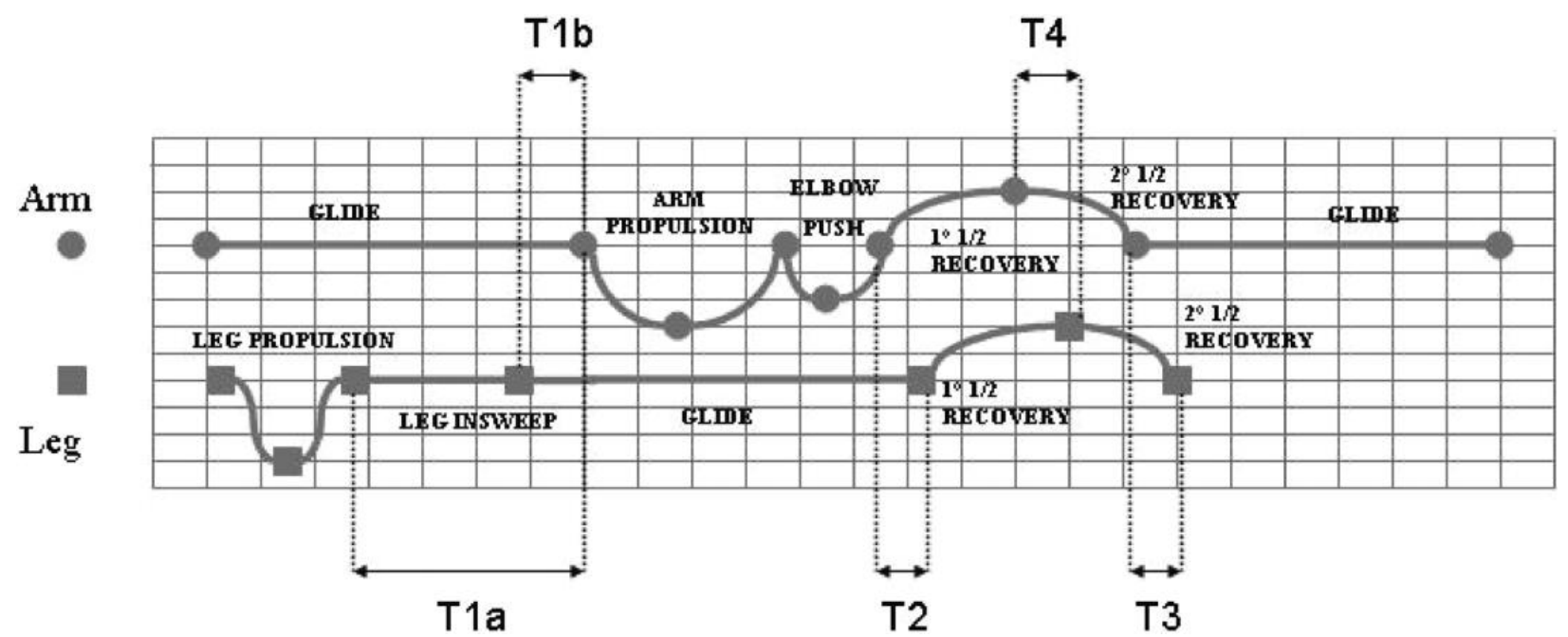

Figure 2.5. Time gaps between arms and legs stroke phases in breaststroke. Note: The graph (figure) is taken completely from Chollet et al. (2004).

According to Maglischo (Maglischo, 2003) and the authors that examined breaststroke coordination three types of breaststroke coordination exist: continuous, glide and overlap (Chollet et al. 2004, Oxford et al. 2010). Takagi et al (2004) stated that $50 \mathrm{~m}$ event could be roughly considered overlapping, $100 \mathrm{~m}$ event as continuous coordination and $200 \mathrm{~m}$ as coordination that is characterized by gliding.

Classification of the breaststroke coordination could be further done according to progression of an event, duration of events, swimmers expertise, gender etc.

\section{Breaststroke coordination in relation to the progression of an event}

Oxford et al. (2014) examined the coordinative changes in each four laps over the course of $200 \mathrm{~m}$ in 25 $\mathrm{m}$ pool. Changes in coordinative patterns that were observed were related to fatigue. Those were the adaptive movements swimmers applied in order to preserve velocity and were characterized in overlap of propulsive actions of arms and legs as well as shortening of the recovery phase (i.e. a glide phase). 
Breaststroke coordination in relation to the duration of an event

The extension of glide time is beneficial only in the case of long events. It has been shown that long duration of glide will reduce the amount of drag the swimmers experience. At the same time, with increase in glide phase duration, the duration of propulsive phases of arms and legs become shorter (Soares et al., 1998). On contrary, in short events (i.e. when swimmers increase velocity from $200 \mathrm{~m}$ velocity to $50 \mathrm{~m}$ velocity), the reduction of glide phase occurred (Chollet et al., 1999). At the same time with decrease of glide phase time, there is increase of propulsive time of arms and legs activity and recovery time from 200 to $100 \mathrm{~m}$ velocity as well as from $100 \mathrm{~m}$ to $50 \mathrm{~m}$ velocity (Chollet et al., 1999).

\section{Breaststroke coordination in relation to the swimmers expertise}

Leblanc et al. (2005) compared recreational with expert swimmers to identified key motor pattern differences that exist in these two classes of swimmers. When the duration of glide phase was evaluated, it was shown shorter in expert swimmers than recreational swimmers. This was expected given that glide phase cause deceleration, and should not be used extensively. Komar et al. (2014) also compared expert and recreational group and found that expert swimmers cover longer distance during gliding phase, but only at the lowest velocities. On the other hand, Takagi et al. (2004) compared elite (e.g. qualified) with less elite (e.g. eliminated) swimmers and found that elite swimmers spent more time gliding (arm gliding and leg gliding) than less elite swimmers. This was already shown by the early study of d'Acquisito et al. (1998), where superior swimmers showed longer glide phase than good swimmers. In the mentioned study duration of glide phase was $56 \%$ from the total cycle duration. In this way, i.e. by extending the glide phase and avoiding the overlaps in propulsion, velocity loss decrease in non-propulsive swimming phases is diminished. 


\section{Breaststroke coordination in relation to the gender}

When glide phase was analyzed in relation to gender, females had longer glide phase compared to males (Seifert \& Cholet, 2005; Seifert \& Chollet, 2009). This was evident both at slow and sprint velocity (Leblanc et al., 2010), where females were able to maintain higher average velocity during this longer gliding time. In addition, glide phase correlated with glide length (only in females) and hydrostatic lift (being highest in females) correlated with glide phase (only in females, too). Moreover, females showed also longer simultaneous (i.e. arms and legs) recovery times than males (Takagi et al., 2004). When highest velocities were examined, only males were able to have overlapped phases of arm and legs propulsions (Capitao et al., 2010). Sometimes, overlapped propulsion of arms and legs indicates poor coordination as this type of coordination was only found in eliminated female group (Takagi et al., 2004). This all indicates that the best way of coordination is motor continuity, where temporal gaps (or relative phase angles) are minimized. In fact, males showed better continuity of breaststroke pattern, as they had lower temporal gaps in general (and significantly lower T3 gap) than women (Seifert \& Chollet, 2005). All these studies were devoted to swimming coordination during surface or free swimming phase. Special segment of breaststroke coordination belongs to underwater (prior to surface swimming) coordination. It consists of fifth phases: first phase is first gliding position, in which arms are stretched overhead; second phase is full arm pull where arms finish its movement at the sides of the trunk; the third phase is second gliding position which ends with starts of leg flexion; the fourth phase implies full leg flexion (from its starts until its end). Most of the studies devoted its research only to the first and second gliding position and either neglecting or implying the other two phases as inherent to gliding phases. For instance, when fourth phase was considered inherent part of the second gliding position, it was indicated detrimental influence of full leg flexing on the velocity loss (Vilas-Boas et al., 2010; Seifert et al. 2007). 


\subsubsection{Segmental aspects of swimming}

The explanation of swimming motion could be related to forces that either move swimmers through water or slow down swimming. Propulsive forces are those that enable swimmers to move forward (Vorontsov \& Rumyantsev, 2000b), while resistive forces slow down swimming (Vorontsov \& Rumyantsev, 2000a). Numerous factors influence swimming resistance, which is typically divided in three types of drags: friction, form and wave drag. Among many factors that influence swimming drag, very often is investigated swimming size or morphology (Kjendlie \& Stallman, 2011). Although there has been identified large contribution of morphology on passive swimming motion (Clarys, 1979), the same authors also accentuated that morphology itself does not have large influence on active swimming. More important than morphology, body orientation and position influence swimming drag. During swimming motion morphology could not be modified, but body positions and orientations can. Another group of factors that influence swimming resistance relates to segmental variables which are body position, depth, orientation etc. Karpovich (Karpovich, 1933) showed greater resistance in supine streamline position (such as during backstroke swimming) than prone position.

Body depth is also one relevant factor that influence resistive or drag forces. It has been shown towing on water surface causes higher drag than on water surface (Jiskoot \& Clarys, 1975), because the appearance of wave drag (Vennell, Pease, \& Wilson, 2006). That can explain why swimmers during gliding part of underwater swimming use higher swimming depths and also during underwater undulatory swimming (UUS). It is interesting to note that 20 years ago researchers recommend gliding depth at $0.5 \mathrm{~m}$ (Lyttle, Lloyd, Blanksby, \& Elliott, 1999), while recently (i.e. 15 years later) quite larger depth for optimal gliding were recommended (i.e. $0.93 \mathrm{~m}$ ) (Tor, Pease, \& Ball, 2015). Although the largest the depth, the lowest the swimming drag swimmers experience (i.e. during towing) (Lyttle, Blanksby, Elliot, \& Lloyd, 1998), swimmers should avoid large body depths as that could delay adequate and timely organized preparation for transition from underwater and surface swimming, which could in turn cause high 
projected area of the body and therefore high form drag (Bixler, Pease, \& Fairhurst, 2007)

In order to assess the projected area of the body, there are usually evaluated body angles either during underwater swimming (Houel, Elipot, André, \& Hellard, 2013) or during surface swimming (Kjendlie, Ingjer, Stallman, \& Stray-Gundersen, 2004; Strzala \& Krezalek, 2010). High negative correlation of body angle with underwater velocity was found (Houel et al., 2013), as a direct consequence of active drag The main factor that contribute to body inclination is the difference of body center of mass and center of volume (buoyancy) (Cureton, 1933) that induce interaction torque in passive conditions (i.e. passive interaction torque) (Kjendlie, Stallman, \& Stray-Gundersen, 2004), which is due to swimming technique compensated (i.e. active rotational/interaction torque) (Yanai, 2001).

Kjendlie and colleagues (Kjendlie, Ingjer, et al., 2004) revealed correlation of body angle and swimming cost. It means that compensation for decreasing natural interaction torque and therefore body inclinations is highly costly (P. Zamparo, 1996).

The greater the distance between center of mass and center of buoyancy the greater will be the passive interaction torque and morphological differences that exist between males and females also revealed different adaptations in controlling passive and active interaction torque and body inclinations (Gatta, Cortesi, Fantozzi, \& Zamparo, 2015; McLean \& Hinrichs, 1998; Zamparo et al., 1996).

For competitive swimming it is important to know how active interaction torques and active body inclinations are controlled. Zamparo and colleagues (Zamparo, Gatta, Pendergast, \& Capelli, 2009) revealed that body inclination were greater during active drag than in passive drag, such emerge during towing.

Therefore, evaluating of segmental parameter such are body depth and swimming inclinations are in addition to kinematics and coordination parameters of utmost importance for evaluation of total swimming performance. 


\section{CHAPTER 2}

\section{AIMS AND HYPOTHESES}




\section{Chapter 2 Aims and hypotheses}

\subsection{The aims of the research}

Using biomechanical swimming approach, this research was directed to the description of transition phase in all competitive swimmers, to identify how male and female swimmers differ when performing transition. Second point of research included one representative gender (males) to compare transition performance to main swimming performance (usually detected in free swimming phase). Third part was devoted in determining the most sensitive factors (out of (kinematics) parameters that directly build up velocity) that shape transition performance.

Therefore, the aims of this research were threefold:

1. To characterize the kinematics, coordinative and segmental variables of the breakout phase in elite international competitive swimmers of both genders.

2. To compare the kinematic and coordinative parameters of elite international competitive swimmers during the transition phase and the free swimming phases.

3. To examine the role of the segmental, kinematic and coordinative parameters on the swimming velocity during the pre-transition and transition phases of the push start.

\subsection{The hypotheses of the research}

According to the state of the research problem and to the aims of the present study, the following aspects were hypothesized:

1. Swimmers would achieve faster velocities during breakout phase than during free swimming due to the previous velocity of the underwater swimming and to greater values of stroking rate.

2. Swimmers would adopt an in-phase stroke coordination during transition from underwater to surface swimming in order to adapt to the faster velocities experienced. 
3. Segmental and coordinative parameters would have a meaningful contribution to the breakout velocity due to influence on drag resistance. 


\section{CHAPTER 3}

\section{GENARAL METHODS}




\section{Chapter 3 General methods}

\subsection{Participants' description}

74 international competitive swimmers: 33 males $(16.5 \pm 1.29$ years old and $62.34 \pm 7.22 \mathrm{~kg})$ and 41 females $(160.0 \pm 12.5 \mathrm{~cm}$ and $50.73 \pm 6.72 \mathrm{~kg})$ were recruited to participate in this swimming project (Table 3.1.). Swimmers' personal best time was within the $85 \%$ of world record. All tested swimmers (> 18 years) or their legal guardians ( $<18$ years) signed written consent document to participate in the study which was approved by the Ethics Committee of the Technical University of Madrid and in accordance to Declaration of Helsinki. The tested swimmers were analyzed in three studies (Chapter 4, 5 and 6). In chapter 5 and 6 only male subjects were presented.

Table 3.1.: Mean \pm standard deviation, minimum and maximum values of participants characteristics.

\begin{tabular}{lcccccc}
\hline & & Male & \multicolumn{3}{c}{ Female } \\
\hline Age (years) & $16.5 \pm 1.29$ & 15 & 18 & $15.5 \pm 1.29$ & 14 & 17 \\
Weight $(\mathrm{kg})$ & $62.34 \pm 7.22$ & 46 & 76 & $50.50 \pm 6.53$ & 39.4 & 70.6 \\
Height $(\mathrm{m})$ & $1.73 \pm 0.05$ & 1.60 & 1.80 & $1.60 \pm 0.05$ & 1.50 & 1.80 \\
Training experience (years) & $7.12 \pm 2.35$ & 2 & 12 & $5.90 \pm 1.68$ & 2 & 10 \\
\hline
\end{tabular}

\subsection{Data acquisition}

The methodology of the present research was observational analysis with videography. Two cameras (JVC GY-DV500E) operating at $50 \mathrm{~Hz}$, with a shutter speed of $1 / 1000 \mathrm{~s}$ and placed behind the underwater windows of a $50 \mathrm{~m} \times 25 \mathrm{~m}$ pool were used to record swimmers. Image resolution was $720 \times 576$ pixels. The cameras had their optical axis perpendicular to the sagittal plane of the swimmers and were located approximately $15 \mathrm{~m}$ at the side of the swimmers' lane and $10 \mathrm{~m}$ or $20 \mathrm{~m}$ (respectively for cameras 1 or 2) from the starting wall (Figure 3.1.). 


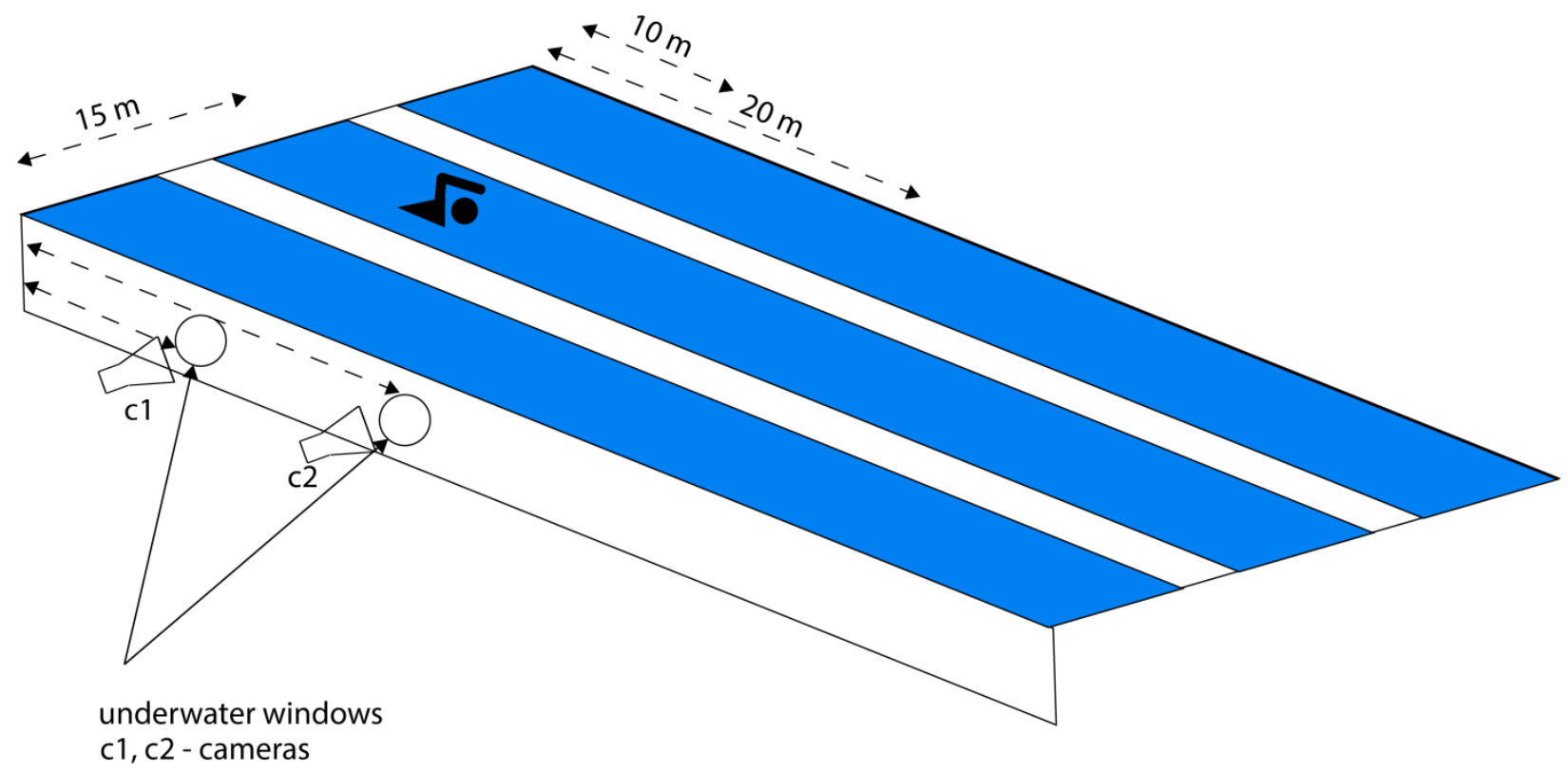

Figure 3.1. Camera positions in relation to the starting pool-wall and to the swimmer's pool-lane.

The swimmers performed $4 \times 25$ m maximal efforts from a push start, one of each stroke in a random order, and with a 3-minute rest between them. Prior to recordings, camera calibration was done using four points of known coordinates located in the swimmer's plane of movement. Control points were formed by the beginning and the end of two non-elastic ropes with a $5 \mathrm{~kg}$ dumbbell attached at the lower end of it to ensure a strictly vertical line (Figure 3.2.) (García-Ramos et al., 2015). These non-elastic ropes were attached to a rectangular structure of PVC situated above the lane ropes as indicated in Figure 3.3 . 


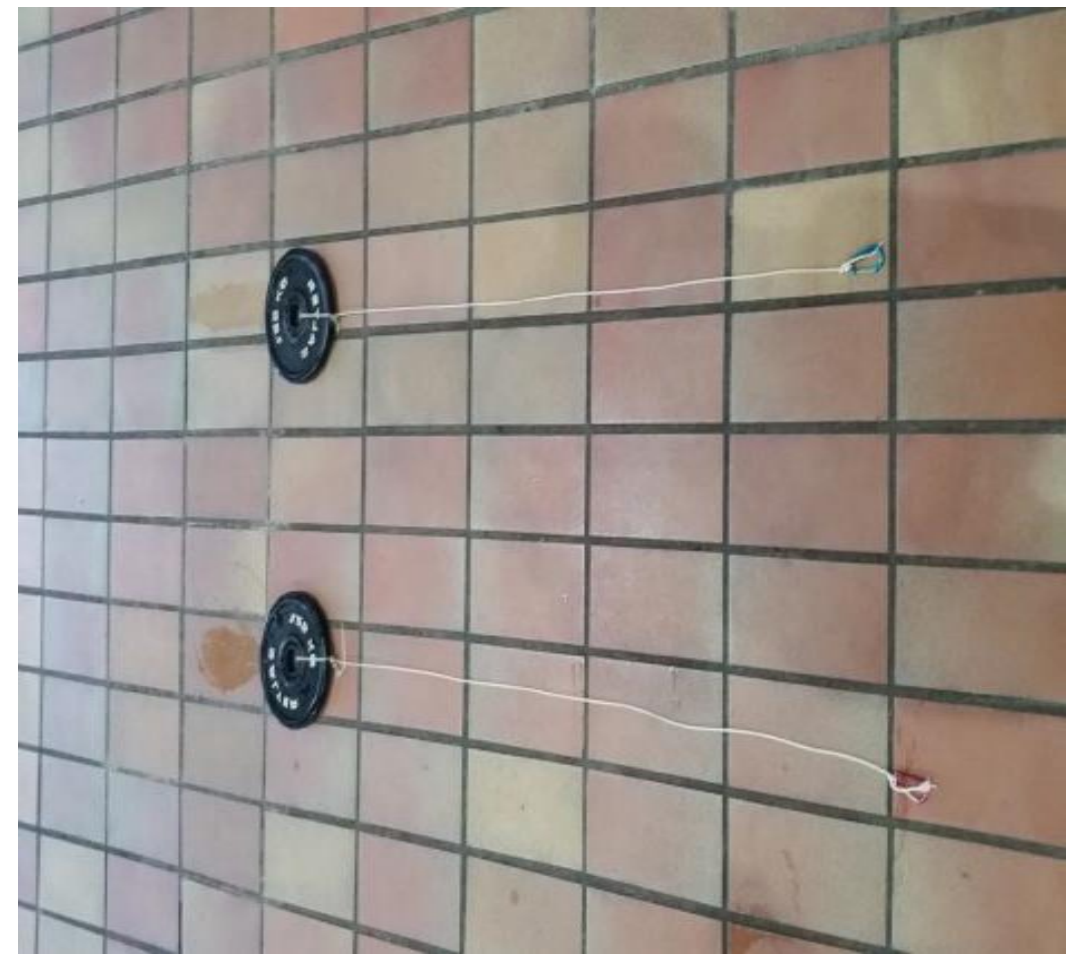

Figure 3.2. Non-elastic ropes with a $5 \mathrm{~kg}$ dumbbell employed for calibration purposes with the DLT-2D technique.

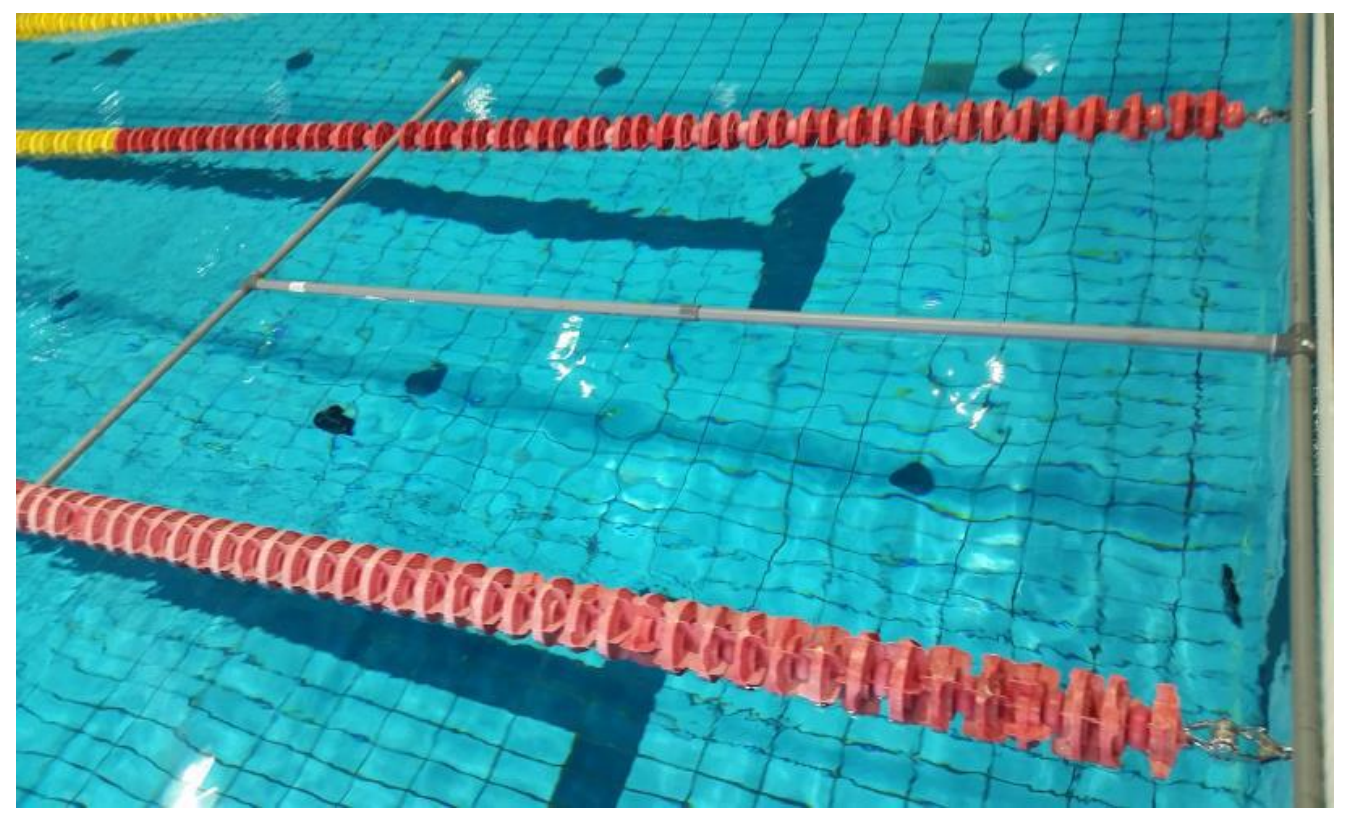

Figure 3.3. PVC structure situated on the lanes ropes for calibration purposes with the DLT-2D technique. 


\subsection{Data processing}

Camera footage was manually digitized and temporally coded by an experienced observer using Photo23D (Cala, Veiga, García, \& Navarro, 2009). Two-dimensional direct linear transformation (2DDLT) algorithms (Abdel-Aziz \& Karara, 1971) were employed for the spatial parameters to transform the two dimensional screen coordinates (in pixels) to real metre coordinates (using BIOMECH.exe software). Breakout analysis included two different phases while swimmers transited from underwater to the water surface: 1) pre-transition, representing the last underwater undulatory kicking in a minimum resistance position before arm movements (Figure 3.4.a.); and 2) transition, representing the first complete arms and legs swimming cycle after pre-transition (Figure 3.4.b.). Also, for comparison purposes, the freeswimming phase represented a complete swimming cycle from $20 \mathrm{~m}$ to $25 \mathrm{~m}$ from the starting wall (Veiga \& Roig, 2017). These three phases were identified in the freestyle, backstroke and butterfly strokes. 


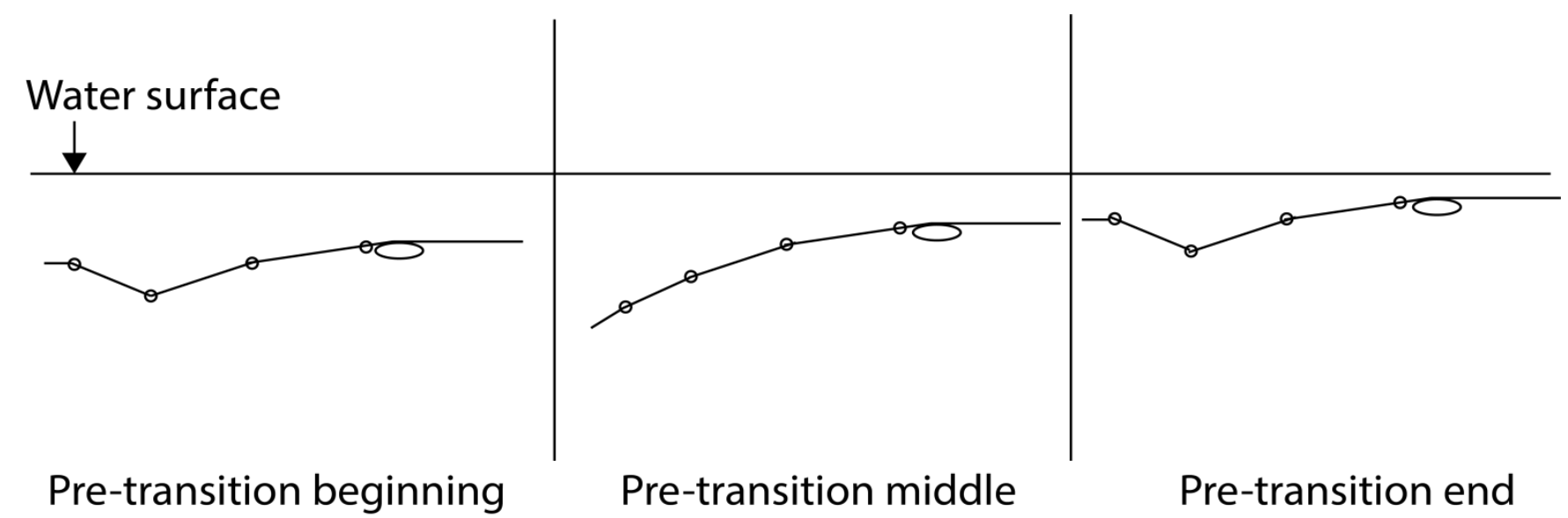

a

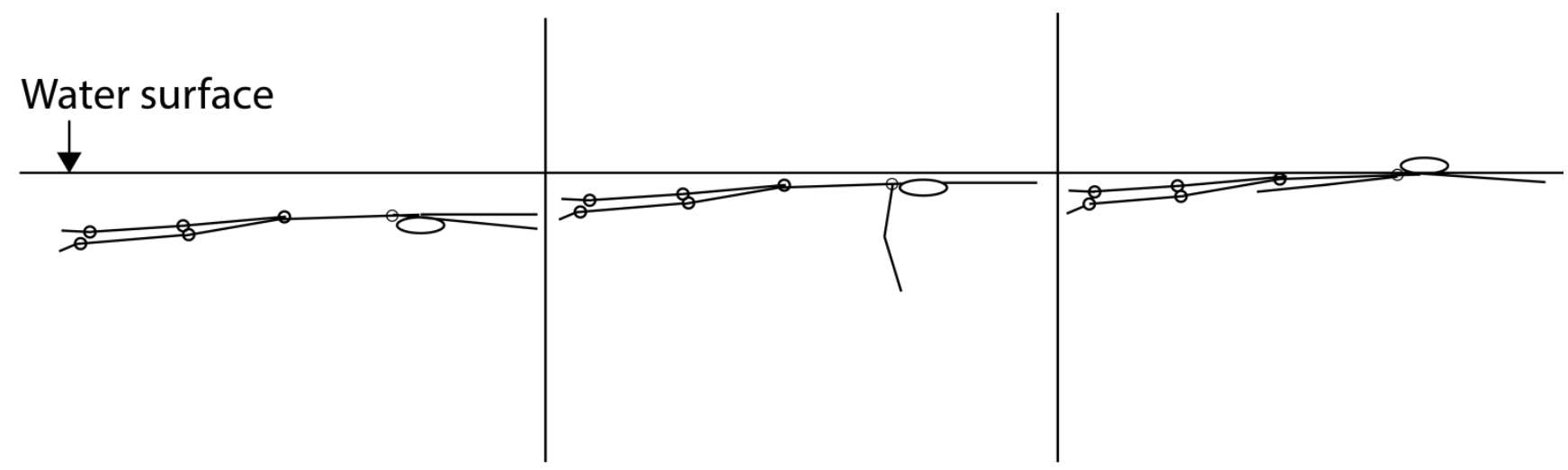

Beginning of transition phase Middle of transition phase End of transition phase

b

Figure 3.4: Schematic illustration of the pre-transition (a) and transition (b) phases from underwater to surface swimming. 
The videos were manually digitized in Photo 23D software (Figure 3.5). The model of the present research had four points in total: shoulder, hip, knee and ankle. After digitizing all the necessary points, videos were exported as ASCII file. Biomec.exe software (Figure 3.6) was used to transfer digitized points which are in pixels into SI real units (i.e. meters). Data from camera calibration were employed in BIOMEC.EXE software. Notepad (ASCII) file (on the left part of Figure 3.7. contains pixels data from Photo 23D software, while real meter units for all spatial variables (right part of Figure 3.7) were obtained after two-dimensional direct linear transformation (2D-DLT) algorithms (Abdel-Aziz \& Karara, 1971) were applied in BIOMEC.EXE software.

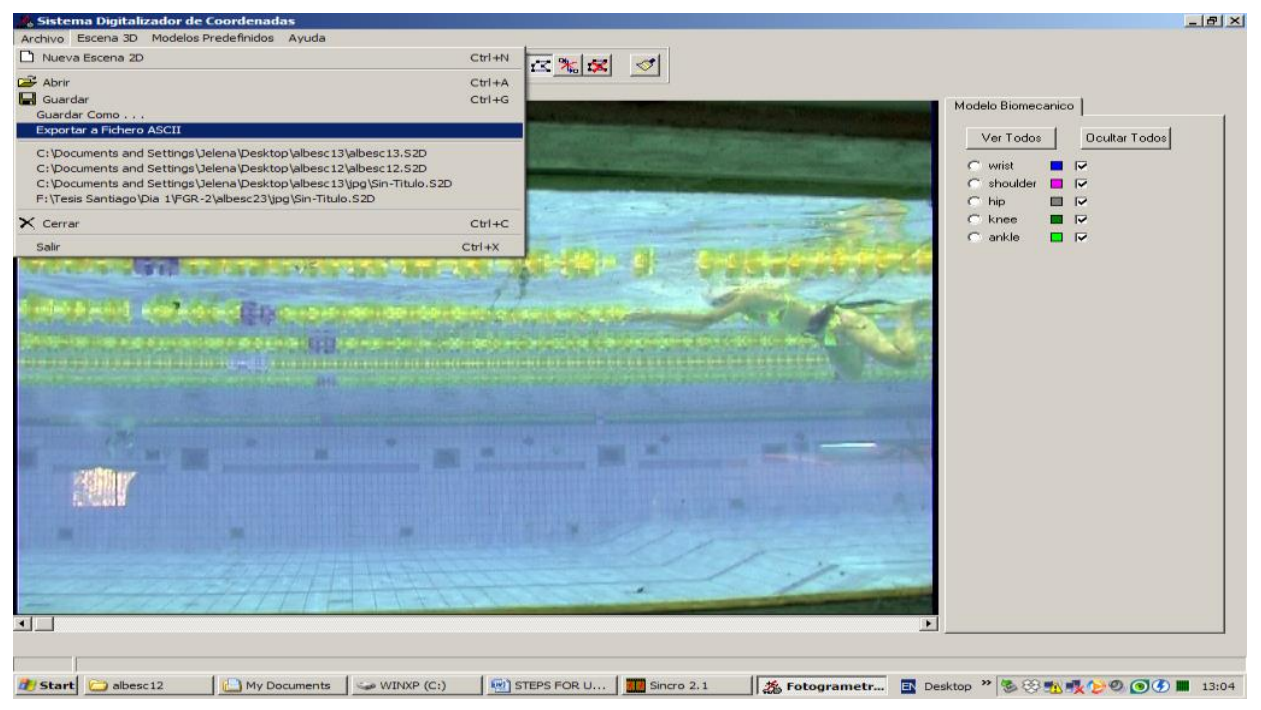

Figure 3.5. The interface of Photo 23D software. 


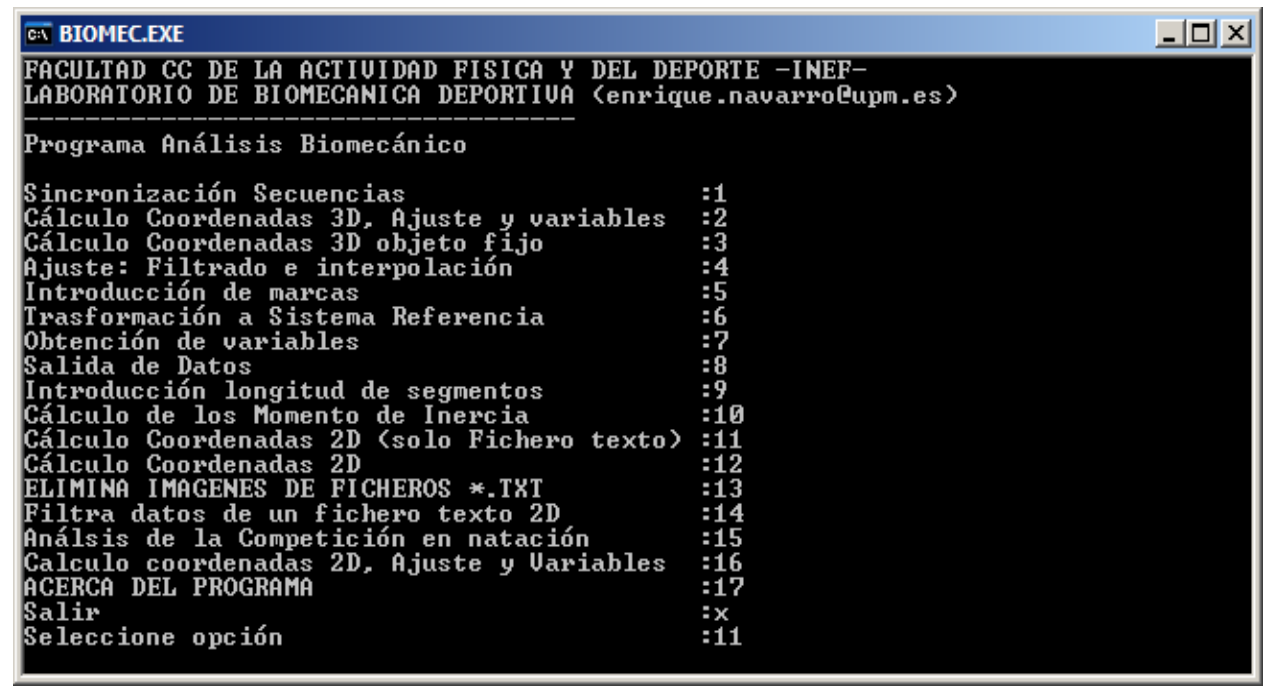

Figure 3.6. The interface of BIOMECH.EXE software.

CTMmc13 - Notepad

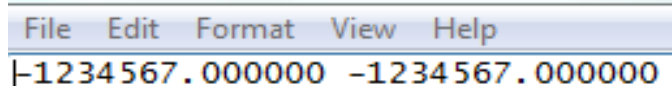

$-1234567.000000-1234567.000000$

$-1234567.000000-1234567$. 000000

$-1234567.000000-1234567.000000$

$-1234567.000000-1234567.000000$

$-1234567.000000-1234567.000000$

$-1234567.000000-1234567.000000$

$-1234567.000000-1234567.000000$

$-1234567.000000-1234567.000000$

$-1234567.000000-1234567.000000$

$-1234567.000000-1234567.000000$

$-1234567.000000-1234567.000000$

$-1234567.000000-1234567.000000$

$-1234567.000000-1234567.000000$

$-1234567.000000-1234567.000000$

$-1234567.000000-1234567.000000$

$-1234567.000000-1234567.000000$

$-1234567.000000-1234567.000000$

$-1234567.000000-1234567.000000$

$-1234567.000000-1234567.000000$

$-1234567.000000-1234567.000000$

$-1234567.000000-1234567.000000$

$-1234567.000000-1234567.000000$

$-1234567.000000-1234567.000000$

$-1234567.000000-1234567.000000$

$-1234567.000000-1234567.000000$

$-1234567.000000-1234567.000000$

$-1234567.000000-1234567.000000$

$-1234567.000000-1234567.000000$

$-1234567.000000-1234567.000000$

$-1234567.000000-1234567.000000$

$-1234567.000000-1234567.000000$

$-1234567.000000-1234567.000000$

$-1234567.000000-1234567.000000$

$-1234567.000000-1234567.000000$

$-1234567.000000-1234567.000000$
젤 3CAMC110

\begin{tabular}{|c|c|c|c|}
\hline 4 & A & B & C \\
\hline 216 & 6.64 & 0.79 & \\
\hline 244 & 7.53 & 0.98 & \\
\hline 253 & 7.88 & 1.03 & \\
\hline 661 & 7.93 & 0.99 & \\
\hline 988 & 6.22 & 0.82 & \\
\hline 1016 & 7.06 & 0.95 & \\
\hline 1025 & 7.37 & 0.97 & \\
\hline 1047 & 7.85 & 1.25 & \\
\hline 1374 & 5.62 & 0.63 & \\
\hline 1402 & 6.49 & 0.75 & \\
\hline 1411 & 6.69 & 0.91 & \\
\hline 1433 & 7.46 & 0.97 & \\
\hline 1462 & 8.35 & 1.10 & \\
\hline 1760 & 5.21 & 0.58 & \\
\hline 1788 & 6.04 & 0.67 & \\
\hline 1819 & 7.04 & 0.78 & \\
\hline 2205 & 6.70 & 1.08 & \\
\hline 2230 & 7.41 & 1.18 & \\
\hline 2253 & 8.30 & 1.26 & \\
\hline 2569 & 5.97 & 0.65 & \\
\hline 2601 & 7.06 & 0.84 & \\
\hline 2623 & 7.76 & 0.89 & \\
\hline 2650 & 8.77 & 0.81 & \\
\hline
\end{tabular}

Figure 3.7. The pixels (notepad file) transferred into real meter units. 


\subsection{Definitions of swimming variables}

There are four major types of dependent variables that were collected and analyzed: performance variables, kinematical (i.e. spatio-temporal variables), segmental and coordinative variables. Performance variable is the swimming velocity. Spatial variables are distances: distance of arm stroke and distance of leg kick. Temporal variables are frequencies: leg kick frequency/rate and stroke frequency/rate. Segmental variables are trunk and body inclinations in relation to water surface. Coordinative variables are discrete relative phase (DRP) angles.

The independent variables were the four swimming strokes (crawl, backstroke, breaststroke and butterfly), two swimming genders and swimming phases: breakout and free swimming phase. Breakout phase contains within itself: pre-transition and transition.

\subsubsection{Breakout kinematics and segmental variables}

\subsubsection{Pre-transition variables}

- Pre-transition velocity - was calculated as the product of pre-transition stroke length (i.e. a kick length) and pre-transition stroke rate (i.e. kick rate).

- Kick length - hip horizontal displacement within last leg cycle, the swimmers' feet in the highest throughout the feet in the lowest position and returning the highest position. It was expressed in meters.

- Kick rate - was the calculated as the inverse of the period of kick length. The period or duration of the cycle was expressed in minutes, and kick rate in cycle(s) per minute.

- Kick amplitude - vertical displacement of the ankle joint from the swimmers' feet in the highest to the feet in the lowest position. It was expressed in meters.

- Trunk inclination - represented the line that passes through shoulder and hip joint in relation to water surface line. Trunk inclination 1 was measured in the beginning of pre-transition phase, i.e. when the 
feet are in the highest position. Trunk inclination 2 was measured in the middle of pre-transition phase, i.e. when the feet are in the lowest position. It was expressed in degrees.

- Body inclination - represented the line that passes through shoulder and knee joint in relation to water surface line. Body inclination 1 was measured in the beginning of pre-transition phase, i.e. when the feet are in the highest position. Body inclination 2 was measured in the middle of pre-transition phase, i.e. when the feet are in the lowest position. It was expressed in degrees.

- For breaststroke:

- Pre-transition stroke length - the horizontal displacement of the hip from the moment of hand separation for the underwater arm pull until the moment leg are fully flexed and ready to start transition movements (a transition cycle). It was expressed in meters.

- Pre-transition stroke rate - was the calculated as the inverse of the period of pre-transition stroke length. The period or duration of the cycle was expressed in minutes, and pre-transition stroke rate in cycle(s) per minute.

- Trunk inclination - represented the line that passes through shoulder and hip joint in relation to water surface line. Trunk inclination 1 was measured in the beginning of pre-transition phase, i.e. in the moment of hand separation for the underwater arm pull. Trunk inclination 2 was measured in the middle of pre-transition phase, i.e. when the arms are in the shoulder plane. It was expressed in degrees.

- Body inclination - represented the line that passes through shoulder and knee joint in relation to water surface line. Body inclination 1 was measured in the beginning of pre-transition phase, i.e. in the moment of hand separation for the underwater arm pull. Body inclination 2 was measured in the middle of pre-transition phase, i.e. when the arms are in the shoulder plane. It was expressed in degrees. 


\subsubsection{Transition variables}

- Transition velocity - was calculated as the product of transition stroke length and transition stroke rate.

- Transition stroke length - hip horizontal displacement measured from the moment of hands separation until of arm(s) entry in the water.

- Transition stroke length (breaststroke) - hip horizontal displacement measured from the moment legs are fully flexed after underwater arm pull until legs are again fully flexed.

- Transition stroke rate - was the calculated as the inverse of the period of transition stroke length. The period or duration of the cycle was expressed in minutes, and stroke rate in cycle(s) per minute.

- Trunk inclination - represented the line that passes through shoulder and hip joint in relation to water surface line. Trunk inclination 1 was measured in the beginning of transition phase, i.e. in the moment of hand separation for the transition stroke. Trunk inclination 2 was measured in the middle of transition phase, i.e. when the arms are in the shoulder plane. It was expressed in degrees.

- Body inclination - represented the line that passes through shoulder and knee joint in relation to water surface line. Body inclination 1 was measured in the beginning of transition phase, i.e. in the moment of hand separation for the transition stroke. Body inclination 2 was measured in the middle of transition phase, i.e. when the arms are in the shoulder plane. It was expressed in degrees.

\subsubsection{Free swimming kinematics variables}

- Free swimming velocity - was calculated as the product of free stroke length and free stroke rate. 
- Free swimming stroke length - hip horizontal displacement measured from the moment of hands re-entry until arm(s) re-entry in the water (in the swimming mid-pool)

- Free swimming stroke length (breaststroke) - hip horizontal displacement measured from the moment legs are fully flexed after transition stroke until legs are again fully flexed (in the swimming mid-pool)

- Free swimming stroke rate - was calculated as the inverse of the period of free stroke length. The period or duration of the cycle was expressed in minutes, and stroke rate in cycle(s) per minute.

\subsubsection{Coordination swimming variables (transition and free swimming)}

Coordination variables were discrete relative phase (DRP) angles that were calculated as the time lag between two cyclic (i.e. sinusoidal) movements (arm-to-arm lag or arm-to-leg lag), divided by the total duration of cycle (i.e. a swimming cycle) and multiplied by 360 (Wheat \& Glazier, 2005) (Figure 3.6.).

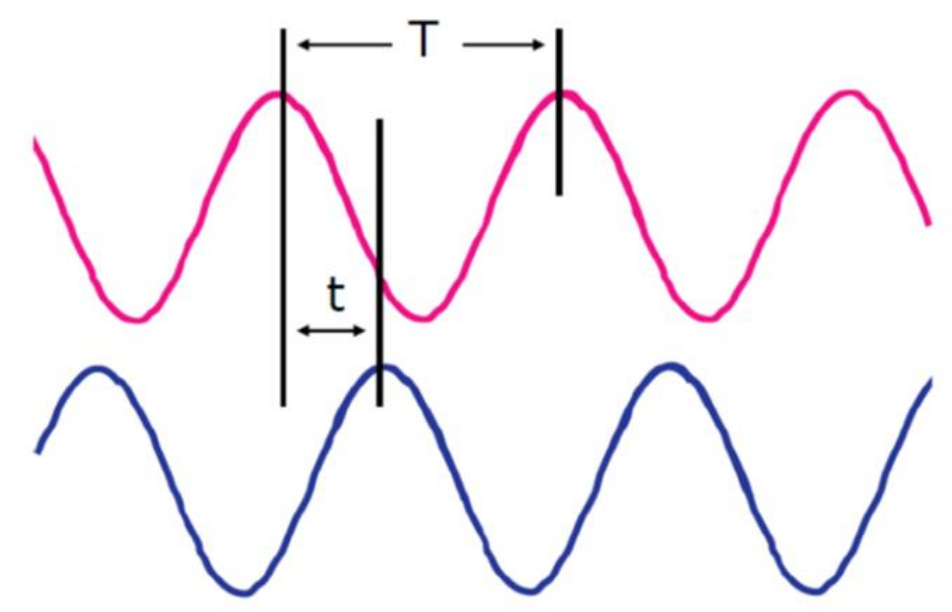

Figure 3.8. Time lag (t) between two sinusoidal rhythmic cyclic activities (T: duration of a cycle).

DRP angles were calculated for each stroke as follows.

Freestyle and Backstroke 
- DRP1 - was calculated as the time lag between the end of the propulsive action (arm exit in freestyle and arm extension in backstroke) of the first pulling arm and the beginning of the propulsive action (arm pull) of the second pulling arm. The obtained value was multiplied by 360 and expressed in degrees.

- DRP2 - was calculated as the time lag between the end of the propulsive action (arm exit in freestyle and arm extension in backstroke) of the second pulling arm and the beginning of the propulsive action (arm pull) of the third pulling arm (during the second swimming cycle). The obtained value was multiplied by 360 and expressed in degrees.

\section{Butterfly}

- DRP1 - was calculated as the time lag between the first hand separation from the streamlined position and the feet in the highest position during kicking. The obtained value was multiplied by 360 and expressed in degrees.

- DRP2 - was calculated as the time lag between the beginning of the arms' first pull and the feet in the lowest position during kicking. The obtained value was multiplied by 360 and expressed in degrees.

- DRP3 - was calculated as the time lag between the beginning of the arms' first push and the feet in the highest position during kicking. The obtained value was multiplied by 360 and expressed in degrees.

- DRP4 - was calculated as the time lag between the arms' exit from underwater and the feet in the lowest position during kicking. The obtained value was multiplied by 360 and expressed in degrees.

\section{Breaststroke}


- DRP1 - was calculated as the time lag between the end of leg propulsion (leg extension) and the beginning of the first arm propulsion (arms' backward movement).

- DRP2 - was calculated as the time lag between the feet together after leg extension and the beginning of arm propulsion (arms' backward movement).

- DRP3 - was calculated as the time lag between the beginning of arm recovery (arms moving forward) and the beginning of leg recovery (legs moving forward)

- DRP4- was calculated as the time lag between the end of arm recovery (arms fully extended) and the end of leg recovery (legs fully flexed).

\subsubsection{Stroke phases swimming variables (transition and free swimming)}

Stroke phases variables were calculated as percentage duration of the full swimming cycle (100\%). Transition freestyle:

- Catch phase - from arms separation to the beginning of backward arm movement.

- Pull phase - from the start of arm backward movement to arm arrival in shoulder vertical plane.

- Push phase - from arm being in shoulder vertical plane to arm exit.

- Recovery phase - from arm exit to arm entry.

Free swimming freestyle:

- Catch phase - from arm entry to the beginning of backward arm movement.

- Pull phase - same as in transition.

- Push phase - same as in transition.

- Recovery phase - from arm exit to arm re-entry.

Transition backstroke:

- Catch phase - from arms separation to the beginning of backward arm movement. 
- Pull phase - from the start of arm backward movement to arm arrival in shoulder vertical plane.

- Push phase - from arm being in shoulder vertical plane to arm extension.

- Clear phase - from arm extension to arm exit.

- Recovery phase - from arm exit to arm entry.

Free swimming backstroke:

- Catch phase - from arm entry to the beginning of backward arm movement.

- Pull phase - same as in transition.

- Push phase - same as in transition.

- Clear phase - same as in transition.

- Recovery - from arm exit to arm re-entry.

Transition butterfly:

Arms

- Catch phase - from arms being extended to the beginning of backward arm movement.

- Pull phase - from the start of arm backward movement to arm arrival in shoulder vertical plane.

- Push phase - from arm being in shoulder vertical plane to arm exit.

- Recovery phase - from arm exit to arm entry.

Legs

- Down 1 - from feet being in the highest position to feet being in the lowest position.

- Up 1 - from feet being in the lowest position to feet being in the highest position.

- Down 2 - repetition of down 1.

- Up 2 - repetition of up 1. 
Free swimming butterfly:

Arms

- Catch phase - from arm entry to the beginning of backward arm movement.

- Pull phase - same as in transition.

- Push phase - same as in transition.

- Recovery - from arm exit to arm re-entry.

Legs

- Down 1 - same as in transition.

- Up 1 - same as in transition.

- Down 2 - same as in transition.

- Up 2 - same as in transition.

Breaststroke - Transition and free swimming:

Arms

- Glide - from arms being extended to first backward movement.

- Pull - from arms start backward movement to the end of backward movement.

- Push - between the end of backward movement and the beginning of arms forward movement, this is combined elbow squeezed and inward movement.

- Recovery 1 - from the end of arms (elbow) push until arms reach angle of 90 degrees.

- Recovery 2 - from arms being at 90 degrees until full extension.

Legs

- Leg extension - from legs being fully flexed to legs being full extended.

- Leg joining - from leg being fully extended until leg joining.

- Glide - from leg joining until start of leg forward movement. 
- Leg flexion 1 - from leg starting forward movement until knee being flexed at 90 degrees.

- Leg flexion 2 - from knee being flexed at 90 degrees until full leg flexion.

\subsection{Validation of the experimental procedures}

Intra-observer reliability was confirmed by checking the agreement when repeatably coding (10 times) the same pre-transition and transition phases in separate weeks (ICC: 0.998). Furthermore, the validity of distance measurements was checked by reconstructing distances within the control space in a known length segment with a root mean square error lower than $0.015 \mathrm{~m}$. These data were in line with previous researches on two dimensional analysis of underwater swimming (Trinidad, Veiga, Navarro, \& Lorenzo, 2020).

\subsection{Data analysis}

After performing exploratory analysis, specific data analysis which addressed each aim of the research was applied for each of the three studies.

Exploratory analysis started with checking for the presence of outliers and missing values using SPSS. After it was checked that no outliers were present, and that missing values were minor and random and would not affect results, the normality of data was checked by Kolmogorov-Smirnov tests. When the normal distribution was satisfied, descriptive statistics including means and standard deviation with 95 percent confidence interval were applied for linear (kinematics, stroke phases) and circular (discrete relative phase (DRP) angles) data. Linear descriptive statistics was calculated using Statistical Package for Social Sciences (IBM SPSS for Windows, Version 20.0. Armonk, NY: IBM Corp., USA); on the other hand, circular descriptive statistics was calculated in NCSS 12.0.12 software (NCSS 2019, LCC, Utah, USA). 
Study 1 - One-way ANOVA (gender) was applied in order to examine differences within the breakout phase regarding kinematics (velocities, lengths and frequencies) and segmental variables (body and trunk inclinations, body depths) and discrete relative phases.

Study 2 - One-way repeated measure ANOVA (swimming phase) was applied in order to examine differences in the stroking parameters and in the relative duration of stroke phase between the pretransition, transition and free-swimming phases.

Study 3 - Multiple regression analysis (backward model) was used to identify the influence of kicking, body positions and coordinative parameters on the average swimming velocity. Stroking parameters (stroke length and rate) were not input variables for backward regression analysis due to their direct influence on velocity. In addition, correlation coefficients (Pearson product moment correlation) were identified between each independent variable and dependent variable (velocity). The threshold values of the correlation coefficient that represented small, moderate, large, very large and nearly perfect correlations were $0.1,0.3,0.5,0.7$ and 0.9 , respectively, according to recommendations in the literature (Hopkins et al., 2009).

Where main effects were found, Bonferroni adjustments with effect sizes (ES, as partial eta-squared values) were used to interpret meaningful effects. All the analysis was performed using Statistical Package for Social Sciences (IBM SPSS for Windows, Version 20.0. Armonk, NY: IBM Corp., USA), arranging data by stroke (freestyle, backstroke, butterfly and breaststroke). For the coordinative parameters, circular statistics was applied by applying Williams-Wilson F test in NCSS 12.0.12 software (NCSS 2019, LCC, Utah, USA). Data were expressed as mean \pm standard deviation with 95\% confidence intervals, unless otherwise indicated. 


\section{CHAPTER 4}

\section{STUDY 1 - GENDER DIFFERENCES IN PERFORMING A SWIMMING BREAKOUT PHASE}




\section{Chapter 4 Gender differences in performing a swimming breakout phase}

\subsection{Introduction}

From early research in swimming, researchers were interested to find out main regularities that exist in male and female swimmers. The main differences that were found out were most commonly discussed and concluded on the basis of anthropometric and strength difference.

Stroke length or distance per stroke is major kinematics factor that differentiate males from females (Letzelter \& Freitag, 1983; Kennedy et al., 1990; Arellano et al. 1994). Males have larger stroke lengths, because of their natural anthropometric differences: i.e. they are taller and stronger than females, have wider arm spam, longer feet and hands and larger cross-sectional area (Kjendlie \& Stallman, 2011). Oxford et al. (2016) have indicated for their study group that males are taller (4.7\%), have longer hand $(5.6 \%)$ and forearm $(8 \%)$ than females. These longitudinal differences of body parts have direct influence on the distances travelled within each SL. In that sense, Letzelter \& Freitag (1983) have shown that males travel $18 \mathrm{~cm}$ more than females within each stroke length. Sum of all stroke lengths in $100 \mathrm{~m}$ event gives advantage of $14.1 \mathrm{~m}$ for males. To balance this, females need $17 \%$ more strokes (91.2) than males (78.1). In addition to longitudinal measures, all other body sizes are larger in man. It means that major factor driving stroke length is body size. The large correlation (79\%) of stroke and body size that had been shown previously (Kjendlie et al., 2004), means that factors other than body size contributed to stroke by only $21 \%$. In conclusion, stroke gender differences exist regardless of the type of stroke and event (Chollet et al., 1996) and the stroke length difference is subject of morphological / size / strength differences of males and females.

In contrast to stroke length which is dependent on body size, stroke rate is not determined by it (Kennedy et al., 1990). Keskinen \& Komi (1993) indicated that SR is dependent on neural activation, while there is no general consensus about stroke rate gender advantage. Most often, studies have shown no differences 
in stroke rate between genders (Pelayo et al., 1996; Arellano et al., 1994; Chollet et al., 1996; Chollet, Chalies, \& Chatard, 1999; Takagi et al., 2004). Still, some studies reported differences. For instance, no differences were shown in freestyle and butterfly stroke rate between genders, while differences were found in backstroke and breaststroke stroke, where males showed slightly higher stroke rate (Keneddy et al., 1990). In contrast, Pai et al. (1984) have shown slightly higher stroke rate in females (for $0.1 \%$ ). Possibly, the less arm strength and corresponding lower stroke length of female swimmers was compensated with higher stroke rate as it has been shown in the study of Wakayoshi et al. (1992) where males built higher velocity with higher stroke length, and females with higher SR.

Based on strength and anthropometrics differences that exist between males and females, coordination mode in which propulsion dominates (superposition mode) is usually seen in males, while all the coordination patterns that refer to catch up coordination mode and gliding were typically connected with females' swimmers (Seifert, Boulesteix, \& Chollet, 2004).

Close association in terms of the nature of differences is also present when stroke phases between genders were compared: males spend more time in propulsive swimming phases, while females use longer non-propulsive swimming phases (Seifert et al., 2004).

This orderliness was reported in surface or free swimming, while for breakout swimming, being novel no comparison between genders was made. Gender anthropometry was mentioned in terms of arm spam and height being longitudinal measures (Akşit et al., 2017; Morais et al., 2012; Zamparo, Turri, Peterson Silveira, \& Poli, 2014), as well as heaviness, while it is also important to have a close look on voluminous measures (Kjendlie \& Stallman, 2011). The most often cited swimming references that arise from differences in the volume, adipose tissue etc. are those that refer to rotational torque (Zamparo, 1996; Zamparo et al., 1996). It is well known that dissociation of the center of mass from center of volume (buoyancy) differ between genders (McLean \& Hinrichs, 1998) and caused passive rotation torque which induce body/trunk inclination (Kjendlie, Stallman, et al., 2004). In swimming, there exists 
only active rotation torque that is regulated by swimming technique and experience (Kjendlie, Ingjer, et al., 2004; McLean \& Hinrichs, 2000). In free swimming this active rotational torque negligible differ between genders, while it is unknown how task constraints embedded with breakout phase influence segmental variables such are swimming depth at which swimmers start transiting etc., as well as body/trunk inclination within this task constraint.

The aim of the study was to characterize the kinematics, coordinative and segmental variables of the breakout phase in elite competitive swimmers of both genders. Male swimmers were expected to present greater swimming velocity and stroke length than females during transition from underwater to surface swimming. This could be accompanied by better coordination (i.e. less time gaps between propulsive stroke phases) by males.

\subsection{Results}

Male swimmers were faster than females transitioning to surface swimming $\left(\delta 0.25 \pm 0.03 \mathrm{~m} / \mathrm{s}, F_{1,283}=\right.$ 63.51, $\mathrm{p}=0.000, \mathrm{ES}=0.18$, small difference) also in the approach to transition (i.e. pre-transitioning phase) males were also faster $\left(\delta 0.23 \pm 0.02 \mathrm{~m} / \mathrm{s} ; F_{1,283}=103.98, \mathrm{p}=0.000, \mathrm{ES}=0.27\right.$, medium difference), and during surface swimming (i.e. free swimming phases) $\left(\delta 0.21 \pm 0.03 \mathrm{~m} / \mathrm{s}, F_{1,253}=36.51\right.$, $\mathrm{p}=0.000, \mathrm{ES}=0.13$, small difference). Table 4.1. shows the differences between genders kinematics across the four strokes.

Stroke length was longer in males than in females during transition $\left(\delta 0.17 \pm 0.05 \mathrm{~m}, F_{1,283}=14.37, \mathrm{p}=\right.$ $0.000, \mathrm{ES}=0.05$, small difference $)$ and free swimming $\left(\delta 0.21 \pm 0.04 \mathrm{~m}, F_{1,251}=33.42, \mathrm{p}=0.000, \mathrm{ES}=\right.$ 0.12, small difference). On the other hand, stroke rate was only different (i.e. larger) in males than in females during transitioning phase $\left(\delta 0.07 \pm 0.021 / \mathrm{s}, F_{1,283}=8.39, \mathrm{p}=0.004, \mathrm{ES}=0.03\right.$, small difference), while no difference were observed during free swimming phase.

No gender differences were found in kick length $\left(F_{1,282}=3.28, \mathrm{p}=0.071, \mathrm{ES}=0.01\right)$, kick rate $\left(F_{1,283}=\right.$ 
$3.20, \mathrm{p}=0.075, \mathrm{ES}=0.01)$ and kick amplitude $\left(F_{1,200}=0.39, \mathrm{p}=0.534, \mathrm{ES}=0.002\right)$ in strokes that have same underwater technique (i.e. freestyle, backstroke and butterfly). 
Table 4.1. Pairwise gender comparison of the kinematic variables (velocities, lengths and frequencies) across swimming phases within breakout (pre-transition and transition) and free swimming in all strokes. Note: Stars denote statistical difference $* \mathrm{p}<0.05$.

\begin{tabular}{|c|c|c|c|c|c|c|c|c|}
\hline \multirow[b]{2}{*}{ Pre-transition } & \multicolumn{2}{|c|}{ Freestyle (mean (SD)) } & \multicolumn{2}{|c|}{ Backstroke (mean (SD)) } & \multicolumn{2}{|c|}{ Butterfly (mean (SD)) } & \multicolumn{2}{|c|}{ Breaststroke (mean (SD)) } \\
\hline & Male & Female & Male & Female & Male & Female & Male & Female \\
\hline Velocity $(\mathrm{m} / \mathrm{s})$ & $1.64(0.23)$ & $1.40(0.16)^{*}$ & $1.51(0.18)$ & $1.25(0.18)^{*}$ & $1.62(0.17)$ & $1.40(0.12)^{*}$ & $1.39(0.14)$ & $1.21(0.11)^{*}$ \\
\hline Length (m) & $0.77(0.12)$ & $0.76(0.16)$ & $0.71(0.10)$ & $0.65(0.11)^{*}$ & $0.77(0.12)$ & $0.75(0.10)$ & $3.66(0.50)$ & $2.82(0.39)^{*}$ \\
\hline Rate (1/min) & $129.02(18.78)$ & $113.21(20.74)^{*}$ & $128.47(18.09)$ & $117.00(16.57)^{*}$ & $128.54(20.88)$ & $113.11(17.44)^{*}$ & $23.15(4.10)$ & $26.19(4.31)^{*}$ \\
\hline Amplitude (m) & $0.29(0.06)$ & $0.30(0.06)$ & $0.37(0.07)$ & $0.34(0.07)$ & $0.31(0.06)$ & $0.29(0.05)$ & & \\
\hline \multicolumn{9}{|l|}{ Transition } \\
\hline Velocity (m/s) & $1.78(0.17)$ & $1.48(0.14)^{*}$ & $1.58(0.20)$ & $1.28(0.12)^{*}$ & $1.80(0.18)$ & $1.52(0.11)^{*}$ & $1.16(0.12)$ & $1.01(0.08)^{*}$ \\
\hline Length (m) & $1.92(0.26)$ & $1.78(0.25)^{*}$ & $2.23(0.41)$ & $2.03(0.35)^{*}$ & $1.83(0.21)$ & $1.60(0.22)^{*}$ & $1.95(0.62)$ & $1.84(0.34)$ \\
\hline Rate $(1 / \mathrm{min})$ & $56.31(7.69)$ & $50.64(7.40)^{*}$ & $43.56(8.04)$ & $38.52(5.09)^{*}$ & 59.59 (7.63) & $57.88(7.24)$ & $38.19(7.74)$ & $34.44(6.50)^{*}$ \\
\hline \multicolumn{9}{|l|}{ Free swimming } \\
\hline Velocity (m/s) & $1.58(0.43)$ & $1.35(0.34)^{*}$ & $1.46(0.13)$ & $1.27(0.10)^{*}$ & $1.62(0.11)$ & $1.38(0.11)^{*}$ & $1.19(0.11)$ & $1.05(0.08)^{*}$ \\
\hline Length (m) & $2.04(0.40)$ & $1.86(0.35)^{*}$ & $2.08(0.24)$ & $1.93(0.18)^{*}$ & $1.85(0.16)$ & $1.62(0.15)^{*}$ & $1.91(0.26)$ & $1.66(0.21)^{*}$ \\
\hline Rate (1/min) & $46.88(10.04)$ & $43.72(8.57)$ & $42.66(4.82)$ & $39.73(3.45)^{*}$ & $52.84(4.13)$ & $51.46(4.92)$ & $37.94(5.71)$ & 38.14 (3.69) \\
\hline
\end{tabular}


During breakout swimming, the female have exhibited greater coordinative parameters (DRP) in almost all cases (Table 4.2.). In freestyle transition, the first discrete relative phase (DRP1) angle of male swimmers showed slight overlapped propulsion of arms (slight superposition), while females where in the lag between arms propulsive actions (or slight catch-up) (Watson-Williams $\mathrm{F}$ Test $=34.25, \mathrm{p}=$ 0.000). In DRP2 of transition freestyle, the gender differences were still present (Watson-Williams F Test $=6.67, \mathrm{p}=0.01)$ although males were in light opposition, while females showed lower lag of propulsive arm activity. Transition butterfly revealed that males showed better synchronization of arms and legs beginning of movement (DRP1) than females (Watson-Williams F Test $=5.51, \mathrm{p}=0.02$ ) as well as better continuity in synchronization of arms and legs propulsion (DRP2) (Watson-Williams F Test $=4.70, \mathrm{p}=$ 0.03). Transition breaststroke revealed that swimmers of both genders could not properly synchronize the end of propulsion of arms and legs (Watson-Williams F Test $=5.51, \mathrm{p}=0.02$ ). 
Table 4.2. Pairwise gender comparison of the coordinative variables (discrete relative phases, DRP) across swimming phases within breakout (i.e. transition phase) and free swimming in all strokes.

\begin{tabular}{|c|c|c|c|c|c|c|c|c|}
\hline & \multicolumn{2}{|c|}{ Freestyle (mean (SD)) } & \multicolumn{2}{|c|}{ Backstroke (mean (SD)) } & \multicolumn{2}{|c|}{ Butterfly (mean (SD)) } & \multicolumn{2}{|c|}{ Breaststroke (mean (SD)) } \\
\hline & Male & Female & Male & Female & Male & Female & Male & Female \\
\hline \multicolumn{9}{|c|}{ Transition } \\
\hline $\mathrm{DRP} 1^{\circ}$ & $7.52(27.92)$ & $-27.25(22.87)^{*}$ & $-34.63(22.69)$ & $-42.29(26.13)$ & $-32.69(23.40)$ & $-47.29(51.29)^{*}$ & $-91.28(55.93)$ & $-109.25(35.84)$ \\
\hline DRP2 ${ }^{\circ}$ & $0.67(31.47)$ & $-16.18(23.07)^{*}$ & $-46.51(16.18)$ & $-44.80(17.86)$ & $-22.17(35.42)$ & $-44.60(49.63)^{*}$ & $-32.59(64.41)$ & $-39.98(53.11)$ \\
\hline $\mathrm{DRP}^{\circ}$ & N.A. & N.A. & N.A. & N.A. & $-7.00(48.00)$ & $-11.00(63.61)$ & $-34.44(33.83)$ & $-39.80(27.78)$ \\
\hline $\mathrm{DRP}^{\circ}{ }^{\circ}$ & N.A. & N.A. & N.A. & N.A. & $-3.55(46.05)$ & $-21.05(63.75)$ & $14.30(17.99)$ & $-7.43(20.35)^{*}$ \\
\hline \multicolumn{9}{|c|}{ Free swimming } \\
\hline $\mathrm{DRP}^{\circ}$ & $16.93(25.91)$ & $-8.44(26.10)^{*}$ & $-42.94(21.68)$ & $38.31(17.81)$ & $-33.33(19.10)$ & $-23.73(23.60)$ & $-99.86(46.55)$ & $-93.05(33.15)$ \\
\hline $\mathrm{DRP} 2^{\circ}$ & $10.53(18.77)$ & $-1.12(17.04)^{*}$ & $-36.97(19.54)$ & $-48.12(16.58)^{*}$ & $-31.36(23.05)$ & $-31.95(28.24)$ & $-51.29(54.21)$ & $-35.22(48.74)$ \\
\hline DRP3 $^{\circ}$ & N.A. & N.A. & N.A. & N.A. & $-11.61(18.20)$ & $-10.09(18.92)$ & $-7.50(12.14)$ & $-30.95(25.41)^{*}$ \\
\hline $\mathrm{DRP}^{\circ}{ }^{\circ}$ & N.A. & N.A. & N.A. & N.A. & $-3.97(21.21)$ & $-7.06(18.00)$ & $12.62(12.27)$ & $-7.82(16.41)^{*}$ \\
\hline
\end{tabular}

Note: Stars denote significant difference $* \mathrm{p}<0.05$ 
Females showed higher trunk inclination 2 than females $\left(\delta 2.44^{\circ} \pm 0.79^{\circ}, F_{1,273}=8.60, \mathrm{p}=0.004\right.$, ES $=$ $0.03)$ and also higher body inclination $2\left(\delta 2.63^{\circ} \pm 0.90^{\circ}, F_{1,281}=9.64, \mathrm{p}=0.002, \mathrm{ES}=0.03\right)$ during transitioning movements. No general effect were observed in pre-transition body depth (when all strokes were considered), while particularly regarding the differences within each stroke, the difference was found in backstroke $\left(F_{1,66}=4.87, \mathrm{p}=0.03, \mathrm{ES}=0.07\right)($ Table 4.3). 
Table 4.3. Pairwise gender comparison of the segmental variables (body and trunk inclinations and body depths) within breakout (i.e. pretransition and transition phase).

\begin{tabular}{|c|c|c|c|c|c|c|c|c|}
\hline & \multicolumn{2}{|c|}{ Freestyle (mean (SD)) } & \multicolumn{2}{|c|}{ Backstroke (mean (SD)) } & \multicolumn{2}{|c|}{ Butterfly (mean (SD)) } & \multicolumn{2}{|c|}{ Breaststroke (mean (SD)) } \\
\hline & Male & Female & Male & Female & Male & Female & Male & Female \\
\hline \multicolumn{9}{|l|}{ Pre-transition } \\
\hline Body depth (m) & $0.39(0.13)$ & $0.39(0.14)$ & $0.62(0.22)$ & $0.51(0.19)^{*}$ & $0.36(0.12)$ & $0.38(0.13)$ & $0.53(0.16)$ & $0.58(0.48)$ \\
\hline Trunk inclination $1^{\circ}$ & $16.20(5.26)$ & $14.67(4.76)$ & $8.25(6.13)$ & $8.39(5.89)$ & $16.13(5.35)$ & $15.91(3.92)$ & $10.89(7.43)$ & $9.45(5.84)$ \\
\hline Trunk inclination $2^{\circ}$ & $4.58(3.07)$ & $5.29(3.78)$ & $9.01(5.22)$ & $8.36(4.76)$ & $4.91(3.57)$ & $4.95(3.39)$ & $7.22(6.38)$ & $7.18(5.23)$ \\
\hline Body inclination $1^{\circ}$ & $14.31(5.07)$ & $12.49(4.59)$ & $6.17(4.55)$ & $6.13(4.61)$ & $13.14(4.87)$ & $13.81(4.04)$ & $9.27(8.05)$ & $7.58(5.11)$ \\
\hline Body inclination $2^{\circ}$ & $6.44(3.96)$ & $7.39(4.19)$ & $4.42(3.70)$ & $5.42(5.44)$ & $6.32(4.50)$ & $8.14(4.94)$ & $6.68(5.31)$ & $7.38(5.75)$ \\
\hline \multicolumn{9}{|l|}{ Transition } \\
\hline Body depth (m) & $0.20(0.11)$ & $0.21(0.14)$ & $0.52(0.18)$ & $0.45(0.19)$ & $0.20(0.11)$ & $0.18(0.10)$ & $0.34(0.14)$ & $0.37(0.19)$ \\
\hline Trunk inclination $1^{\circ}$ & $9.00(4.77)$ & $9.95(7.00)$ & $9.02(7.98)$ & $6.73(4.78)$ & $9.00(5.07)$ & $9.12(5.97)$ & $9.34(6.03)$ & $6.83(5.03)$ \\
\hline Trunk inclination $2^{\circ}$ & $7.45(3.67)$ & $8.55(4.87)$ & $12.78(6.07)$ & $15.31(5.47)$ & $14.29(6.76)$ & $17.34(7.14)$ & $17.86(6.08)$ & $21.65(8.09) *$ \\
\hline Body inclination $1^{\circ}$ & $11.66(6.46)$ & $13.43(6.89)$ & $6.38(4.49)$ & $6.98(5.21)$ & $12.62(5.56)$ & $11.98(6.49)$ & $24.91(6.78)$ & $22.93(5.19)$ \\
\hline Body inclination $2^{\circ}$ & $9.66(4.27)$ & $10.49(4.35)$ & $12.98(5.99)$ & $14.00(6.24)$ & $11.15(4.75)$ & $14.48(7.37)^{*}$ & $15.81(5.48)$ & $20.57(5.22)^{*}$ \\
\hline
\end{tabular}

Note: Stars denote significant difference $* \mathrm{p}<0.05$ 


\subsection{Discussion}

The present study aimed to characterize breakout kinematic, coordinative and segmental parameters in relation to both genders. Male swimmers exhibited faster transition velocities than females, not only due to strength factors (i.e. larger stroke lengths), but due to larger stroke rate. Moreover, the ability of male swimmers to better control inclinations was the additional reason of total better transition performance of males. Males presented shorter times gaps than females, that is, a better propulsive continuity than females.

\section{Kicking and stroke kinematics}

Male swimmers were characterized with higher pre-transition velocities as compared to female swimmers. The higher velocity was due to males' higher kicking rate than females, while no difference was observed in kick length (Table 4.1). The present finding is not in agreement with previous results on kicking kinematics, where no difference in underwater kinematics (i.e. kick rate) was reported between genders (Zamparo et al., 2012). This suggests that males start accelerating during pre-transition phase as a preparatory strategy for proper transition. This tactic skill is recognized beneficial by males, as they start accelerating towards the end of underwater swimming, by which they tried to get transfer of momentum of kicking rate into transitioning phase (Veiga \& Roig, 2017).

Male swimmers showed larger velocities than females in all four swimming strokes and the velocities were larger due to larger distances per cycle (stroke lengths) (Table 4.1). Larger velocity in males' swimmers than females were more pronounced during transition $(19.13 \%)$ than during free swimming $(16.21 \%)$. The percentage differences during transition overreached differences obtained in free swimming of freestyle (Craig et al., 1979; Pelayo et al., 1996), 
backstroke (Craig et al., 1979; Klentrou et al., 1992), butterfly (Craig et al., 1979; Seifert et al., 2008) and breaststroke (Thompson et al., 2000).

The stroke lengths values were comparable with the values reported in previous studies (Letzelter \& Freitag, 1983; Kennedy et al., 1990; Arellano et al., 1994). Although, it is inevitable that strength factors play a differentiating role for it, it is probably that males in addition to larger strength have better tactical approach (including sense to set proper fire on motor units) on how to emerge to surface swimming the fastest possible. First, they prepare adequately for transition already in pre-transition phase using fast kicking (i.e. larger kicking rate than in females). Since genders do not differ in the underwater kicking rate, this is a strategy per se that is applied only in last underwater cycle (i.e. pre-transitioning phase) by male swimmers in order to timely prepare for transition. Second, males probably amplify stroking rate by increasing frequency of leg kicking by which they possibly decrease excessive inclinations especially during head emerging (body and trunk inclinations).

However, in addition to stroke lengths that differ between genders among all three phases (Table 4.1), stroke rate was only different in the transition phase. This is a novel finding of the present study, showing that males adapt differently to transitioning constraints than females. Apart to advantage gained from anthropometric (Letzelter \& Freitag, 1983) and strength differences (Bishop, Cureton, \& Collins, 1987) expressed in larger stroke lengths, male swimmers additionally increase velocity by enhancing stroke rate (i.e. stroke rate amplification) by which genders in free swimming usually do not differ (Pelayo et al., 1996; Arellano et al., 1994; Chollet et al., 1996; Chollet et al., 1999; Takagi et al., 2004). Indeed, in the present research, stroke rate did not differ in free swimming phase $(\mathrm{p}=0.76)$. 
At this point, there could be differentiated at least two reasons by which male swimmers shows better transition performance (i.e. higher velocity) than female swimmers. First, males had higher transition velocity due to larger stroke lengths, which origins are from anthropometric (muscle mass, tallness, arm span...) (Letzelter \& Freitag, 1983) and strength distinguishing sources (Bishop, Cureton, \& Collins, 1987). Second, over and above male swimmers were characterized with increased transition velocity compared to females due to higher stroke rates which origins lie not in genders strength difference, but are likely to be of neural origins (Keskinen \& Komi, 1993; Herda et al., 2019). Keskinen \& Komi (1993) indicated that stroke rate is defined by "the ability to set adequate neural activation". In addition, when muscular mass and strength were not different such is case in children; males produced higher motor unit firing rates (Herda et al., 2019). Higher firing rates probably induced higher stroke rate in males compared to females and the ability to have sense to employ this neural capacity on task constraints (i.e. transition swimming) determined males to have better transition performance than female swimmers.

\section{Segmental parameters during pre-transition and transiting swimming}

Swimming inclinations represented important constraints which differentiated male transitioning performance from female. Interestingly, no gender differences were found in pre-transition inclinations, suggesting that underwater kicking technique was similar in males and females, while task (i.e. transitioning body undulations) and environmental constraints of the transition phase were high enough to trigger gender differences.

Females showed higher trunk and body inclinations 2 than males $\left(\delta 2.63^{\circ} \pm 0.90^{\circ}, \delta 2.44^{\circ} \pm\right.$ $0.79^{\circ}$ ), not due to the anthropometric differences (intrinsic constraints), but due to lower 
adaptations to task constraints and environmental constraints. Indeed, intrinsic constraints which refer to the control of buoyancy and passive underwater torque should give the advantage to females, due to better buoyancy (Mc Lean \& Hinrichts, 1998) and consequently lower leg sink (Zamparo et al., 1996), but that was not the case. Possibly, the females advantage of better buoyancy and lower underwater torque manifested in passive condition was cancelled out due to complex environmental constraints associated with active swimming (Cohen et al., 2014), especially during swimming transition.

Task constraint of synchronous strokes (butterfly and breaststroke) produced more instantaneous changes of active underwater torque which caused larger inclinations (Cohen et al., 2014). In synchronous strokes, females were likely less able to control those momentary changes as they owned larger inclinations than males, which were $16.8 \%$ and $16.5 \%$ larger for trunk 2 and body inclinations 2 , respectively. On the other hand, the males ability to reduce active underwater torque and consequently inclinations is most likely linked to their better kicking actions (Kjendlie et al., 2004b), which in final line displayed higher stroke rate.

\section{Coordination patterns}

The differences in coordinative parameters between genders are directly related to strength factors (Didier Chollet \& Seifert, 2011), although other anthropometric factors such as the distribution of fat could be also taken into account (Avlonitou, Georgiou, Douskas, \& Louizi, 1997). Both, during transition and free swimming, males of the present study showed shorter time lag and therefore greater inter-limb synchronization than females. This is consistent with coordinative data obtained in free swimming including freestyle (Vantorre, Seifert, Fernandes, Boas, \& Chollet, 2010), backstroke (Silva et al., 2013) and breaststroke (Seifert \& Chollet, 
2005). Interestingly, in sprint butterfly time lag was minimal in both genders, while it only differed between less elite males and females (Seifert, Boulesteix, Chollet, \& Vilas-Boas, 2008). Although no differences in free swimming butterfly were reported in present study which coincides with previous studies, the differences existed during transition phase, where females had longer time/coordination gaps (DRP1 and DRP2). Longer time gap of the first coordinative parameter (DRP1) in free swimming is usually related to energy saving mechanism (Seifert et al., 2014) where swimmers extend the period of arms being extended and therefore gliding, so arms motion starts late in relation to leg propulsion. Since the gender differences in butterfly coordination were not found during free swimming phase, some other factors rather than energy saving mechanisms probably caused the gender differences in butterfly coordination during transition. It could be argued that females wanted to preserve the underwater velocity benefits by keeping gliding longer (Chollet \& Seifert, 2011), where they preserved hydrodynamic body position by holding the arms extended and locked (Von Loebbecke, Mittal, Fish, \& Mark, 2009) and that was the reason of arms motion being late in relation to leg motion. Finally, this caused delay in the "catch of swimming rhythm" in the first part of propulsive actions of arms and legs, measured by DRP2, so there was still slight time lag or motor discontinuity in females. Already during second part of propulsion (DRP3) (beginning of arm push and the second leg down propulsion) the swimming rhythm or motor continuity was established (Chollet, Seifert, Boulesteix, \& Carter, 2006). 


\title{
CHAPTER 5
}

\section{STUDY 2 - EFFECT OF BREAKOUT PHASE ON}

\author{
KINEMATIC
}

AND COORDINATIVE SWIMMING PARAMETERS 


\section{Chapter 5 Effect of breakout phase on kinematic and coordinative}

\section{swimming parameters}

\subsection{Introduction}

Competitive swimming performances have observed a great evolution over the last few years due to improvements in the underwater segments of the race (Connaboy, Coleman, \& Sanders, 2009), after swimmers push off the starting or turning pool wall. In these segments, swimmers obtain the maximum swimming velocities between $1.9 \mathrm{~m} / \mathrm{s}$ and $2.2 \mathrm{~m} / \mathrm{s}$ (Elipot et al., 2009) by employing undulatory movements (Lyttle \& Blanksby, 2000) that are extended more or less (at a maximum distance of $15 \mathrm{~m}$ from the wall) according to the demands of the race (Veiga, Cala, Frutos, \& Navarro, 2014). In the last Swimming World Championships, small increases in the underwater distances travelled during start and turns would have represented changes in race performances of critical importance (Veiga et al., 2016).

The importance of underwater swimming is highlighted by its beneficial effect on the subsequent surface swimming, as there is a transfer of momentum that allows competitors to achieve greater stroke lengths and swimming velocities compared to mid-pool segments (Takeda, Ichikawa, Takagi, \& Tsubakimoto, 2009). Indeed, swimmers travelling longer underwater in the butterfly and backstroke events achieved faster velocities on the first strokes of international level race laps (Veiga \& Roig, 2017). However, the effect of underwater swimming on the race velocity may only be achieved if a proper transition from underwater to surface (or from undulatory to arm stroke movements) is performed. The so-called breakout (Allnutt, 2014) imposes changing constraints on the swimmers whereby they must begin with their arm stroking movements and cope with changes in the resistive drag forces from underwater to the water surface. As a highly constrained movement and from a biophysical approach, the analysis of the movement patterns employed by swimmers when transiting to surface could give some insight into how propulsion 
could be maximized (Seifert et al., 2014a).

Previous research has employed discrete relative phase in all strokes (Seifert et al., 2014b) and continuous relative phase measurements in breaststroke (Seifert et al. 2011) to quantify the armto-leg coordination patterns during free-swimming. The time gaps measured in these studies indicate the time difference (relative to the duration of the swimming cycle and expressed by phase angles) between two specific events within the swimming cycle to occur (Wheat \& Glazier, 2005). The general outcome of these studies was that better synchronization (i.e. lower relative phase) was achieved in highly expert swimmers when pace was increased in addition to a greater ability to modify the coordination patterns according to the pace demands (Chollet \& Seifert, 2011). This was probably achieved by modifying the percentage of the stroke propulsive phases according to the swimming velocity (Takagi, Sugimoto, Nishijima, \& Wilson, 2004). However, when swimmers resume surface swimming after the start or turn underwater phase, it is unknown whether the stroking patterns could be modified, as this may be an important role in the overall starting or turning performance.

Therefore, in the present research, we aimed to examine the effect of the breakout movements on the kinematic and coordinative swimming parameters. It was hypothesized that swimmers would achieve faster velocities during breakout than in free-swimming and that the stroking patterns would be modified according to the transition from underwater to surface swimming.

\subsection{Results}

The breakout phase of competitive swimmers was faster $\left(F_{3,120}=19.61, \mathrm{p}<0.001, \mathrm{ES}=0.33\right)$ than the subsequent free-swimming $(\delta 0.27 \pm 0.04 \mathrm{~m} / \mathrm{s})$ but also faster than the previous underwater swim $(\delta 0.04 \pm 0.01 \mathrm{~m} / \mathrm{s}$,$) in all strokes but breaststroke (\mathrm{p}=1.000)$. Stroking parameters were modified during breakout phase $\left(F_{2,107}=29.99, \mathrm{p}<0.001, \mathrm{ES}=0.36\right)$, with the stroking rate being greater in breakout than in free swimming $(\delta 4.68 \pm 0.79$ cycles $/ \mathrm{min})$, 
although the stroking length remained unchanged. Some differences were also observed in the stroking parameters between the strokes (Table 5.1.).

Table 5.1. Swimming kinematics of competitive swimmers in the different phases from underwater to surface swimming.

\begin{tabular}{lccc}
\hline & Pre-Transition & Transition & Free-Swimming \\
Velocity (m/s) & & & \\
Butterfly & $1.62 \pm 0.17$ & $1.80 \pm 0.18^{*}$ & $1.62 \pm 0.11^{*}$ \\
Breaststroke & $1.39 \pm 0.14$ & $1.16 \pm 0.12^{*}$ & $1.19 \pm 0.11^{*}$ \\
Freestyle & $1.64 \pm 0.24$ & $1.78 \pm 0.17^{*}$ & $1.69 \pm 0.14^{*}$ \\
Backstroke & $1.56 \pm 0.19$ & $1.61 \pm 0.19$ & $1.46 \pm 0.13^{*}$ \\
Length (m/cycle) & & & \\
Butterfly & & $1.83 \pm 0.21$ & $1.85 \pm 0.16$ \\
Breaststroke & $1.83 \pm 0.34$ & $1.91 \pm 0.26$ \\
Freestyle & $1.90 \pm 0.25$ & $2.10 \pm 0.16^{*}$ \\
Backstroke & $2.22 \pm 0.43$ & $2.08 \pm 0.24$ \\
Frequency (cycles/min) & & \\
Butterfly & & $59.59 \pm 7.63$ & $52.84 \pm 4.13^{*}$ \\
Breaststroke & $38.52 \pm 7.64$ & $37.94 \pm 5.71$ \\
Freestyle & $56.81 \pm 7.40$ & $48.39 \pm 5.35^{*}$ \\
Backstroke & $44.72 \pm 7.92$ & $42.66 \pm 4.82$ \\
\hline
\end{tabular}

Note: *statistically different from the previous phase.

For the $\%$ duration of the propulsive and non-propulsive stroke phases, swimmers employed more time in the arm propulsion phases during free-swimming in the butterfly arm stroke $(\delta$ $\left.5.3 \pm 1.3 \%, \mathrm{~F}_{1,32}=17.10, \mathrm{p}<0.0001, \mathrm{ES}=0.35\right)$ and the first freestyle and backstroke arm strokes $(\delta$ $3.4 \pm 1.5 \%, \mathrm{~F}_{1,32}=5.48, \mathrm{p}=0.026, \mathrm{ES}=0.15$ for freestyle and $\delta 3.0 \pm 1.0 \%, \mathrm{~F}_{1,32}=8.91, \mathrm{p}=0.005$ $\mathrm{ES}=0.22$ for backstroke). However, they presented a greater \% propulsion time in the butterfly 
leg kick $\left(\delta 3.7 \pm 1.7 \%, \mathrm{~F}_{1,32}=4.75, \mathrm{p}=0.037, \mathrm{ES}=0.13\right)$ and the breaststroke swimming $(\delta$ $\left.5.8 \pm 2.3 \%, \mathrm{~F}_{1,32}=6.54, \mathrm{p}=0.015, \mathrm{ES}=0.17\right)$ during breakout. Specific differences in each of stroke phases are shown in Table 5.2. 
Table 5.2. Stroke phases duration (\%) of competitive swimmers from underwater to surface swimming.

Catch Pull $\quad$ Push $\quad$ Clear $\quad$ Recovery

Freestyle arm stroke 1

$\begin{array}{lcccc}\text { Breakout } & 0.11 & 0.21 & 0.31 & 0.37 \\ \text { Free-swimming } & 0.15^{*} & 0.28^{*} & 0.27^{*} & 0.30^{*}\end{array}$

Freestyle arm stroke 2

$\begin{array}{lllcc}\text { Breakout } & 0.20 & 0.22 & 0.28 & 0.32 \\ \text { Free-swimming } & 0.21 & 0.25 & 0.26^{*} & 0.28^{*}\end{array}$

Backstroke arm stroke 1

$\begin{array}{llllll}\text { Breakout } & 0.10 & 0.15 & 0.21 & 0.22 & 0.32 \\ \text { Free-swimming } & 0.09 & 0.20^{*} & 0.19^{*} & 0.19^{*} & 0.33\end{array}$

Backstroke arm stroke 2

$\begin{array}{lllccc}\text { Breakout } & 0.11 & 0.20 & 0.20 & 0.17 & 0.32 \\ \text { Free-swimming } & 0.11 & 0.17 & 0.17^{*} & 0.15^{*} & 0.38^{*}\end{array}$

Butterfly arm stroke

$\begin{array}{lllll}\text { Breakout } & 0.18 & 0.21 & 0.20 & 0.41 \\ \text { Free-swimming } & 0.17 & 0.29^{*} & 0.17 & 0.38\end{array}$

$\begin{array}{lccccc}\text { Breaststroke arm stroke } & \text { Glide } & \text { Pull } & \text { Push } & \text { Recovery1 } & \text { Recovery2 } \\ \text { Breakout } & 0.35 & 0.27 & 0.15 & 0.11 & 0.13 \\ \text { Free-swimming } & 0.47^{*} & 0.22^{*} & 0.09^{*} & 0.11 & 0.11\end{array}$

$\begin{array}{lcccc}\text { Butterfly kick } & \text { Down1 } & \text { Up1 } & \text { Down2 } & \text { Up2 } \\ \text { Breakout } & 0.21 & 0.30 & 0.21 & 0.28 \\ \text { Free-swimming } & 0.17^{*} & 0.34 & 0.19 & 0.29\end{array}$

\begin{tabular}{|c|c|c|c|c|c|}
\hline Breaststroke kick & Leg-ext & Feet-join & Glide & Leg-flex1 & Leg-flex2 \\
\hline Breakout & 0.16 & 0.20 & 0.31 & 0.21 & 0.12 \\
\hline Free-swimming & 0.15 & $0.14^{*}$ & $0.43 *$ & $0.15^{*}$ & 0.13 \\
\hline
\end{tabular}


Finally, for the coordinative parameters, there were no statistical differences between the breakout and the free-swimming coordination in most of the stroke comparisons (Table 5.3). Greater propulsive continuity (shorter time gap) was observed in the backstroke freeswimming compared to the breakout phase $\left(\mathrm{RP} 2 \delta 9.24 \pm 3.02^{\circ}\right.$, Watson-Williams $\mathrm{F}$ test $=$ $4.30, \mathrm{p}=0.04)$. There was also a shorter time gap between arms and legs in the breaststroke free-swimming compared to breakout $\left(\mathrm{RP} 3 \delta 27.02 \pm 21.90^{\circ}\right.$, Watson-Williams $\mathrm{F}$ test $=$ $18.58, \mathrm{p}=0.0001)$. 
Table 5.3. Coordinative parameters (discrete relative phase, DRP) in degrees of competitive swimmers from underwater to surface swimming.

\begin{tabular}{|c|c|c|c|c|c|}
\hline & Relative phase & DRP1 & DRP2 & DRP3 & DRP4 \\
\hline \multirow[t]{2}{*}{ Freestyle } & Breakout & $7.52 \pm 27.92^{\circ}$ & $0.68 \pm 31.47^{\circ}$ & & \\
\hline & Free -swimming & $16.97 \pm 25.72^{\circ}$ & $10.65 \pm 18.52^{\circ}$ & & \\
\hline \multirow[t]{2}{*}{ Backstroke } & Breakout & $-34.63 \pm 22.69^{\circ}$ & $-46.51 \pm 16.18^{\circ}$ & & \\
\hline & Free-swimming & $-42.33 \pm 21.19^{\circ}$ & $-37.27 \pm 19.20^{\circ} *$ & & \\
\hline \multirow[t]{2}{*}{ Butterfly } & Breakout & $-32.69 \pm 23.40^{\circ}$ & $-22.17 \pm 35.42^{\circ}$ & $-7.00 \pm 48.00^{\circ}$ & $-3.55 \pm 46.05^{\circ}$ \\
\hline & Free -swimming & $-33.43 \pm 18.89^{\circ}$ & $-30.99 \pm 22.74^{\circ}$ & $-10.97 \pm 17.52^{\circ}$ & $-3.33 \pm 20.16^{\circ}$ \\
\hline \multirow[t]{2}{*}{ Breaststroke } & Breakout & $-91.28 \pm 55.93^{\circ}$ & $-32.59 \pm 64.41^{\circ}$ & $-34.44 \pm 33.83^{\circ}$ & $14.30 \pm 17.99^{\circ}$ \\
\hline & Free -swimming & $-105.90 \pm 33.56^{\circ}$ & $-57.17 \pm 52.61^{\circ}$ & $-7.42 \pm 11.93^{\circ} *$ & $12.59 \pm 12.08^{\circ}$ \\
\hline
\end{tabular}

Note: *statistical differences between breakout and free-swimming phases.

\subsection{Discussion and implications}

The present study aimed to examine the influence of transition from underwater to surface swimming on the kinematic and coordinative parameters of competitive swimmers. According to our results, swimming velocity during breakout seems to be faster than during subsequent free-swimming not because of a faster previous underwater kicking or a modified coordinative swimming pattern, but because of an increase in the stroking rate with changes in the relative duration of selected stroke phases.

\section{Stroke kinematics}

Competitive swimmers in the present research obtained faster breakout velocities than freeswimming in all strokes (except breaststroke) and in a range from $0.09 \mathrm{~m} / \mathrm{s}$ to $0.15 \mathrm{~m} / \mathrm{s}$. 
These data were in line with faster velocities during emersion from underwater swimming in the FINA 2013 World Swimming Championships (Veiga \& Roig, 2017). However, swimming velocities in the referred study did not specifically correspond to breakout but to the swimming phase from emersion to the $15 \mathrm{~m}$ mark. In the present research, faster breakout velocities of competitive swimmers were not justified by a transfer of momentum from previous underwater swimming, as previously suggested by Veiga and Roig (2017), because mean velocities on the last underwater kick before emersion were $7.82 \%$ or $10.51 \%$ slower (in freestyle or butterfly, respectively) than breakout velocities (Table 2). This probably suggests that swimmers extended the underwater swimming for too long before emersion and, therefore, they slowed down too much before initiating the breakout. Indeed, underwater distances by the national level swimmers of the present research (between $9.14 \mathrm{~m}$ and $11.04 \mathrm{~m}$ in freestyle and butterfly, respectively) were longer than previous distances $(7.04 \mathrm{~m}$ and $9.66 \mathrm{~m})$ reported in national level swimmers (Veiga et al., 2014). It has been extensively acknowledged that swimmers must optimize the underwater distance after the start and turns in order to maximize underwater velocity and to avoid forward momentum falling below the surface swimming (Burkett, Mellifont, \& Mason, 2010; Veiga et al., 2016).

The average velocity during breakout ranged from $1.16 \mathrm{~m} / \mathrm{s}$ in breaststroke to $1.80 \mathrm{~m} / \mathrm{s}$ in butterfly stroke. These values were similar to $1.65-1.80 \mathrm{~m} / \mathrm{s}$ freestyle (Lyttle \& Mason, 1997; Puel et al., 2012; Takeda et al., 2009) and 1.43 m/s backstroke (Veiga, Cala, Frutos, \& Navarro, 2013) emerging velocities from push start, faster than $0.94 \mathrm{~m} / \mathrm{s}$ breaststroke (Blanksby, Simpson, Elliott, \& McElroy, 1998), $1.1 \mathrm{~m} / \mathrm{s}$ backstroke (Blanksby, Skender, Elliott, McElroy, \& Landers, 2004; Veiga et al., 2013) and $1.58 \mathrm{~m} / \mathrm{s}$ butterfly (Lyttle \& 
Mason, 1997; Tourny-Chollet, Chollet, Hogie, \& Papparodopoulos, 2002) resumption velocities and, as expected, lower than previous studies measuring freestyle emersion velocities from a dive start (Vantorre et al., 2010; Veiga \& Roig, 2017). Surprisingly, and according to our results, breakout butterfly velocities were faster than freestyle despite it being extensively acknowledged that freestyle swimming is the fastest stroke. Probably, it was easier for swimmers to handle the task constraints in a simultaneous (butterfly) than in an alternate (freestyle) stroke as well as taking benefit of a lower hydrodynamic drag from the previous glide position (Marinho et al., 2009).

The main reason for swimmers to increase velocity during breakout seemed to be an increased stroking rate compared to free-swimming, as swimmers presented $14.82 \%$ and $11.33 \%$ greater stroke rate values during breakout than during free-swimming in the freestyle and butterfly, respectively. Swimmers probably benefited from the lack of local fatigue in arms after underwater swimming (Suito et al., 2008) adopting greater stroking rates than in the remaining lap distance that allowed them to achieve faster velocities. This had been previously observed in the first stroke laps of the Olympic Champion during the $200 \mathrm{~m}$ freestyle final (Hellard et al., 2008). However, swimmers during transition also benefited from a decrease in the hydrodynamic resistive forces due to sudden change from a denser media (i.e. water) to a less dense media (air), similar to what swimmers experience during drafting (Chatard \& Wilson, 2003).

In breaststroke, the preparation for the first full breaststroke stroke (breakout stroke) that swimmers performed after the so-called underwater pull-out was detrimental for swimming velocity. The reason is that during pull-out recovery swimmers reach forward velocities close to $0 \mathrm{~m} / \mathrm{s}$ (Seifert, Vantorre, \& Chollet, 2007b) and, therefore, begin their breakout movement at forward velocities much slower than in the remaining strokes. Also, the 
greater drag resistance due to the arm position at the end of the pull-out stroke (resting at thighs) as well as the leg flexion opposing movement direction explains differences with the other strokes where swimmers begin breakout from a streamlined position.

\section{Relative duration of stroke phases}

Swimming velocity modifications during breakout (compared to free-swimming) and changing constraints from underwater to surface swimming (Glazier \& Davids, 2009; Seifert et al., 2014b) probably forced swimmers to modify their swimming strokes, as previously observed in the freestyle (Chollet et al., 2000), breaststroke (Takagi et al., 2004), backstroke (Lerda \& Cardelli, 2003) or butterfly (Seifert et al., 2007a) strokes when changing from middle-distance to sprint-distance velocities.

In freestyle and backstroke, interestingly, swimmers decreased the relative duration of propulsive phases on the first arm stroke with a pull phase duration decreased from $28 \%$ to $21 \%$ in freestyle and from $25 \%$ to $20 \%$ in backstroke. This also occurred in the relative duration of the butterfly arm propulsive phases (from 59\% to 55\%). During breakout, swimmers focused on moving forward but also on elevating their body position from underwater to water surface. Thus, unavoidably, the role of the propulsive phases could be affected (Gourgoulis et al., 2015). Specifically, in backstroke, the reduction in the propulsive phases of breakout was accompanied by an increase in the clear non-propulsive phase (19\% to $22 \%$ ), which is considered a technical mistake in backstroke (Chollet, Carter, \& Seifert, 2006b). The increase in the non-propulsive actions was probably compensated by an amplified leg propulsive activity (Sortwell, 2011), as shown in butterfly where the relative duration of the breakout downward kick was $21 \%$ versus $17 \%$ in freeswimming. Compared to previous studies, the relative duration of the freestyle pull phase 
was similar to national level swimmers (Potdevin, Bril, Sidney, \& Pelayo, 2006) as well as the catch, pull, push and clear backstroke phases (Lerda \& Cardelli, 2003).

In breaststroke, and contrary to the previous strokes, swimmers increased the relative duration of the propulsive phases of arms and kicking during breakout. In this case, swimmers began breakout with very low velocities (Seifert et al., 2007b) and were constrained to maximize the propulsion to accelerate the body forward. Indeed, average velocity when transiting from underwater to surface was still lower than velocity obtained in the free-swimming. The relative duration of arm pull was in line with previous studies at maximal velocities, whereas gliding duration was shorter (Seifert \& Chollet, 2005).

\section{Coordination patterns}

In relation to the coordinative patterns, the decrease in the relative duration of the freestyle, backstroke and butterfly propulsive stroke phases during breakout resulted in a tendency for a greater propulsive discontinuity at that point. However, the large inter-subject variability (large standard deviation) observed indicated that swimmers managed the changing constraints from underwater to surface swimming in different ways.

In freestyle, previous data from 50 m events (Vantorre, Seifert, Fernandes, Boas, et al., 2010) indicated that swimmers tended to increase a superposition coordination pattern from the race beginning (10 to $12.5 \mathrm{~m})$ to the free-swimming $(15-17.5 \mathrm{~m})$. This was employed by highly expert swimmers to diminish velocity loss that inevitably occurs due to the drag swimmers encounter throughout a swimming event (Toussaint, Van Den Berg, \& Beek, 2002). In the present research, swimmers presented an opposition coordination pattern during breakout which evolved to a superposition mode in the free-swimming (although no statistical coordination changes were observed), indicating a light overlapping between 
propulsive phases of both arms. This is in line with previous observations from Seifert and Chollet (Seifert \& Chollet, 2009) who indicate superposition coordination patterns when swimming velocity reaches values close to $1.70 \mathrm{~m} / \mathrm{s}$.

In backstroke, swimmers presented a catch-up coordination with a time gap between the end of the propulsive action of one arm and the beginning of propulsion with the contralateral arm (Lerda \& Cardelli, 2003). This was expected, as backstroke swimming presents rhythmic body rotations around the axial axis with each arm 'catching' the water alternately and because of the nature of the shoulder joint with limited flexibility (Chollet et al., 2006b; Richardson, 1986). Only expert swimmers in the sprint events with high velocity demands have been reported to decrease the absolute time gap between the two arms (Lerda \& Cardelli, 2003).

In butterfly, previous research (Seifert et al., 2007a) had indicated that the preferable coordination patterns are those where time gaps between selected events of arms and legs are close to 0 (considered as movement in-phase, or DRP from $-30^{\circ}$ to $+30^{\circ}$ ). These time gaps tend to be reduced when butterfly swimmers increase their stroking rates (Seifert, Boulesteix, Chollet, \& Vilas-Boas, 2008), as occurred in the transition phase (Table 2). Indeed, most of the discrete relative phases tested in the swimmers of the present research showed in-phase patterns, both for the breakout and free-swimming segments. Interestingly, swimmers modified the relative duration of arm and leg propulsive actions during breakout (i.e. pull duration decrease and first down-kick increase) probably to prioritize the coupling of the arms and legs. As an example, the third and fourth discrete relative phases (measuring the timing between the second downward kick and the end of the propulsive action of arm), which are two key events that usually characterize expertise butterfliers (Seifert et al., 2007a) and allow them to reach high velocities before arm 
recovery (Martins-Silva \& Alves, 2000; Seifert et al., 2007a) were lower than $10^{\circ}$.

Finally, in breaststroke, the first and second discrete relative phases presented a nonstatistical decrease during breakout (from $-105.90^{\circ}$ to $-91.28^{\circ}$ and from $-57.17^{\circ}$ to $-32.59^{\circ}$, respectively) in the glide time from the end of leg kick to the beginning of arm propulsion. This is in line with the shorter relative duration of non-propulsive stroke phases during breaststroke breakout discussed above. Previous data from sprinting breaststroke events had reported minimum time gaps or even swimmers beginning arm propulsion while feet were still kicking to overcome great active drag levels of breaststroke swimming (Chollet et al., 2004). During breakout, active drag was supposed to be even greater than during freeswimming due to arm position at the end of the pull-out stroke, so this could explain the diminution of non-propulsive time gaps. In the same vein, competitive swimmers in the breakout began leg recovery when arms where still propelling (DRP3), inevitably opposing, therefore, movement direction and causing velocity loss (Leblanc, Seifert, Baudry, \& Chollet, 2005). However, in the free-swimming, they adapted coordination from mechanically inappropriate (in which the activity of one pair of limbs decelerates the propulsion of another) to coordination closer to mechanical continuity (i.e. relative phase closer to zero degree). 


\section{CHAPTER 6}

\section{STUDY 3 - HOW SHOULD THE TRANSITION}

FROM UNDERWATER TO SURFACE SWIMMING

\section{BE PERFORMED IN COMPETITIVE SWIMMERS}




\section{Chapter 6 How should the transition from underwater to}

\section{surface swimming be performed in competitive}

\section{swimmers?}

\subsection{Introduction}

In the last years, the importance of the underwater segment of the start and turns in swimming competitions has increased both quantitatively and qualitatively. The contribution of underwater swimming to the total race distances has considerably increased over the last 20 years (Veiga et al., 2013) and elite swimmers now spend between 15\% and $25 \%$ of the $100 \mathrm{~m}$ race distances underwater (Veiga and Roig, 2017). Also, swimmers achieving the fastest underwater velocities (especially on $100 \mathrm{~m}$ events) or the longest underwater distances (on $200 \mathrm{~m}$ events) have a critical advantage on their performances during World Championships (Veiga, Roig, \& Gómez-Ruano, 2016). The lower drag resistance experienced by swimmers underwater (Nicolas \& Bideau, 2009) as well as the improvement on the undulatory techniques (Takeda et al., 2020) allow swimming competitors to achieve the fastest race velocities underwater and to prioritize these segments over the mid-pool swimming techniques.

The benefits of the underwater swimming for competitive swimmers also include a transfer of momentum to the subsequent surface swimming during starts and turns (Connaboy, Coleman, Moir, \& Sanders, 2010). Elite swimmers exhibited 5\%-10\% faster swimming velocities after the start emersion compared to mid-pool swimming, with small increases of both stroke frequency and length (Veiga \& Roig, 2017). After the turn, those swimmers achieving the longest underwater distances (backstroke and butterfly) also obtained 5\%-6\% 
faster velocities at emersion compared to mid-pool. This positive impact of underwater on surface swimming can be achieved if a correct transition from underwater (the so-called breakout - Allnutt et al., 2014) is performed. Swimmers must restart their arm propulsion at this point and they no longer maintain the hydrodynamic position they adopt during underwater kicking (Naemi et al., 2009). While doing so, they must optimize the stroke timing in order to finish the arm pull (and begin their aerial recovery) when the head reaches the water surface. Also, in this phase, swimmers change location (from fully submerged to emerged at water surface) that could have implications on active drag (Kolmogorov \& Duplisheva, 1992), associated with wave drag increase (Vennell et al., 2006). The simultaneous (butterfly and breaststroke) or alternate (freestyle and backstroke) arm stroke techniques, the dorsal (backstroke) or ventral (freestyle, butterfly and breaststroke) body position and the beginning of the flutter kick versus the undulatory kick (Takeda et al., 2020) are other constraints that swimmers must handle in this phase.

In relation to the beginning of arm propulsion, previous studies have quantified the interlimb coordination by measuring the time gap between the propulsive actions of arms and/or legs. Chollet and colleagues (Chollet, Chalies, \& Chatard, 2000) found positive correlations between shorter inter-limb time gaps and the free-swimming velocity, although dependent on the swimmer skill (Schnitzler, Seifert, Aignan, Aignan, \& Aignan, 2010) and speciality (Seifert et al. 2010). For the swimmers' body positions, both body inclination and body depth have been examined as the different locations of the centre of mass and centre of flotation cause an active rotational torque which influences body positions in respect to water surface (Kjendlie et al., 2004a). An increased body angle has been correlated negatively with swimming underwater velocity (Houel et al., 2013) and surface velocity 
(Kjendlie et al., 2004b) due to increased projected area and therefore frontal drag (Wang et al., 2007; Kolmogorov, Rumyantseva, Gordon, \& Cappaert, 1997). On the other hand, body depth has been correlated positively with underwater velocity (Ruschel, Araujo, Pereira, \& Roesler, 2007) due to decreased swimming resistance (Lyttle, Blanksby, Elliot, \& Lloyd, 1998; Machado et al., 2010). Finally, for the underwater kicking, Arellano et al. (Arellano et al., 2002; 2003) indicated that the underwater undulatory swimming (UUS) velocity is dependent on kicking kinematics (i.e. kicking frequency, amplitude, and length (distance per kick)) and that kicking frequency is the major kinematic factor in controlling UUS velocity. When competitive swimmers begin first UUS cycle they are located at relatively high depth (-0.92 $\mathrm{m}$ from water surface) (Tor et al., 2015) and display greater kicking frequency and amplitude compared to the end of underwater swimming (de Jesus et al., 2012.)

However, despite all these kinematic parameters have been examined on the mid-pool swimming or on the underwater undulatory kicking, no information about their role on the transition from underwater to surface swimming has been explored yet. For example, it is unknown whether great depth could be beneficial during transition given that it would require higher body angles (i.e. higher active drag) to reach water surface in a relatively restricted distance. Therefore, the aim of the present study was to examine the role of the segmental, kinematic and coordinative parameters on the swimming velocity during the pre-transition and transition phases of the push start. Considering the positive influence of underwater on the subsequent surface swimming, it could be expected that swimmers would decrease the time gaps between the propulsive arm actions, would minimize body inclinations and would maximize USS velocity for faster transitioning velocity. 


\subsection{Results}

Table 6.1. and Figure 6.1. show the kinematic parameters during pre-transition and transition phases of the push start and their relationships with the average swimming velocity. There were differences between strokes in the majority of the kicking and body position parameters, except the trunk inclination 1 in transition phase. During pretransition, average velocity was limitedly correlated with body depth in freestyle $(r=$ 0.262) and butterfly $(r=0.283)$ strokes, whereas no correlations were observed for the body inclination. For the kicking variables, kick rate and kick length (but not amplitude) were correlated with faster velocities in all strokes, except the backstroke kicking rate. During transition, body inclination and body depth were negatively correlated with velocity in backstroke whereas no relationships were observed for the remaining strokes. Coordinative parameters were positively related to transition velocity, except in freestyle.

Backward regression analysis (table 6.2) of pre-transition phase revealed that the body position parameters did not statistically predict the average velocity in this phase. In transition, the regression model significantly predicted swimming velocity in all strokes $\left(\mathrm{R}^{2}\right.$ ranging from 0.263 in freestyle to 0.364 in butterfly), being all inclinations and depth parameters predictors in freestyle and backstroke whereas all coordinative parameters predictors in butterfly and breaststroke. 
Table 6.1. Descriptive statistics - mean (standard deviation) - of the pre-transition and transition variables in all four strokes for competitive swimmers

\begin{tabular}{|c|c|c|c|c|}
\hline Dependent variable & Freestyle & Backstroke & Butterfly & Breaststroke \\
\hline \multicolumn{5}{|l|}{ Pre-transition } \\
\hline Kick length (m/cycle) & $0.77(0.12)$ & $0.72(0.10)$ & $0.77(0.12)$ & $3.66(0.50)$ \\
\hline Kick rate (cycles/s) & $2.15(0.31)$ & $2.14(0.30)$ & $2.14(0.35)$ & $0.39(0.07)$ \\
\hline Kick amplitude (m) & $0.29(0.06)$ & $0.37(0.07)$ & $0.31(0.06)$ & - \\
\hline Body depth (m) & $-0.39(0.13)$ & $-0.62(0.22)^{\mathbf{a}}$ & $-0.36(0.12)^{\mathbf{a}}$ & $-0.53(0.16)^{\mathbf{a c}}$ \\
\hline Trunk inclination $1^{\circ}$ & $16.20(5.26)$ & $8.25(6.13)^{\mathbf{a}}$ & $16.13(5.35)^{\mathbf{a}}$ & $10.56(7.30)^{\mathbf{a c}}$ \\
\hline Trunk inclination $2^{\circ}$ & $4.58(3.07)$ & $9.01(5.22)^{\mathbf{a}}$ & $4.91(3.57)^{\mathbf{a}}$ & $7.42(6.38)$ \\
\hline Body inclination $1^{\circ}$ & $14.31(5.07)$ & $6.17(4.55)^{\mathrm{a}}$ & $13.14(4.87)^{\mathbf{a}}$ & $9.25(8.19)^{\mathbf{c}}$ \\
\hline Body inclination $2^{\circ}$ & $6.44(3.96)$ & $4.42(3.70)$ & $6.32(4.50)$ & $6.63(5.39)$ \\
\hline \multicolumn{5}{|l|}{ Transition } \\
\hline Stroke length (m/cycle) & $1.90(0.25)$ & $2.22(0.43)^{\mathbf{a}}$ & $1.83(0.21)^{\mathbf{a}}$ & $1.83(0.34)^{\mathbf{b}}$ \\
\hline Stroke rate (cycles/min) & $56.81(7.40)$ & $44.72(7.92)^{\mathbf{a}}$ & $59.59(7.63)^{\mathbf{a}}$ & $38.52(7.64)^{\mathbf{a b c}}$ \\
\hline Body depth (m) & $-0.20(0.11)$ & $-0.52(0.17)^{\mathbf{a}}$ & $-0.20(0.11)^{\mathbf{a}}$ & $-0.34(0.14)^{\mathbf{a b c}}$ \\
\hline Trunk inclination $1^{\circ}$ & $9.00(4.77)$ & $9.02(7.98)$ & $9.00(5.07)$ & $9.80(5.77)$ \\
\hline Trunk inclination $2^{\circ}$ & $7.45(3.67)$ & $12.78(6.07)^{\mathbf{a}}$ & $14.28(6.76)^{\mathbf{b}}$ & $17.50(6.39)^{\mathbf{b c}}$ \\
\hline Body inclination $1^{\circ}$ & $11.66(6.46)$ & $6.37(4.49)^{\mathbf{a}}$ & $12.62(5.56)^{\mathbf{a}}$ & $25.26(6.83)^{\mathbf{a b c}}$ \\
\hline Body inclination $2^{\circ}$ & $9.66(4.27)$ & $12.98(5.99)$ & $11.15(4.75)$ & $15.42(5.76)^{\mathbf{a c}}$ \\
\hline $\mathrm{DRP} 1^{\circ}$ & $7.52(27.92)$ & $-34.63(22.69)$ & $-32.69(23.40)$ & $-91.28(55.93)$ \\
\hline $\mathrm{DRP} 2^{\circ}$ & $0.68(31.47)$ & $-46.51(16.18)$ & $-22.17(35.42)$ & $-32.59(64.41)$ \\
\hline $\mathrm{DRP} 3^{\circ}$ & - & & $-7.00(48.00)$ & $-34.44(33.83)$ \\
\hline $\mathrm{DRP} 4^{\circ}$ & - & & $-3.55(46.05)$ & $14.30(17.99)$ \\
\hline
\end{tabular}

Note: Superscript a denotes the difference of superscripted value from first left value, superscript b denotes the difference from second left value, and superscript $\mathbf{c}$ denotes the difference from third left value 

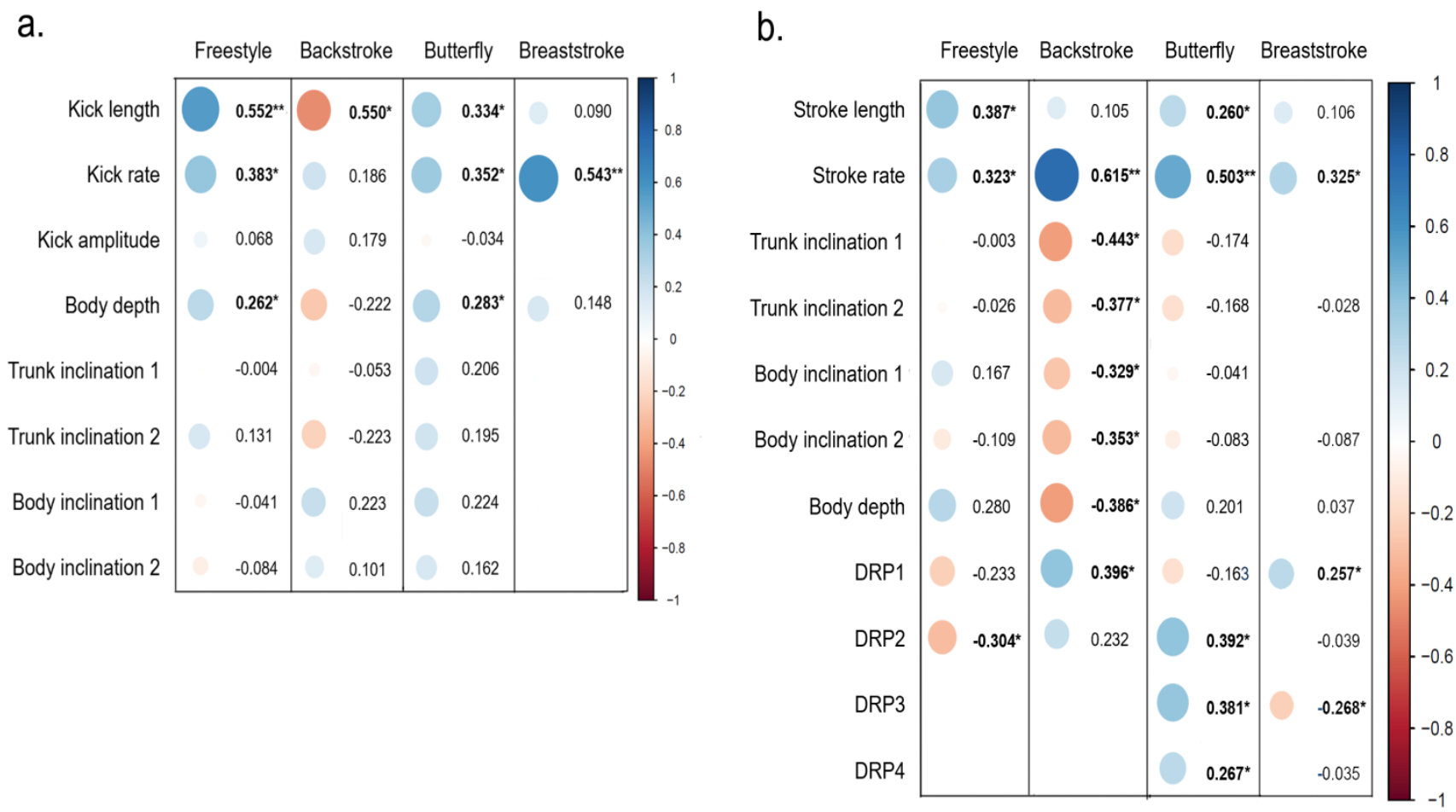

Figure 6.1. Relationships between the kinematic, segmental and coordination variables with average velocity of the competitive swimmers in the pre-transition (a) and transition (b) of the push start. 
Table 6.2. Backward regression analysis (the influence of segmental and coordination parameters on performance in pre-transition and transition phase in all four strokes)

\begin{tabular}{|c|c|c|c|c|}
\hline \multirow[t]{2}{*}{ Dependent variables } & \multicolumn{4}{|c|}{ Backward regression model } \\
\hline & Freestyle & Backstroke & Butterfly & Breaststroke \\
\hline \multicolumn{5}{|l|}{ Pre-transition } \\
\hline \multicolumn{5}{|l|}{ Beta standardized coefficients } \\
\hline Body depth & 0.55 & -0.47 & 0.28 & 0.23 \\
\hline Trunk inclination 1 & & -0.43 & & -0.36 \\
\hline Trunk inclination 2 & & & & -0.38 \\
\hline Body inclination 2 & -0.44 & & & 0.39 \\
\hline$y$-intercept (constant) & $1.17 \pm 0.38$ & $1.96 \pm 0.20$ & $1.46 \pm 0.10$ & $1.35 \pm 0.09$ \\
\hline$R^{2}$ & 0.181 & 0.226 & 0.080 & 0.200 \\
\hline$R^{2}$ adjusted & 0.127 & 0.135 & 0.049 & 0.077 \\
\hline Standard error of estimate & 0.219 & 0.189 & 0.168 & 0.137 \\
\hline$F$ & 3.325 & 2.483 & 2.530 & 1.626 \\
\hline$p$ & $0.050^{*}$ & 0.113 & 0.123 & 0.198 \\
\hline \multicolumn{5}{|l|}{ Transition } \\
\hline \multicolumn{5}{|l|}{ Beta standardized coefficients } \\
\hline Body depth & 0.32 & -0.40 & 0.18 & \\
\hline Trunk inclination 1 & -0.36 & 0.32 & & \\
\hline Body inclination 1 & 0.38 & -0.30 & & 0.20 \\
\hline DRP1 & & 0.33 & -0.52 & -0.49 \\
\hline DRP2 & -0.35 & & 0.62 & 0.97 \\
\hline DRP3 & & & & -0.81 \\
\hline$y$-intercept (constant) & $1.67 \pm 0.08$ & $1.92 \pm 0.12$ & $1.69 \pm 0.08$ & $0.73 \pm 0.16$ \\
\hline$R^{2}$ & 0.263 & 0.321 & 0.364 & 0.292 \\
\hline$R^{2}$ adjusted & 0.154 & 0.213 & 0.293 & 0.157 \\
\hline Standard error of estimate & 0.161 & 0.178 & 0.152 & 0.109 \\
\hline$F$ & 2.407 & 2. 959 & 5.141 & 2.161 \\
\hline$p$ & 0.074 & $0.039 *$ & $0.006 * *$ & 0.109 \\
\hline Number of observations & 3383 & 33 & 33 & 33 \\
\hline
\end{tabular}




\subsection{Discussion}

The aim of the current study was to examine the factors relevant for swimming performance during transition from underwater to surface swimming by applying correlation and regression analysis. Previously, it had been indicated that swimming velocities of elite swimmers after emersion from underwater were faster than during midpool swimming (Veiga \& Roig, 2017). However, no information about how swimmers should perform this transition phase had been revealed. Our results indicate that body position and coordinative swimming parameters (besides stroking rate and length) have an influence on the transition performance, which depends on the swimming strokes.

\section{Pre-transition phase}

Before swimmers emerged from underwater, during the last underwater kicking cycle (the so-called pre-transition phase), the body position parameters (depth and inclination) did not statistically predict the average velocity. At this point, only the kicking parameters (kicking length and kicking frequency) presented large correlations with velocity (Figure 6.1.) highlighting the importance of kicking propulsion rather than technical position of the body (Nakashima, 2009). More specifically, the present study detected medium correlation between kick frequency and velocity ( $r=0.383$, for freestyle pre-transition), whereas the previous studies were in the domain of large correlations between velocity and kick rate $(r=0.519)$ (Arellano et al., 2003). On the other hand, both present study $(r=0.552)$ and previous studies $(r=0.630)$ revealed high correlations between kick length and velocity (Arellano et al., 2003). For the kicking amplitude, on the other hand, no significant relationships with swimming velocity were observed. Values obtained of kicking kinematics were similar to those previously reported (Arellano et al., 2002; 2003; Hochstein et al., 2014; Alves et al., 2006). 
The body position parameters on the pre-transition phase were between $6^{\circ}$ and $16^{\circ}$ degrees (in respect to horizontal) for the body inclination and from $-0.36 \mathrm{~m}$ (butterfly) to $-0.62 \mathrm{~m}$ (backstroke) for the body depth (Table 6.1.). These inclinations were in line with previous study of Arellano et al. (Arellano et al., 2002) who found body angles of attack of 17 degrees during underwater swimming. However, body depths were obviously lower than the recommended body depth (from -0.74 to $-1.03 \mathrm{~m}$ ) for underwater swimming (Tor et al., 2015). These data interestingly suggest that, when transiting from underwater to surface swimming, swimmers diminish depth but maintain body inclinations with a correct alignment almost parallel to water surface, not different from the underwater swimming (Houel et al., 2013). Otherwise, there would be an increase in frontal drag (Kolmogorov \& Duplishcheva, 1992) with a concomitant velocity reduction (Toussaint et al., 1988). As previously mentioned, the body position parameters presented small correlations with pretransition velocity. However, the direction of correlations for the body depth was opposed for the ventral (positive correlations) or dorsal (negative correlations) strokes, where (i.e. in backstroke) the body depth was highest (Figure 6.1.). Probably, greater drag experimented in supine compared to prone towing (Pease et al., 2013) due to a more incongruent body side approaching water surface (Anderson, McGillis, \& Grosenbaugh, 2001), prevented swimmers to stay at greater depths where a reduced contribution of the wave drag to the total drag is observed (Vennell et al., 2006). Also, visual control of the water surface in backstroke transition from underwater to surface swimming probably eased swimmers to carefully approach the water surface. 


\section{Transition phase}

During transition, the swimmers' stroking rate in all strokes showed greater correlations (medium to large) with average velocity than the stroking length (small to medium) (Figure 6.1.). This was in line with the increased stroking rate values of elite swimmers after start and turn emersion compared to mid-pool swimming (Veiga and Roig, 2017), due to a shorter relative duration of the propulsive stroke phases (Chapter 5). In a situation of an increased overall drag due to wave drag emergence (Vennell et al., 2006), unfatigued swimmers (Suito et al., 2008) probably prioritised to increase the stroking rate to overcome resistance. Compared to correlations examined in the mid-pool swimming, the swimmers' stroking parameters during transition exhibited lower relationships with swimming velocity than previously observed at mid-pool with swimmers of a certain level. For instance, the freestyle stroking rate had been largely correlated 0.897 (Wakayoshi et al., 1995) or 0.92 (Seifert, Chollet, \& Bardy, 2004), the butterfly stroke rate 0.87 (Barbosa et al., 2005), the freestyle stroke length 0.52 (Craig \& Pendergast, 1979) and the backstroke stroke length 0.62 in $250 \mathrm{~m}$ swim (Smith, Montpetit, \& Perrault, 1988) or 0.74 in $100 \mathrm{~m}$ swim (Lerda \& Cardelli, 2003). This highlights the specific characteristic of the transition phase, where other kinematic factors (depth, inclination) besides stroking parameters seem to have an important role for building velocity. Indeed, the regression models proposed in the present research based on the body position and inter-limb coordination of transition explained up to the $30 \%$ of the average velocity for the butterfly stroke, which represents a meaningful finding for swimmers and coaches.

When beginning the transition phase, swimmers in the present research situated themselves between $0.20 \mathrm{~m}$ and $0.52 \mathrm{~m}$ below (greater values for backstroke and lower values for 
freestyle and butterfly strokes) the water surface and, interestingly, the body inclinations averaged $9^{\circ}$ degrees regardless of stroke, and was similar $\left(10.68^{\circ}\right)$ in surface swimming (Kjendlie et al., 2004b). Probably, maximum velocity at which swimming trials were performed in the present research and the swimmer's skill level helped them to counteract the active rotational torque and maintaining a close body alignment to horizontal (Strzala et al., 2010; Kjendlie et al., 2004a). This could be the reason why the correlations between body inclinations and average velocity were low, especially in alternate strokes where no undulations were present. However, in backstroke where swimmers' depth was the greatest at this point, average velocity was negatively correlated to greater depth.

For the coordinative parameters, shorter time gap between the arm propulsion of both backstroke arms was related to faster transition velocities, which is in line with positive correlations between inter-limb coordination and free swimming velocity (Chollet, Chalies, \& Chatard, 2000; Seifert et al., 2004). However, surprisingly, the second discrete relative phase in freestyle was negatively correlated with transition velocity (more time gap, faster velocity). This could be related to the role of breathing on the inter-limb coordination (Seifert, Chollet, \& Allard, 2005) after the second arm pull, as swimmers are usually encouraged to avoid breathing on the first arm propulsion after underwater (Seifert, Chollet, \& Allard, 2005). This could result in larger time gaps between propulsive actions of arms on the second arm pull. In the simultaneous strokes, shorter time gaps between the arm and leg butterfly propulsion were correlated with faster velocities during transition, indicating a preferable propulsion continuity to overcome drag forces. In breaststroke, on the contrary, longer times gaps between the arm and leg propulsion (DRP1) were related to faster velocities. Although motor continuity is recommended (Seifert, Leblanc, Chollet, \& 
Delignières, 2010), this did not happen in the transition breaststroke phase because swimmers must recover arms from the underwater pullout (hands close to thighs) instead of a regular arm pull. This represents an interesting point linked to the correct coordination of the underwater pullout (Seifert et al., 2007b).

Generally speaking, the body position and inter-limb coordinative parameters of competitive swimmers during transition phase statistically predicted an important amount (between the $15 \%$ and $29 \%$ depending on the stroke, Table 6.2.) of the variance in the average velocity. Regression models included the body depth in all four strokes and the body or trunk inclination in the alternate strokes (freestyle and backstroke), highlighting the importance of an appropriate body positioning when approaching the water surface. This should be done minimizing body depth and maintaining trunk inclination in backstroke but minimizing inclination in freestyle and maintaining depth with water surface. Obviously, on the simultaneous techniques (butterfly and breaststroke) where body undulations occur (Sanders et al., 1995; Sanders et al., 1998), the effect of trunk/body position for velocity was probably hindered. For the inter-limb propulsion coordination, in butterfly, the time gaps related to the beginning of arm propulsion (DRP1 and 2) were included in the regression model. This data probably indicates that swimmers had to primarily adapt their arm to leg movements at the beginning of the arms propulsion (not in DRP3 and 4) when the body position was still underwater. For the alternate strokes, shorter times gaps at the end of the first arm pull in backstroke and longer time gaps at the end of the second arm pull in freestyle were included in the regression model. These results highlight the technical demands of swimmers who successfully adapt to the changing constraints of the transition phase (Glazier \& Davids, 2009), i.e. increased drag forces (underwater to surface 
swimming), modified body position (while ascending to water surface) and arm-to-leg propulsion (compared to primarily leg propulsion in underwater). 


\section{CHAPTER 7}

\section{GENERAL DISCUSSION}




\section{Chapter 7 General discussion}

\subsection{Summary and discussion of main findings}

The present research has processed in total 74 national swimmers (33 males and 41 females) in order to address the transitioning movement from underwater to surface swimming from the push-off start. In the first part of the research characterization of the transitioning phase from the aspects of swimming kinematics, segmental and coordinative parameters and in relation to both genders was given. After that, second part of the research was devoted to comparison of transitioning kinematical, stroke phase and coordinative parameters with the same parameters in free swimming. Finally, in the third part of the research, the model of swimming parameters (excluding kinematics since their direct prediction of velocity) which best predict transitioning performance was proposed. The aim of this discussion part is to synthesize all the finding into unique chapter.

Swimmers of the present research used quick transiting movement to reach surface swimming which is reflected in higher stroke rate than displayed in free swimming and also with shorter propulsive stroke phases than showed in free swimming. In the preparation for transition (pre-transition phase), they change body depth in range from $0.2 \mathrm{~m}$ in freestyle to $0.1 \mathrm{~m}$ in backstroke. They start full stroke movement at depths close to surface in freestyle and butterfly and around $0.2 \mathrm{~m}$ deeper in backstroke and breaststroke. It could be said that swimmers are at optimal depth to start transition from underwater to surface swimming only in freestyle and butterfly. This was shown by the regression analysis of male swimmers where body depth had positive contribution to freestyle and butterfly transition velocities, while the negative contribution was observed to backstroke transition velocities. 
Large trunk inclinations produce large frontal drag which negatively influences velocity. This environmental constraint (i.e. increased frontal drag) was shown not be an obstacle for proper backstroke technique with negative DRP1 (a lag between propulsive arms actions) contributing positively (in the regression model) to transition velocity. Although lag between propulsive actions (DRP1) would be expected to positively correlate with stroke length, DRP1 was only limitedly correlated with stroke rate. That finally suggests that in the case of backstroke as it is in the case of other strokes, quickness of transition movement (i.e. high stroke rate) that was properly coordinated (lagged coordination) is the most important for adequate transition.

Body depth at which swimmers start transitioning movements was shown to differ among strokes, suggesting that freestyle and butterfly swimmers were at lower depths in relation to surface, while butterfly and breaststroke swimmers observed higher depths in relation to water surface. In contrary, no difference in the trunk inclination was observed at the beginning of transitioning movement. However, apart from inclinations, there were series of factors that point out breaststroke velocity as the lowest among all strokes. Firstly, the factors associated with preceding underwater movements (pre-transition phase and before), where velocity drop to almost zero (Seifert et al., 2007b), create conditions in which swimmers have no base from which they could accelerate their transitioning swimming using high stroke frequency (rate) and reach the peak of velocity (i.e. the velocity which is higher than pre-transition and free swimming velocity). Secondly, in order to overcome this obvious obstacle, swimmers try to use overlaps in propulsions. However, this was shown to be detrimental because negative correlation was found between DPR3 and males breaststroke stroke rate (as one component of velocity) and therefore indirectly caused the negative influence on transition breaststroke velocity. 
From all the strokes processed and analysed, butterfly proposes itself as the stroke with best transition performance. This is interesting as butterfly was reported with the fastest transitioning velocity, forasmuch that freestyle is fastest stroke when free swimming is observed (Kennedy et al., 1990). Both, freestyle and butterfly are in good hydrodynamic position for starting transitioning movement (close to water surface and with body / trunk inclinations which are not high and do not negatively influence velocity). One reason which propose butterfly as best among strokes in terms of transitioning performance is its technique or coordination where leg movements / coordination is replicated from underwater movements and where the arms movements are just embedded. Freestyle is stroke where transitioning is second best performed, from already mentioned reasons (swimmer body close to surface and body / trunk inclinations not high enough to negatively influence velocity).

\subsection{Practical applications}

Swimming breakout (pre-transition and transition itself) represents an important and integral part of total swimming performance and this part of the event should be separately trained and developed from swimming coaches as it is the case for other parts of a swimming event which are separately trained (i.e. starting and turning segments).

Pre-transition segment of breakout performance:

- Swimmers should optimize the underwater distances to maintain fast velocities when transiting to the water surface.

- Regarding legs, the accent should be placed on practicing frequency of underwater kicking to assure good base for transition velocities itself. 
Transition segment of breakout performance:

- Swimmers should perform transition as fast as possible using quick arm motion that relies/continues on already active high frequency of simultaneous kicking.

- In addition, they should reinforce the alternate kicking propulsive movements during breakout (in freestyle, backstroke and butterfly).

- Second, they should focus on the propulsive parts of the arm stroke to avoid losing forward propulsion when reaching the water surface (especially in breaststroke where leg recovery is detrimental for velocity).

- Finally, they should aim to maximize the inter-limb coupling during breakout to compensate for the decrease in the relative duration of propulsive stroke phases.

- Coaches are encouraged to organize different training regimes for males and females, respectively, especially the protocols by which kicking and stroke rate in females could be improved.

- They are advised to control trunk and body inclinations in females, so that the gender differences were less present during transition.

- Coaches should focus on improving transition segmental parameters in the strokes where swimmers were positioned at depths larger than optimal (i.e. backstroke and breaststroke), especially on improving backstroke transition technique where body depth and inclination were shown to have negative contribution to swimming velocity.

Applying all the recommendations proper technique of transitioning movement will be gradually developed and the performance of this segment will be advances which will lead to the enhancement of total swimming performance. 


\subsection{Research limitations and future research}

\section{Limitations}

The present research was performed by single testing protocol that enabled only intersubjects comparison. Repeated testing protocols would permit intra-subject comparisons and their evaluations of adaptations. Another limitation was that only discrete relative measure was applied regarding swimming coordination (i.e. DRP angles) and inclinations. Continuous relative measure of coordination variables (continuous relative phase angles) and inclinations would give full insight of swimming behaviour throughout each time point of swimming cycle.

\section{Future research}

Future research should focus more on settings closer possible to competitive settings. At the first place testing transition performance from starting block under fatiguing conditions. Moreover, it would be interesting to impose different swimming velocities relevant for different swimming events to explore novel constraints and swimmers' adaptations on those settings. Finally, velocity does not reflect energetics of swimming performance, so exploring swimming bioenergetics capacities accompanied with the efficiency of swimming during transition is something that should be employed in the near future. 


\section{CHAPTER 8}

\section{GENERAL CONCLUSIONS}




\section{Chapter 8 General conclusions}

\subsection{General conclusions}

This project revealed that transition swimming represents a novel portion of swimming event where swimmers behave and adapt differently in comparison to free swimming portion of the event. The differences were reflected at the level of behaviour of male vs. female swimmers. Moreover, it is revealed that swimmers adapt to transition segment, independently of causal interference of previous underwater swimming. Finally, swimming coordination that classified strokes into alternate and simultaneous appropriated the factors typical in building the transition performance of the each type of stroke, respectively.

The main conclusions are:

1. In addition to the stroke length, which is the main factor in differentiating free swimming velocity in genders, the stroking rate also contributed to the gender differences in velocity during breakout phase.

2. The swimming velocity during breakout was faster than free-swimming (in all strokes but breaststroke), not because of a faster previous underwater kicking or a modified coordinative swimming pattern, but because of an increase in the stroking rate with changes to the relative duration of selected stroke phases.

3. The body position and inter-limb coordination of competitive swimmers when transiting from underwater to surface swimming represented important factors on the swimming velocity, explaining from $15 \%$ to $30 \%$ of the variance during the first arm stroke cycle. 
4. The arm-to-leg coordination at the beginning of arm propulsion was the predictor variable of the breakout swimming velocity in the simultaneous strokes whereas, for the freestyle and backstroke (alternate) strokes, the body depth and inclination seemed to be the key factors. 


\section{BIBLIOGRAPHY}




\section{Bibliography}

Abdel-Aziz, Y. I., \& Karara, H. M. (1971). Direct linear transformation from comparator coordinates into space coordinates in close range photogrammetry. Proceedings of the Symposium on Close Range Photogrammetry, 1-18. Falls-Church, VA: American Society of Photogrammetry.

Alberty, M., Potdevin, F., Dekerle , J., Pelayo, P., Gorce, P., \& Sidney, M. (2008). Changes in swimming technique during time to exhaustion at freely chosen and controlled stroke rates. Journal of Sports Sciences, 26(11), 1191-120.

Alley, L. E. (1952). An analysis of water resistance and propulsion in swimming the crawl stroke. Research Quarterly 23, 253-270.

Allnutt, S. (2014). A kinematic analysis of the "break-out" phase of the freestyle, backstroke and butterfly swimming strokes. A thesis submitted to the graduate division of the University of Hawaii at Manoa in partial fulfillment of the requirements for the degree of Master of science in kinesiology.

Alves, F., Gomes-Pereira, J., \& Pereira, F. (1996). Determinants of energy cost of front crawl and backstroke swimming and competitive performance. In J. P. Troup, A. P. Hollander, D. Strasse, S. W. Trappe, J. M. Cappaert, \& T. A. Trappe (Eds.), (pp. 185 - 191), Swimming Science VII. London: E \& FN Spon.

Alves, F., Lopes, P., Veloso, A., Martins-Silva, A. (2006). Influence of body position on dolphin kick kinematics. In H. Schwameder, G. Strutzenberger, V. Fastenbauer, S. Lindinger, E. Müller (Eds.), (pp. 3-6), Proceedings of the 24 International Symposium on Biomechanics in Sports, Salzburg - Austria 
Anderson, E. J., McGillis, W. R., \& Grosenbaugh, M. A. (2001). The boundary layer of swimming fish. Journal of Experimental Biology, 204(1), 81-102.

Arellano, R., Brown, P., Cappaert, J. \& Nelson, R. C. (1994). Analysis of 50-,100-, and 200m freestyle swimmers at the 1992 Olympic Games. Journal of Applied Biomechanics, 10 (2), 189-199.

Arellano, R., Pardillo, S., \& Gavilan, A. (2002). Underwater undulatory swimming: Kinematic characteristics, vortex generation and application during the start, turn and swimming strokes. In K. E. Gianikellis (Ed.), Proceedings of the XXth international symposium on biomechanics in sports, pp. 29-41. Spain: Universidad de Granada.

Arellano, R., Pardillo, S. \& Gavilán, A. (2003). Usefulness of the Strouhal number in evaluating human underwater undulatory swimming. In J. Chatard (Ed.), Biomechanics and Medicine in Swimming IX, pp. 213-218. Saint-Etienne: Publications de l'Université de Saint-Étienne.

Akşit, T., Zeki Özkol, M., Vural, F., Pekünlü, E., Aydinoğlu, R., \& Varol, R. (2017). Contribution of anthropometric characteristics to critical swimming velocity and estimated propulsive force. Journal of Physical Education and Sport, 17(1), 212-218. https://doi.org/10.7752/jpes.2017.01032

Atkison, R. R., Dickey, J. P., Dragunas, A., \& Nolte, V. (2014). Importance of sagittal kick symmetry for underwater dolphin kick performance. Human Movement Science, 33(1), 298-311. http://doi.org/10.1016/j.humov.2013.08.013

Avlonitou, E., Georgiou, E., Douskas, G., \& Louizi, A. (1997). Estimation of body composition in competitive swimmers by means of three different techniques. International Journal of Sports Medicine, 18(5), 363-368.

Barbosa, T. M., Keskinen, K. L., Fernandes, R., Colaço, P., Carmo, C., \& Vilas-Boas, J. P. 
(2005). Relationships between energetic, stroke determinants, and velocity in butterfly. International Journal of Sports Medicine, 26(10), 841-846. https://doi.org/10.1055/s-2005-837450

Barbosa, T. M., Marinho, D. A., Costa, M. J., Silva. A. J. (2011). Biomechanics of competitive swimming strokes. In: V. Klika (Ed.) (pp. 367-388), Biomechanics in applications, Chapter 16. In Tech, Rijeka, Croatia.

Barbosa, T. M., Pinto, E., Cruz, A. M., Marinho, D. A., Silva, A. J., Reis, V. M., ... Queirós, T. M. (2010). The evolution of swimming science research: Content analysis of the "Biomechanics and Medicine in Swimming" Proceedings Books from 1971 to 2006. In P.-L. Kjendlie, R. K. Stallman, \& J. Cabri (Eds.), Biomechanics and Medicine in Swimming XI (pp. 312-313). Oslo: Norwegian School of Sport Science.

Belokovsky, V. V. (1971) An analysis of pulling motions in the crawl arm stroke. In L. Lewillie, J. P. Clarys (Eds.), (pp. 217-221), Swimming Science I, Brussels, Belgium, Universite libre de Bruxelles.

Bernstein, N. (1967). The co-ordination and regulation of movement. Elmsford, NY: Pergamon Press.

Bixler, B., Pease, D., \& Fairhurst, F. (2007). The accuracy of computational fluid dynamics analysis of the passive drag of a male swimmer. Sports Biomechanics, 6(1), 81-98.

Bishop, P., Cureton, K., Collins, M. (1987). Sex difference in muscular strength in equallytrained men and women. Ergonomics 30(4), 675-687

Blanksby, B. A., Simpson, J. R., Elliott, B. C., \& McElroy, K. (1998). Biomechanical factors influencing breaststroke turns by age-group swimmers. Journal of Applied Biomechanics, 14(2), 180-189. 
Blanksby, B., Skender, S., Elliott, B., McElroy, K., \& Landers, G. (2004). An analysis of the rollover backstroke turn by age-group swimmers. Sports Biomechanics, 3(1), 114. https://doi.org/10.1080/14763140408522826

Bober, T. \& Czabanski, B. (1975). Changes in breaststroke techniques under different speed conditions. In J. P. Clarys, L. Lewillie (Eds.), (pp. 188-193), Swimming Science II, Baltimore, MD, University Park Press.

Burkett, B., Mellifont, R., \& Mason, B. (2010). The influence of swimming start components for selected olympic and paralympic swimmers. Journal of Applied Biomechanics, 26(2), 134-141. https://doi.org/10.1123/jab.26.2.134

Cala, A., Veiga, S., García, A., \& Navarro, E. (2009). Previous cycling does not affect running efficiency during a triathlon world cup competition. Journal of Sports Medicine and Physical Fitness, 49(2), 152-158.

Capitão, F., Lima, A. B., Gonçalves, P., Morouço, P., Silva, M., Fernandes, R., VillasBoas, J. (2010). Videogrametrically and velocimetrically assessed intra-cyclic variations of the velocity in breaststroke. Biomechanics and Medicine in Swimming $X I$.

Charbonnier, J. P., Lacour, J. R., Riffat, J., Flandrois, R. (1975). Experimental study of the performance of competition swimmers. European Journal of Applied Physiology and Occupational Physiology 34(3), 157-67.

Chatard, J., \& Wilson, B. (2003). Drafting distance in swimming. Medicine and Science in Sports and Exercise, 35(7), 1176-1181.

Chatard, J. C., Collomp, C., Maglischo, E., \& Maglischo, C. (1990). Swimming skill and stroking characteristics of front crawl swimmers. International Journal of Sports Medicine, 11,156-161. 
Chollet, D., Pelayo, P., Tourny, C., \& Sidney, M. (1996). Comparative analysis of $100 \mathrm{~m}$ and $200 \mathrm{~m}$ events in the four strokes in the top level. Journal of Human Movement Studies, 31, 25-37.

Chollet, D., Chalies, S., \& Chatard, J. C. (1999). A new index of coordination for the crawl: description and usefulness. / Description et utilite d'un nouvel index de la coordination pour le crawl. International Journal of Sports Medicine, 21(1), 54-59.

Chollet, D., Tourny-Chollet, C., \& Gleizes, F. (1999). Evolution of co-ordination in flat breaststroke in relation to velocity. In K. L. Keskinen, P. V. Komi, \& A. P. Hollander (Eds.), Biomechanics and Medicine in Swimming VIII (pp. 29-32). Jyvaskyla, Finland: University of Jyvaskyla.

Chollet, D., \& Boulesteix. L. (2001). Evolution of the butterfly coordination in relation to velocity and skill level of swimmers. In J. R. Blackwell, R. H. Sanders (Eds.) (pp. 2226). XIX International Symposium on Biomechanics in Sports. University of San Francisco, San Francisco, USA

Chollet, D., Seifert, L., Leblanc, H., Boulesteix, L., \& Carter, M. (2004). Evaluation of arm-leg coordination in flat breaststroke. International Journal of Sports Medicine, 25(7), 486-495. https://doi.org/10.1055/s-2004-820943

Chollet, D., Seifert, L., Boulesteix, L., Carter, M. (2006). Arm to leg coordination in elite butterfly swimmers. International Journal of Sports Medicine 27(4), 322-9. https://doi.org/10.1055/s-2005-865658

Chollet, D., Carter, M., \& Seifert, L. (2006). Effect of technical mistakes on arm coordination in backstroke. Revista Portuguesa de Ciencias Do Desporto, 6(2 Suppl), $30-32$. 
Chollet, D., Seifert, L. Carter, M. (2008). Arm coordination in elite backstroke swimmers. Journal of Sports Sciences, 26(7), 675 - 682. https://doi.org/10.1080/02640410701787791

Chollet, D. \& Seifert, L. (2010). Inter-limb coordination in the four competitive strokes. In L. Seifert, D. Chollet, \& I. Mujika (Eds.), World Book of Swimming (Chapter 7). Nova Science Publishers.

Chollet, D., \& Seifert, L. (2011). Inter-limb coordination in the four competitive strokes. In World Book of Swimming: From Science to Performance (pp. 153-172).

Clarys, J. P. (1979). Human morphology and hydrodynamics. Swimming III, 3-41.

Colman, V., Daly, D., Desmet, S. \& Persyn U. (1992). Relation between physical characteristics and undulation in the breaststroke. In D. MacLaren, T. Reilly, A. Lees (Eds.) (pp. 365-370), Biomechanics and Medicine in Swimming VI, Taylor \& Francis.

Cohen, R.C.Z. Cleary, P. W, Harrison, S. M., Mason, B. R. and D.L. (2014). Pitching effects of buoyancy during four competitive swimming strokes effects of body size, body density, gender and growth on underwater torque. Journal of Applied Biomechanics 30, 609-618

Connaboy, C., Coleman, S., \& Sanders, R. H. (2009). Hydrodynamics of undulatory underwater swimming: A review. Sports Biomechanics, 8(4), 360-380. https://doi.org/10.1080/14763140903464321

Cortesi, M., Fantozzi, S., Gatta, G. (2012). Effects of distance specialization on the backstroke swimming kinematics. Journal of Sports Science and Medicine 11, 526532.

Cossor, J. M., \& Mason, B. R. (2001). Swim start performances at the Sydney 2000 
Olympic Games. In J. Blackwell \& R. Sanders (Eds.), XIX International Symposium on Biomechanics in Sports ISBS (pp. 70-74). San Francisco: University of San Francisco.

Costill, D. L., Maglischo, E. W., \& Richardson, A. B. (1992). Swimming. Oxford : Blackwell Scientific Publications.

Counsilman, J. E. \& Counsilman, B. E. (1994). The new science of swimming. Englewood Cliffs: Prentice Hall.

Craig, A. B., \& Pendergast, D. R. (1979). Relationships of stroke rate, distance per stroke and velocity in competitive swimming. Medicine and Science in Sports, 11(3), 278283.

Craig, A. B., Skehan, P. L., Pawelczyk, J. A., \& Boomer, W. L. (1985). Velocity, stroke rate and distance per stroke during elite competition. Medicine and Science in Sports and Exercise, 17(6), 625-634.

Cureton, T. (1933). Natural and artificial buoyancy, flotation and body balance in the water. Beach and Pool, 7(272), 282-287.

Curry, I. (1975). Stroke length, stroke frequency and performance. Swimming Technique $12(3), 88-91$

D Acquisito, L. J., Costill, D. L. (1998). Relationship between linear body velocity swimming fluctuations, power, and sprint breaststroke performance. The Journal of Swimming Research 13, 8-15

Davids, K., Button, C., Bennett, S. J. (2008). Dynamics of skill acquisition: a constraintsled approach. Champaign: Human Kinetics.

de Jesus, K., de Jesus, K., Figueirdeo, P., Gonçalves, P., Pereira, S., Villa-Boas, J. P., \& Fernandes, R. J. (2011). Biomechanical analysis of backstroke swimming starts. 
International Journal of Sports Medicine, 32, 546-551.

de Jesus, K., de Jesus, K., Figueiredo, P., Gonçalves, P., Pereira, S., Vilas-Boas, J. P., Fernandes R. (2013). Backstroke start kinematic and kinetic changes due to different feet positioning. Journal of Sports Science, 31 (15), 1665-75.

de Jesus, K., de Jesus, K., Machado, L., Fernandes, R.J. Vilas-Boas, J.P. (2012). Linear kinematics of the underwater undulatory swimming phase performed after two backstroke starting techniques. 30th Annual Conference in Biomechanics and Sport, $371-374$

Elipot, M., Hellard, P., Taïar, R., Boissière, E., Rey, J. L., Lecat, S., \& Houel, N. (2009). Analysis of swimmers' velocity during the underwater gliding motion following grab start. Journal of Biomechanics, 42(9), 1367-1370. https://doi.org/10.1016/j.jbiomech.2009.03.032

Figueiredo, P., Vilas-Boas, J.-P., Seifert, L., Chollet, D., \& Fernandes, R. J. (2010). The Open Sports Sciences Journal 3, 25-27.

Gatta, G., Cortesi, M., Fantozzi, S., \& Zamparo, P. (2015). Planimetric frontal area in the four swimming strokes: Implications for drag, energetics and speed. Human Movement Science, 39, 41-54. https://doi.org/10.1016/j.humov.2014.06.010

Glazier, P. S., \& Davids, K. (2009). Constraints on the complete optimization of human motion. Sports Medicine, 39(1), 15-28. https://doi.org/10.2165/00007256-200939010$\underline{00002}$

Gourgoulis, V., Boli, A., Aggeloussis, N., Antoniou, P., Toubekis, A., \& Mavromatis, G. (2015). The influence of the hand's acceleration and the relative contribution of drag and lift forces in front crawl swimming. Journal of Sports Sciences, 33(7), 696-712.

Hay, J. G. (1985). The biomechanics of sports techniques. Englewood Cliffs, NJ: Prentice Hall. 
Hellard, P., Dekerle, J., Avalos, M., Caudal, N., Knopp, M., \& Hausswirth, C. (2008). Kinematic measures and stroke rate variability in elite female $200-\mathrm{m}$ swimmers in the four swimming techniques: Athens 2004 Olympic semi-finalists and French National 2004 Championship semi-finalists. Journal of Sports Sciences 26(1), 35-46. https://doi.org/10.1080/02640410701332515

Herda, T. J., Miller, J. D., Wray, M. E., Sterczala, A. J., Dimmicka, H. L., Trevino, M. A. (2019). Motor unit firing rates of the first dorsal interosseous differ between male and female children aged 8-10 years. Human Movement Science 66, 416-424.

Hochstein, S., Blickhan, R. (2014). Body movement distribution with respect to swimmer's glide position in human underwater undulatory swimming. Human Movement Science 38, 305-318.

Hopkins, W. G., Marshall, S. W., Batterham, A. M., Hanin, J. (2009). Progressive statistics for studies in sports medicine and exercise science. Medicine and Science in Sports and Exercise, 41, 3-13.

Houel, N., Elipot, M., André, F., Hellard, P. (2013) Influence of angles of attack, frequency and kick amplitude on swimmer's horizontal velocity during underwater phase of a grab start. Journal of Applied Biomechanics 29, 49-54.

Jiskoot, J., \& Clarys, J. P. (1975). Body resistance on and under the water surface. In J. P. Clarys \& L. Lewillie (Eds.), Swimming II (pp. 105-109).

Karpovich, P. V. (1933). Water resistance in swimming. Research Quarterly 4, 21-28.

Karpovich, P. V. (1935). Analysis of the propelling force in the crawl stroke. Research Quarterly 6, 49-58

Kelso, J. A. S., Scholz, J. P., Schöner, G. (1988). Dynamics governs switching among 
patterns of coordination in biological movement. Physics Letters A 134 (1), 8-12.

Kelso, J. A. S., Scholz, J. P., Schöner, G. (1986). Nonequilibrium phase transitions in coordinated biological motion: critical fluctuations. Physics Letters A 118(6), 279284.

Keskinen, K. L., \& Komi, P. V. (1993). Stroking characteristics of front crawl swimming during exercise. Journal of Applied Biomechanics, 9, 219-226.

Kennedy, P., Brown, P., Chengalur, S. N., Nelson, R. C. (1990). Analysis of male and female Olympic swimmers in the 100-meter events. International Journal of Sport Biomechanics, 6(2), 187-197.

Kjendlie P. -L, Stallman, R. K, Stray-Gundersen J. (2004a). Passive and active floating torque during swimming. European Journal Applied Physiology 93, (1-2): 75-81. https://doi.org/10.1007/s00421-004-1165-7

Kjendlie, P. -L., Ingjer, F., Stallman, R. K., Stray-Gundersen, J. (2004b). Factors affecting swimming economy in children and adults. European Journal of Applied Physiology 93, 65-74. https://doi.org/10.1007/s00421-004-1164-8

Kjendlie, P. -L. \& Stallman, R. K. (2011). Morphology and swimming performance. In L. Seifert, D. Chollet and I.Mujika (Eds.), (pp. 203-221) World Book of Swimming: From Science to Performance, Nova Science Publishers, Inc.

Klentrou, P. P., \& Montpetit, R. R. (1992). Energetics of backstroke swimming in males and females. Medicine and Science in Sports and Exercise, 24(3), 371-5.

Kolmogorov, S., \& Duplisheva, O. (1992). Active drag, useful mechanical power output and hydrodynamic force coefficient in different swimming strokes at maximal velocity. Journal of Biomechanics 25, 311-318.

Kolmogorov, S. V., Rumyantseva, O. A., Gordon, B. J., \& Cappaert, J. M. (1997). 
Hydrodynamic characteristics of competitive swimmers of different genders and performance levels. Journal of Applied Biomechanics, 13, 88-97.

Komar, J., Sanders, R. H., Chollet, D., \& Seifert, L. (2014). Do qualitative changes in interlimb coordination lead to effectiveness of aquatic locomotion rather than efficiency? Journal of Applied Biomechanics, 30(2), 189-196. https://doi.org/10.1123/jab.2013-0073

Leblanc, H., Seifert, L., Baudry, L., \& Chollet, D. (2005). Arm-leg coordination in flat breaststroke: A comparative study between elite and non-elite swimmers. International Journal of Sports Medicine, 26(9), 787-797. https://doi.org/10.1055/s$\underline{2004-830492}$

Leblanc, H., Seifert, L., \& Chollet, D. (2009). Arm-leg coordination in recreational and competitive breaststroke swimmers. Journal of Science and Medicine in Sport, 12(3), 352-356. https://doi.org/10.1016/j.jsams.2008.01.001

Leblanc, H., Seifert, L., \& Chollet, D. (2010). Does floatation influence breaststroke technique? Journal of Applied Biomechanics, 26(2), 150-158. https://doi.org/10.1123/jab.26.2.150

Lerda, R., \& Cardelli, C. (2003). Analysis of stroke organization in the backstroke as a function of skill. Research Quarterly in Exercise and Sport, 74(2), 215 - 219. https://doi.org/10.1080/02701367.2003.10609083

Lerda, R., Cardelli, C., \& Coudereau, J. P. (2005). Backstroke organization in physical education students as a function of skill and sex. Perceptual and Motor Skills, 100, $779-790$.

Lezelter, H., Freitag, W. (1983). Stroke length and stroke frequency variation in men's and women's 100-m freestyle swimming. In Hollander, A. P., Huijing, P. A., de Groot, G. 
(Eds.), Biomechanics and medicine in swimming IV. Champaign, IL: Human Kinetics, pp. $315-322$.

Lyttle, A. D., Blanksby, B. A., Elliot, B. C., \& Lloyd, D. G. (1998). The effect of depth and velocity on drag during the streamlined guide. Journal of Swimming Research, 13(January), 15-22.

Lyttle, A., Lloyd, D., Blanksby, B., \& Elliott, B. (1999). Optimal glide path during the freestyle flip turn. Journal of Science and Medicine in Sport, 2(4), 413-414. https://doi.org/10.1016/s1440-2440(99)80023-1

Lyttle, A., \& Blanksby, B. (2000). A look at gliding and underwater kicking in the swim turn. In Y. Hong, D. P. Johns, \& R. Sanders (Eds.), 18 International Symposium on Biomechanics in Sports. Hong Kong, China.

Lyttle, A. D., \& Mason, B. (1997). A kinematic and kinetic analysis of freestyle and butterfly turns. Journal of Swimming Research, 12, 7-11.

Machado, L., Ribeiro, J., Costa, L., Silva, A. J., Rouboa, A. I., Mantripragada, N., ... Vilas-Boas, J. P. (2010). The effect of depth on the drag force during underwater gliding: A CFD approach. International Society of Biomechanics in Sports, 4-5.

Maglischo, E. W. (2014). Is it time to consider a different way of swimming backstroke? Swimming Research, 22(1), 1-24.

Maglischo, C. W., Maglischo, E. W., Higgins, J., Hinrichs, R., Luedtke, D., Schleihauf, R. E., Thayer, A. (1988) A biomechanical analysis of the 1984 U.S. Olympic freestyle distance swimmers. In: B E. Ungerechts, K. Wilke, K. Reischle (Eds.). (pp. 351-360). Swimming Science V, Champaign: Human Kinetics (Verlag).

Maglischo, E. W. (1993). Swimming even faster. Mountain View: Mayfield Publishing. Maglischo, E. W. (2003). Swimming fastest. Champaign, IL: Human Kinetics. 
Marinho, D. A., Reis, V. M., Alves, F. B., Vilas-Boas, J. P., Machado, L., Silva, A. J., \& Rouboa, A. I. (2009). Hydrodynamic drag during gliding in swimming. Journal of Applied Biomechanics, 25(3), 253-257.

Martins-Silva, A., \& Alves, F. (2000). Determinant factors related to the variation in horizontal velocity of the body centre of mass in butterfly. In Y. Hong, D. P. Johns, \& R. Sanders (Eds.), 18 International Symposium on Biomechanics in Sports. Hong Kong, China.

Masset, J. B., Rouard, A. H., \& Taiar, R. (1999). 3-D analysis of the backstroke style. Journal of Human Movement Studies, 6, 253 - 271.

McLean, S. P., \& Hinrichs, R. N. (1998). Sex differences in the centre of buoyancy location of competitive swimmers Journal of Sports Sciences, 16(4), 373-383. https://doi.org/10.1080/02640419808559365

McLean, S. P., \& Hinrichs, R. N. (2000). Buoyancy, gender, and swimming performance. Journal of Applied Biomechanics, 16(3), 248-263. https://doi.org/10.1123/jab.16.3.248

Mooney, R., Corley, G., Godfrey, A., Osborough, C., Newell, J., Quinlan, L. R., ... Ólaighin, G. (2016). Analysis of swimming performance: perceptions and practices of US-based swimming coaches swimming coaches. Journal of Sports Sciences, 34(11), 997-1005. https://doi.org/10.1080/02640414.2015.1085074

Morais, J. E., Jesus, S., Lopes, V., Garrido, N., Silva, A., Marinho, D., \& Barbosa, T. M. (2012). Linking selected kinematic, anthropometric and hydrodynamic variables to young swimmer performance. Pediatric Exercise Science, 24(4), 649-664. https://doi.org/10.1123/pes.24.4.649

Nakashima, M. (2009). Simulation analysis of the effect of trunk undulation on swimming 
performance in underwater dolphin kick of human. Journal of Biomechanical Science and Engineering, 4(1), 94-104. https://doi.org/10.1299/jbse.4.94

Naemi, R., Easson, W.J., Sanders, R.H. (2010). Hydrodynamic glide efficiency in swimming. Journal of Science and Medicine in Sport, 13, 444-451, doi:10.1016/j.jsams.2009.04.009

Nemessuri, M., Vaday, M. (1971). Motor pattern of free-style swimming. In L. Lewillie, J. P. Clarys (Eds.), (pp. 161-166), Swimming Science I, Brussels, Belgium, Universite libre de Bruxelles.

Nemessuri, M., Vaday, M. (1971). Breaststroke motor pattern. In L. Lewillie, J. P. Clarys (Eds.), (pp. 161-166), Swimming Science I, Brussels, Belgium, Universite libre de Bruxelles

Nicolas, G., Bideau, B. (2009). A kinematic and dynamic comparison of surface and underwater displacement in high level monofin swimming. Human Movement Science, 28, 480-493, doi:10.1016/j.humov.2009.02.004

Nguyen, C., Bradshaw, E., Pease, D., Wilson, C. (2014). Is starting with the feet out of the water faster in backstroke swimming? Sports Biomechanics, 13 (1), 1-12.

Oxford, S. W., James, R. S., Price, M. J., Payton, C. J. \& Duncan, M. J. (2017). Changes in kinematics and arm-leg coordination during a 100-m breaststroke swim. Journal of Sports Sciences 35(16), 1658-1665.

Pai, Y. -C., Hay, J. G., Wilson, B. D., (1984). Stroking techniques of elite swimmers. Journal of Sports Science 2, 225-239.

Payton, C. J., Barlett, R. M. (1995). Estimating propulsive forces in swimming from three dimensional kinematic data. Journal of Sports Sciences 13, 447-454.

Potdevin, F., Bril, B., Sidney, M., \& Pelayo, P. (2006). Stroke frequency and arm 
coordination in front crawl swimming. International Journal of Sports Medicine, 27(3), 193-198. https://doi.org/10.1055/s-2005-837545

Puel, F., Morlier, J., Avalos, M., Mesnard, M., Cid, M., \& Hellard, P. (2012). 3D kinematic and dynamic analysis of the front crawl tumble turn in elite male swimmers. Journal of Biomechanics, 45(3), 510-515. https://doi.org/10.1016/j.jbiomech.2011.11.043

Rackham, G. W. (1975). An analysis of arm propulsion in swimming. In J. P. Clarys, L. Lewillie (Eds.), (pp. 188-193), Swimming Science II, Baltimore, MD, University Park Press.

Richardson, A. B. (1986). The biomechanics of swimming: The shoulder and knee. Clinics in Sports Medicine, 5, 103-113.

Richardson, A. B., Jobe, F. W., \& Collins, H. R. (1980). The shoulder in competitive swimming. American Journal of Sports Medicine, 8, 159 - 163.

Ruschel, C., Araujo, L. G., Pereira, S. M., \& Roesler, H. (2007). Kinematical analysis of the swimming start : block, flight and underwater phases. XXV ISBS Symposium, 385388. Ouro Preto.

Riewald, S. (2001) Assessment of normalized distance per stroke and swimming efficiency in the 2000 Olympic Games. In J. R. Blackwell, R. H. Sanders (Eds.), (pp. 43 - 47), Proceedings of the XIX International Symposium on Biomechanics in Sports, San Francisco, USA

Sanchez, J. A., Arellano. R. (2002). Stroke index values according to level, gender, swimming style and event race distance. In K. E. Gianikellis (Ed.), (pp. 157-161), Proceedings of the XIX International Symposium on Biomechanics in Sports, Caceres, Spain.

Sanders, R. H., Cappaert, J. M., Devlin, R. K. (1995). Wave characteristics of butterfly 
swimming. Journal of Biomechanics, 28, 9-16, doi:10.1016/0021-9290(95)80002-6.

Sanders, R. H., Cappaert, J. M., Pease, D. L. (1998). Wave characteristics of Olympic breaststroke swimmers. Journal of Applied Biomechanics, 14, 40-51, doi:10.1123/jab.14.1.40.

Schleihauf, R. E., Higgins, J. R., Hinrichs, R,, Leudke, D., Maglischo, C., Maglischo E. W., Thayer, A. (1988). Propulsive techniques: front crawl stroke, butterfly, backstroke, and breaststroke. In: B. E. Ungerechts, K. Reischle, K. Wilke (Eds.). Swimming Science V, International Series on Sport Sciences, vol. 18. Champaign: Human Kinetics.

Schleihauf, R. E. (1974). A biomechanical analysis of freestyle. Swimming technique 11, 89-96.

Schleihauf, R.E. (1979). A hydrodynamical analysis of swimming propulsion. In: TA Bedingfield (Ed.). Swimming III. Baltimore: University Park Press.

Schleihauf, R. E., Gray, L., \& DeRose, J. (1983). Three-dimensional analysis of swimming propulsion in the sprint front crawl stroke. In A. P. Hollander, P. Huijing, \& G. de Groot (Eds.), Biomechanics and medicine in swimming IV (pp. 173-184). Champaign, IL: Human Kinetics.

Schnitzler, C., Seifert, L., Alberty, M., Chollet, D. (2010). Hip velocity and arm coordination in front crawl swimming. International Journal of Sports Medicine, 31, 875-881.

Seifert, L., \& Chollet, D. (2009). Modelling spatial-temporal and coordinative parameters in swimming. Journal of Science and Medicine in Sport, 12(4), 495-499. https://doi.org/10.1016/j.jsams.2008.03.002 
Seifert, L., Komar, J., Crettenand, F., Dadashi, F., Aminian, K., \& Millet, G. P. (2014a). Inter-limb coordination and energy cost in swimming. Journal of Science and Medicine in Sport, 17(4), 439-444. https://doi.org/10.1016/j.jsams.2013.07.003

Seifert, L., Komar, J., Barbosa, T., Toussaint, H., Millet, G., \& Davids, K. (2014b). Coordination pattern variability provides functional adaptations to constraints in swimming performance. Sports Medicine, 44(10), 1333-1345. https://doi.org/10.1007/s40279-014-0210-X

Seifert, L., L’Hermette, M., Komar, J., Orth, D., Mell, F., Merriaux, P., ... Davids, K. (2014). Pattern recognition in cyclic and discrete skills performance from inertial measurement units. Procedia Engineering, 72, 196-201. https://doi.org/10.1016/i.proeng.2014.06.033

Seifert, L. M., Delignieres, D., Boulesteix, L., \& Chollet, D. (2007a). Effect of expertise on butterfly stroke coordination. Journal of Sports Sciences, 25(2), 131-141. https://doi.org/10.1080/02640410600598471

Seifert, L., Vantorre, J., \& Chollet, D. (2007b). Biomechanical analysis of the breaststroke start. International Journal of Sports Medicine, 28(11), 970-976. https://doi.org/10.1055/s-2007-965005

Seifert, L., Komar, J., Lepretre, P. M., Lemaitre, F., Chavallard, F., Alberty, M., ... Hellard, P. (2010c). Swim specialty affects energy cost and motor organization. International Journal of Sports Medicine, 31(9), 624-630. https://doi.org/10.1055/s-0030-1255066

Seifert, L, Chollet, D., \& Bardy, B. (2004). Effect of swimming velocity on arm coordination in the front crawl: a dynamic analysis. Journal of Sports Sciences, 22(7), 651-660. https://doi.org/10.1080/02640410310001655787

Seifert, L., Boulesteix, L., \& Chollet, D. (2004). Effect of gender on the adaptation of arm 
coordination in front crawl. International Journal of Sports Medicine, 25(3), 217-223. https://doi.org/10.1055/s-2003-45253

Seifert, L, \& Chollet, D. (2005). A new index of flat breaststroke propulsion: A comparison of elite men and women. Journal of Sports Sciences, 23(3), 309-320. https://doi.org/10.1080/02640410410001729964

Seifert, L., Chollet, D., Allard, P. (2005). Arm coordination symmetry and breathing effect in front crawl. Human Movement Science, 24, 234-256, doi:10.1016/j.humov.2005.05.003.

Seifert, L., Boulesteix, L., Chollet, D., \& Vilas-Boas, J. P. (2008). Differences in spatialtemporal parameters and arm-leg coordination in butterfly stroke as a function of race pace, skill and gender. Human Movement Science, 27(1), 96-111. https://doi.org/10.1016/j.humov.2007.08.001

Seifert, L., Chollet, D., \& Sanders, R. H. (2010). Does breathing disturb coordination in butterfly? International Journal of Sports Medicine, 31, 167-173.

Seifert, L., Leblanc, H., Chollet, D., \& Delignières, D. (2010a). Inter-limb coordination in swimming: Effect of speed and skill level. Human Movement Science, 29(1), 103-113. https://doi.org/10.1016/j.humov.2009.05.003

Seifert, L., Leblanc, H., Chollet, D., \& Delignières, D. (2010b). Inter-limb coordination in swimming: Effect of speed and skill level. Human Movement Science, 29(1), 103-113. https://doi.org/10.1016/j.humov.2009.05.003

Seifert, L., Komar, J., Lepretre, P. M., Lemaitre, F., Chavallard, F., Alberty, M., ... Hellard, P. (2010c). Swim specialty affects energy cost and motor organization. International 
Journal of Sports Medicine, 31(9), 624-630. https://doi.org/10.1055/s-0030-1255066

Seifert, L., Leblanc, H., Herault, R., Komar, J., Button, C., \& Chollet, D. (2011). Interindividual variability in the upper-lower limb breaststroke coordination. Human Movement Science, 30(3), 550-565. https://doi.org/10.1016/j.humov.2010.12.003

Serrien, D. J. (2009). Functional connectivity patterns during motor behaviour: The impact of past on present activity. Human Brain Mapping, 30(2), 523-531.

Silva, A., Colman, V., Soons, B., Alves, F., \& Persyn, U. (2001). Performance relevant time-space variables in breaststroke: sex differentiation. XIXth International Symposium on Biomechanics in Sports, 179-183.

Silva, A. F., Figueiredo, P., Seifert, L., Soares, S., Vilas-Boas, J. P., \& Fernandes, R. J. (2013). Backstroke technical characterization of 11-13 year-old swimmers. Journal of Sports Science and Medicine, 12(4), 623-629.

Smith, H. K., Montpetit, R. R., \& Perrault, H. (1988). The aerobic demand of backstroke swimming, and its relation to body size, stroke technique, and performance. European Journal of Applied Physiology and Occupational Physiology, 58(1-2), 182-188. https://doi.org/10.1007/BF00636624

Soares, P. M., Sousa, F., \& Vilas-Boas, J. (1999). Differences in breaststroke synchronisation induced by different race velocities. In K. L. Keskinen, P. V. Komi, \& A. P. Hollander (Eds.), Swimming science VIII (pp. 53-57). Jyvaskyla: Gummerus Printing House.

Sortwell, A. (2011). Relationship between stroking parameters and leg movement quantity in 100 metre front crawl. International Journal of Exercise Science, 4(1), 261-268.

Strzala, M., \& Krezalek, P. (2010). The body angle of attack in front crawl performance in young swimmers. Human Movement, 11(1), 23-28. 
Suito, H., Ikegami, Y., Nunome, H., Sano, S., Shinkai, H., \& Tsujimoto, N. (2008). The effect of fatigue on the underwater arm stroke motion in the $100 \mathrm{~m}$ front crawl. Journal of Applied Biomechanics, 24, 316-324.

Takagi, H., Sugimoto, S., Nishijima, N., \& Wilson, B. (2004). Differences in stroke phases, arm-leg coordination and velocity fluctuation due to event, gender and performance level in breaststroke. Sports Biomechanics / International Society of Biomechanics in Sports, 3(1), 15-27. https://doi.org/10.1080/14763140408522827

Takeda, T., Ichikawa, H., Takagi, H., \& Tsubakimoto, S. (2009). Do differences in initial speed persist to the stroke phase in front-crawl swimming? Journal of Sports Sciences, 27(13), 1449-1454. https://doi.org/10.1080/02640410903046228

Takeda, T., Takagi, H., Tsubakimoto, S. (2012). Effect of inclination and position of new swimming starting block's back plate on track-start performance. Sports Biomechanics, 11, 370-381, doi:10.1080/14763141.2011.637122

Takeda, T., Sakai, S., Takagi, H. (2020). Underwater flutter kicking causes deceleration in start and turn segments of front crawl. Sports Biomechanics, doi:DOI: $10.1080 / 14763141.2020 .1747528$

Thayer, A. L., \& Hay, J. G. (1984). Motivating start and turn improvement. Swimming Technique, 20(4), 17-20.

Thompson, K. G., Haljand, R., \& MacLaren, D. P. (2000). An analysis of selected kinematic variables in national and elite male and female 100-m and 200-m breaststroke swimmers. Journal of Sports Sciences, 18(6), 421-431. https://doi.org/10.1080/02640410050074359

Tor, E., Pease, D. L., \& Ball, K. A. (2015). Comparing three underwater trajectories of the swimming start. Journal of Science and Medicine in Sport, 18(6), 725-729. 
https://doi.org/10.1016/j.jsams.2014.10.005

Tourny-Chollet, C., Chollet, D., Hogie, S., \& Papparodopoulos, C. (2002). Kinematic analysis of butterfly turns of international and national swimmers. Journal of Sports Sciences, 20(May), 383-390. https://doi.org/10.1080/026404102317366636

Toussaint, H. M., de Groot, G., Savelberg, H. H., Vervoorn, K., Hollander, A. P., van Ingen Schenau, G. J. (1988). Active drag related to velocity in male and female swimmers. Journal of Biomechanics, 21, 435-438.

Toussaint, H. M., Van Den Berg, C., \& Beek, W. J. (2002). "Pumped-up propulsion” during front crawl swimming. Medicine and Science in Sports and Exercise, 34(2), 314-319. https://doi.org/10.1097/00005768-200202000-00020

Trinidad, A., Veiga, S., Navarro, E., \& Lorenzo, A. (2020). The transition from underwater to surface swimming during the push-off start in competitive swimmers. Journal of Human Kinetics, 72(1), 61-67. https://doi.org/10.2478/hukin-2019-0125

Vantorre, J., Seifert, L., Fernandes, R. J., Boas, J. P. V., \& Chollet, D. (2010). Kinematical profiling of the front crawl start. International Journal of Sports Medicine, 31, 16-21.

Veiga, S., Cala, A., Frutos, P. G., \& Navarro, E. (2013). Kinematical comparison of the 200 $\mathrm{m}$ backstroke turns between national and regional level swimmers. Journal of Sports Science and Medicine, 12(4), 730-737.

Veiga, S., Cala, A., G. Frutos, P., \& Navarro, E. (2014). Comparison of starts and turns of national and regional level swimmers by individualized-distance measurements. Sports Biomechanics, 13(3), 285-295. https://doi.org/10.1080/14763141.2014.910265

Veiga, S., Cala, A., Mallo, J., \& Navarro, E. (2013). A new procedure for race analysis in swimming based on individual distance measurements. Journal of Sports Sciences, 31(2), 159-165. https://doi.org/10.1080/02640414.2012.723130 
Veiga, S., Mallo, J., Navandar, A., \& Navarro, E. (2014). Effects of different swimming race constraints on turning movements. Human Movement Science, 36, 217-226. https://doi.org/10.1016/j.humov.2014.04.002

Veiga, S., \& Roig, A. (2017). Effect of the starting and turning performances on the subsequent swimming parameters of elite swimmers. Sports Biomechanics, 16(1), 3444. https://doi.org/10.1080/14763141.2016.1179782

Veiga, S., Roig, A., \& Gómez-Ruano, M. A. (2016). Do faster swimmers spend longer underwater than slower swimmers at World Championships? European Journal of Sport Science, 16(8), 919-926. https://doi.org/10.1080/17461391.2016.1153727

Vennell, R., Pease, D., \& Wilson, B. (2006). Wave drag on human swimmers. Journal of Biomechanics, 39(4), 664-671.

Vilas-Boas, P., Ligia Costa, Fernandes, R.J., Ribeiro, J., Figueiredo, P., Marinho, D., Silva, A.J., Rouboa, A., Machado, L. (2010). Determination of the drag coefficient during the first and second gliding positions of the breaststroke underwater stroke. Journal of Applied Biomechanics 26(3), 324-331.

Vorontsov, A., \& Rumyantsev, V. (2000a). Resistive forces in swimming. In Vladimir M. Zatsiorsky (Ed.), Biomechanics in Sport: Performance Enhancement and Injury Prevention (Volume IX, pp. 184-204). https://doi.org/10.1002/9780470693797.ch9

Vorontsov, A. R., \& Rumyantsev, V. A. (2000b). Propulsive forces in swimming. In V. M. Zatsiorsky (Ed.), Biomechanics in Sport: Performance Enhancement and Injury Prevention (Volume IX, pp. 205-231). https://doi.org/10.1002/9780470693797.ch10

Von Loebbecke, A., Mittal, R., Fish, F., \& Mark, R. (2009). Propulsive efficiency of the underwater dolphin kick in humans. Journal of Biomechanical Engineering, 131(5), 1-4. https://doi.org/10.1115/1.3116150 
Wakayoshi, K., D'Acquisto, L. J., Cappaert, J. M., Troup, J. P. (1995) Relationship between oxygen uptake, stroke rate and swimming velocity in competitive swimming. International Journal of Sports Medicine, 16(1), 19-23

Wakayoshi, K., Nomura, T., Takahashi, G., Mutoh, Y., Miyashito, M. (1992). Analysis of swimming races in the 1989 Pan Pacific Swimming Championships and 1988 Japanese Olympic Trials. In D. MacLaren, T. Reilly, A. Lees, Biomechanics and Medicine in Swimming VI, (pp. 135-144), E \& FN Spon, London

Wang, K. F., Wang, L. Z., Yan, W. X. Li, D.J., Shen X. (2007). A new device for estimating active drag in swimming at maximal velocity. Journal of Sports Science, 25(4), 375-379

Wheat, J., \& Glazier, P. (2005). Techniques for measuring coordination and coordination variability. In K. Davids, S. J. Bennett, \& K. Newell (Eds.), Variability in the Movement System: A Multi-Disciplinary Perspective. Champaign, IL: Human Kinetics.

Zamparo, P. (1996). Effect of the underwater torque on the energy cost, drag and efficiency of front crawl swimming. European Journal of Applied Physiology and Occupational Physiology, 73(3-4), 195-201. https://doi.org/10.1007/BF02425476

Zamparo, P., Antonutto, G., Capelli, C., Francescato, M. P., Girardis, M., Sangoi, R., ... Pendergast, D. R. (1996). Effects of body size, body density, gender and growth on underwater torque. Scandinavian Journal of Medicine and Science in Sports, 6(5), 273-280. https://doi.org/10.1111/j.1600-0838.1996.tb00470.x

Zamparo, P., Gatta, G., Pendergast, D., \& Capelli, C. (2009). Active and passive drag: The role of trunk incline. European Journal of Applied Physiology, 106(2), 195-205. https://doi.org/10.1007/s00421-009-1007-8 
Zamparo, P., Turri, E., Peterson Silveira, R., \& Poli, A. (2014). The interplay between arms-only propelling efficiency, power output and speed in master swimmers. European Journal of Applied Physiology, 114(6), 1259-1268. https://doi.org/10.1007/s00421-014-2860-7

Yanai, T. (2001). Rotational effect of buoyancy in frontcrawl: Does it really cause the legs to sink? Journal of Biomechanics, 34(2), 235-243. https://doi.org/10.1016/S0021$\underline{9290(00) 00186-X}$ 
APPENDIX 


\section{Appendix}

\section{Publications and Conference Proceedings}

\section{Publications}

Stosic, J., Veiga, S. Trinidad, A, Dopsaj, M, Navarro, E. Effect of breakout phase on kinematic and coordinative swimming parameters. Sports Biomechanics (under review)

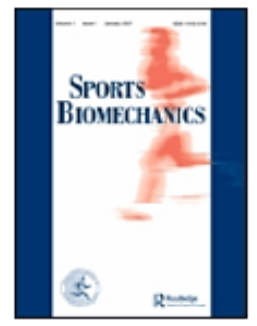

Effect of breakout phase on kinematic and coordinative swimming parameters

\begin{tabular}{|r|l|}
\hline Journal: & Sports Biomechanics \\
\hline Manuscript ID & Draft \\
\hline Manuscript Type: & Original Research \\
\hline Duthor: & nubmitted by the \\
\hline Complete List of Authors: & $\begin{array}{l}\text { Stosic, Jelena; Universidad Politécnica de Madrid, Health and Human } \\
\text { Performance Department } \\
\text { Veiga, Santiago; Universidad Politecnica de Madrid, Health and Human } \\
\text { Performance } \\
\text { Trinidad, Alfonso; Francisco de Vitoria University, Faculty of Education } \\
\text { and Humanities } \\
\text { Dopsaj, Milivoj; Univerzitet u Beograd Fakultet sporta i fizickog } \\
\text { vaspitanja, Department of Theory and Technology of Sports Training } \\
\text { Science Analysis and Diagnosis in Sport; South Ural State University } \\
\text { (National Research University), Institute of Sport, Tourism and Service } \\
\text { Navarro, Enrique; Universidad Politecnica de Madrid, Health and Human } \\
\text { Performance }\end{array}$ \\
\hline Keywords: & $\begin{array}{l}\text { inter-limb coordination, relative phase, underwater swimming, } \\
\text { Performance < Sport Topics }\end{array}$ \\
\hline
\end{tabular}

SCHOLARONE"

Manuscripts 
Title: Effect of breakout phase on kinematic and coordinative swimming parameters

\begin{abstract}
The underwater swimming of the start and turn provides beneficial effects on the subsequent swimming velocities, provided a correct transition from underwater to surface is performed. The aim of the present research was to examine the effect of the breakout movements on the kinematic and coordinative swimming parameters. Thirty-three national level male swimmers performed $4 \times 25 \mathrm{~m}$ maximal efforts (one of each stroke in random order) from a push start and were recorded by two sequential cameras in sagittal plane. The average velocity, stroke length, stroke frequency, the relative duration (\%) of the stroke phases as well as the inter-limb discrete relative phases were calculated with direct linear transformation (DLT) algorithms for the breakout and free-swimming phases. In general terms, swimming velocity during breakout was faster ( $0.27 \pm 0.04 \mathrm{~m} / \mathrm{s}, \mathrm{p}<0.001, \mathrm{ES}=0.33$ ) than free-swimming (in all strokes but breaststroke), not because of a faster previous underwater kicking or a modified coordinative swimming pattern, but because of an increase in the stroking rate ( $\delta 4.68 \pm 0.79$ cycles $/ \mathrm{min}, \mathrm{p}<$ $0.001, E S=0.36$ ). These results indicate how swimmers manage the changing constraints during breakout from underwater to surface swimming.
\end{abstract}

Keywords: inter-limb coordination; relative phase; underwater swimming; performance

\title{
Introduction
}

Competitive swimming performances have observed a great evolution over the last few years due to improvements in the underwater segments of the race (Connaboy, Coleman, \& Sanders, 2009), after swimmers push off the starting or turning pool wall. In these segments, swimmers obtain the maximum swimming velocities between $1.9 \mathrm{~m} / \mathrm{s}$ and $2.2 \mathrm{~m} / \mathrm{s}$ (Elipot et al., 2009) by employing undulatory movements (Lyttle \& Blanksby, 2000) that are extended more or less (at a maximum distance of $15 \mathrm{~m}$ from the wall) according to the demands of the race (Veiga, Cala, Frutos, \& Navarro, 2014). In the last Swimming World Championships, small increases in the underwater distances travelled during start and turns would have represented changes in race performances of critical importance (Veiga, Roig, \& Gómez-Ruano, 2016).

The importance of underwater swimming is highlighted by its beneficial effect on the subsequent surface swimming, as there is a transfer of momentum that allows competitors to achieve greater

URL: http://mc.manuscriptcentral.com/rspb Email: RSPB-peerreview@journals.tandf.co.uk 
Stosic, J. Veiga, S., Trinidad, A. Navarro, E. How should the transition from underwater to surface swimming be performed in competitive swimmers? Applied Sciences (under review)

\section{คิก Applied}

ü sciences

Article

2 How should the transition from underwater to surface swimming be performed in competitive swimmers?

Jelena Stosic ${ }^{1}$, Santiago Veiga ${ }^{1, *}$, Alfonso Trinidad ${ }^{2}$ and Enrique Navarro ${ }^{1}$

1 Health and Human Performance Department, Technical University of Madrid, Madrid,

Spain; istosic@gmail.com (J.S.); santiago.veiga@upm.es (S.V.); enrique.navarro@upm.es (E.N.)

2 Faculty of Education and Humanities, Francisco de Vitoria University, Pozuelo de Alarcón- Madrid, Spain; alfonso.trinidad@ufv.es (A.T.)

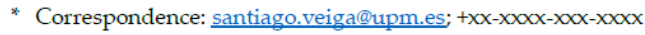

Received: date; Accepted: date; Published: date

Abstract: Despite the increasing importance of underwater segment of start and turns in competition and its positive influence on the subsequent surface swimming, there is no evidence on how transition from underwater to surface swimming should be performed. Therefore, the aim of the present study was to examine the role of the segmental, kinematic and coordinative parameters on the swimming velocity during the pre-transition and transition phases. 30 national male swimmers performed $4 \times 25 \mathrm{~m}$ (one each stroke) from a push start at maximum velocity while recorded from a lateral view by two sequential cameras $(50 \mathrm{~Hz})$, and their kinematic and coordinative swimming parameters were calculated by means of two-dimensional DLT algorithms. Unlike pre-transition, backward regression analysis of transition significantly predicted swimming velocity in all strokes except breaststroke ( $R^{2}$ ranging from 0.263 in freestyle to 0.364 in butterfly). The inter-limb coordination was predictor in butterfly stroke $(\mathrm{p}=0.006)$ whereas the body depth and inclination were predictors in the alternate strokes (freestyle $(\mathrm{p}=0.05)$ and backstroke $(\mathrm{p}=0.04)$ ). These results suggest that the body position and coordinative swimming parameters (apart from kicking or stroking rate and length) have an important influence on the transition performance, which depends on the swimming strokes.

Keywords: kinematics; inter-limb coordination; performance; direct linear transformation

1. Introduction

In the last years, the importance of the underwater segment of the start and turns in swimming competitions has increased both quantitatively and qualitatively. The contribution of underwater swimming to the total race distances has considerably increased over the last 20 years [1] and elite swimmers now spend between $15 \%$ and $25 \%$ of the $100 \mathrm{~m}$ race distances underwater [2]. Also, swimmers achieving the fastest underwater velocities (especially on $100 \mathrm{~m}$ events) or the longest underwater distances (on $200 \mathrm{~m}$ events) have a critical advantage on their performances during World Championships [3]. The lower drag resistance experienced by swimmers underwater [4] as well as the improvement on the undulatory techniques [5], allow swimming competitors to achieve the fastest race velocities underwater and to prioritize these segments over the mid-pool swimming techniques.

The benefits of the underwater swimming for competitive swimmers also include a transfer of momentum to the subsequent surface swimming during starts and turns [2]. Elite swimmers exhibited $5 \%-10 \%$ faster swimming velocities after the start emersion compared to mid-pool 


\title{
Conference Proceedings
}

Stosic, J., Trinidad, A, Navarro, E., Veiga, S. 2018. Kinematic analysis of the transition phase from underwater to surface swimming. XII World Congress of the Performance Analysis of Sport, Opatia, Croatia, September 19-23 (Oral)

\section{Kinematic analysis of transition phase from underwater to surface swimming in national level swimmers}

\author{
Jelena Stosic, Alfonso Trinidad, Enrique Navarro, Santiago Veiga \\ Faculty of Physical Activity and Sport, Technical University of Madrid, Spain
} Purpose: The main aim of this study was to describe the kinematical parameters of the
transition phase from underwater to surface swimming in national level competitors.

\begin{abstract}
Methods: Seventy-four swimmers ( 33 males and 41 females), all participants in national level championships and at least nine years of training experience ( $>20$ hours per week) were recorded $(50 \mathrm{~Hz})$ with two cameras JVC GY-DV500E (from a lateral view) while performing $25 \mathrm{~m}$ maximal effort from a push start. Swimmers footage were manually digitized by an experimented observer and calibrated by mean of 2D-DLT algorithms (Abdel-Aziz and Karara, 1971). Some key events (hand(s) separation to hand(s) entry in freestyle, backstroke and butterfly strokes and leg fully flexed to leg fully flexed in breaststroke) from underwater to surface swimming were identified to define the transition phase and the following variables were calculated: transition stroke length (TSL) in meters as the horizontal hip to hip distance, transition stroke rate (TSR) in hertz as the inverse of transition stroke time, and transition velocity (TV) in $\mathrm{m} / \mathrm{s}$ as TSL divided by transition stroke time. SPSS 20.0 (IBM Corporation, New York, NY, USA) was used to obtain descriptive statistics (mean and standard deviation).
\end{abstract}

Results: Table 1 shows the transition phase kinematical parameters in national-level male swimmers. The freestyle TV was different than from the study by Allnutt (2014) where freestyle TV was $1.62 \pm 0.13 \mathrm{~m} / \mathrm{s}$ (both genders). Similarly, differences were observed with two backstroke TV $(1.55 ; 1.32 \mathrm{~m} / \mathrm{s})$ possibly because group data in the study by Allnutt (2014). Freestyle TSL was lower than from study by Vantorre et al. (2010) who measured surface SL between 10 and $12.5 \mathrm{~m}$ (i.e. $2.24 \pm 0.16 \mathrm{~m}$ ). Very long TSL in backstroke may be due to supine position of swimmers where resistance to movement is higher (Pease 2013). Freestyle TSR (55.8 stroke/min) was similar as from the study by Vantorre (2010) (i.e. $53.3 \pm 4.5$ stroke/min).

Conclusions: Transition phase cyclic parameters allow evaluating the swimmer's performance during transition from underwater to surface swimming. Velocity and stroke length values were lower than in surface swimming in previous study, indicating technical modifications due to task constraints from underwater to surface position.

Table 1. Transition velocity (TV), transition stroke length (TSL) and rate (TSR) of males in all strokes (mean \pm standard deviation) during transition phase

\begin{tabular}{lcccc}
\hline Transition & Freestyle & Backstroke & Butterfly & Breaststroke \\
\hline $\operatorname{TV}(\mathrm{m} / \mathrm{s})$ & $1.79 \pm 0.17$ & $1.60 \pm 0.23$ & $1.80 \pm 0.17$ & $1.32 \pm 0.32$ \\
$\operatorname{TSL}(\mathrm{m})$ & $1.92 \pm 0.26$ & $2.27 \pm 0.55$ & $1.83 \pm 0.23$ & $2.17 \pm 0.91$ \\
$\operatorname{TSR}(\mathrm{Hz})$ & $0.94 \pm 0.13$ & $0.73 \pm 0.13$ & $0.99 \pm 0.13$ & $0.59 \pm 0.13$ \\
\hline
\end{tabular}


Stosic, J., Veiga, S. Trinidad, A, Dopsaj, M, Navarro, E. 2020. Body inclination in males and females during resumption of swimming after push-off start. $9^{\text {th }}$ International Scientific Conference on Kinesiology, May 13-17 (Postponed)

\section{Abstract}

Introductions: It is well known that rotational torque (passive torque) differ between males and females due to differences in the distance between the body center of mass and the body center of buoyancy. However, it is unknown whether active torque or angle of attack and / or active body inclinations differ between genders when swimmers resume from underwater to surface swimming. Therefore, the present study aimed to investigate differences between genders in active body inclinations measured by two angles. Methods: National level swimmers (33 males and 40 females) were recorded with two cameras (50 $\mathrm{Hz}, 1 / 1000 \mathrm{~s}$ ) whereas optical axis was perpendicular to sagittal plane of the swimmers. Measured body inclinations were: $\mathrm{SH}$ - the angle between the line that passes through the shoulder (S) and the hip (H) and the line of water surface (i.e. the water surface); and SK the angle between the line that passes through the shoulder $(\mathrm{S})$ and the knee $(\mathrm{K})$ and the water surface. These two angles were measured on two occasions: firstly in the last underwater kick: 1) feet in the highest position, 2) feet in the lowest position (middle position, $\mathrm{m}$ ); and secondly in the transition: 1) the beginning of transition stroke, 2) arms in shoulder plane (middle position, m). Results: Females showed higher body inclinations (SH) during the transition only in all strokes but freestyle: backstroke (males: $12.78 \pm 6.07$ degrees, females: 15.31 \pm 5.47 degrees, $\mathrm{p}<0.05$ ), butterfly (males: $14.28 \pm 6.7$ degrees, females: $17.34 \pm 7.14$ degrees, $\mathrm{p}<0.05$ ), breaststroke (males: $17.86 \pm 6.08$ degrees, females: 21.65 \pm 8.09 degrees, $\mathrm{p}<0.05)$. Discussion: This suggests that males better handle constraints associated with transition movements. The present finding is not in accordance 
with previous studies which stated that active torque (angle of attack or active body inclinations) depends exclusively on technical skills and not on gender differences (Kolmogorov et al 1997, Clarys 1979).

References:

Kolmogorov et al. 1997. J Appl Biomech 13, 88-97

Clarys 1979. Swim Sci III, 3-41 